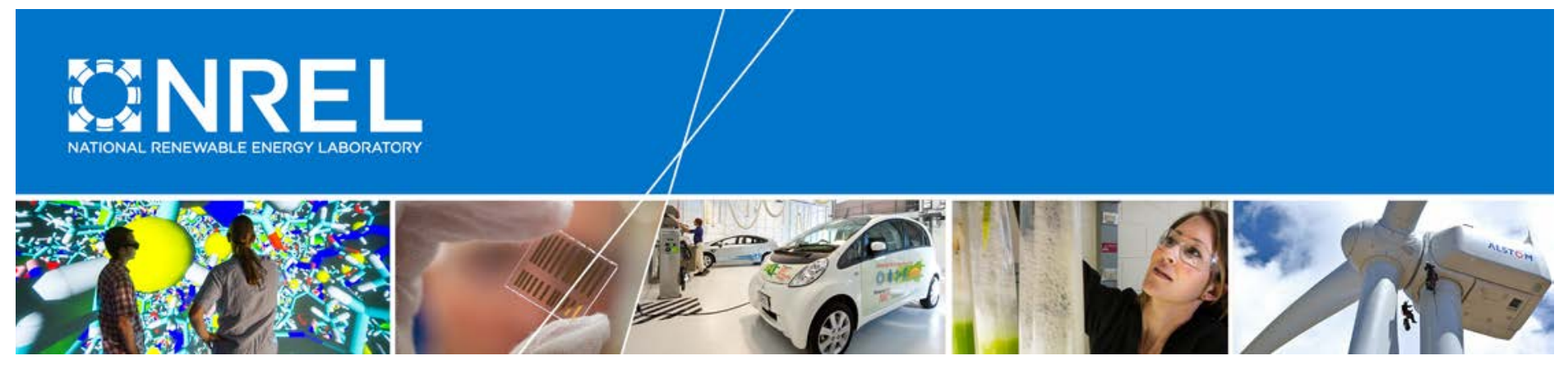

\title{
SunShot 2030 for Photovoltaics (PV): Envisioning a Low-cost PV Future
}

Wesley Cole, Bethany Frew, Pieter Gagnon, James Richards, Yinong Sun, Jarett Zuboy, Michael Woodhouse, and Robert Margolis National Renewable Energy Laboratory

NREL is a national laboratory of the U.S. Department of Energy Office of Energy Efficiency \& Renewable Energy Operated by the Alliance for Sustainable Energy, LLC

This report is available at no cost from the National Renewable Energy Laboratory (NREL) at www.nrel.gov/publications.

Technical Report

NREL/TP-6A20-68105

September 2017

Contract No. DE-AC36-08G028308 


\section{SunShot 2030 for Photovoltaics (PV): Envisioning a Low-cost PV Future}

Wesley Cole, Bethany Frew, Pieter Gagnon, James Richards, Yinong Sun, Jarett Zuboy, and Robert Margolis National Renewable Energy Laboratory

Prepared under Task No. SETP.10310.11.01.13

NREL is a national laboratory of the U.S. Department of Energy Office of Energy Efficiency \& Renewable Energy Operated by the Alliance for Sustainable Energy, LLC

This report is available at no cost from the National Renewable Energy Laboratory (NREL) at www.nrel.gov/publications.

National Renewable Energy Laboratory 15013 Denver West Parkway Golden, CO 80401

303-275-3000 • www.nrel.gov

\section{Technical Report}

NREL/TP-6A20-68105

September 2017

Contract No. DE-AC36-08GO28308 


\section{NOTICE}

This report was prepared as an account of work sponsored by an agency of the United States government. Neither the United States government nor any agency thereof, nor any of their employees, makes any warranty, express or implied, or assumes any legal liability or responsibility for the accuracy, completeness, or usefulness of any information, apparatus, product, or process disclosed, or represents that its use would not infringe privately owned rights. Reference herein to any specific commercial product, process, or service by trade name, trademark, manufacturer, or otherwise does not necessarily constitute or imply its endorsement, recommendation, or favoring by the United States government or any agency thereof. The views and opinions of authors expressed herein do not necessarily state or reflect those of the United States government or any agency thereof.

This report is available at no cost from the National Renewable Energy Laboratory (NREL) at www.nrel.gov/publications.

Available electronically at SciTech Connect http:/www.osti.gov/scitech

Available for a processing fee to U.S. Department of Energy and its contractors, in paper, from:

U.S. Department of Energy

Office of Scientific and Technical Information

P.O. Box 62

Oak Ridge, TN 37831-0062

OSTI http://www.osti.gov

Phone: 865.576.8401

Fax: 865.576.5728

Email: reports@osti.gov

Available for sale to the public, in paper, from:

U.S. Department of Commerce

National Technical Information Service

5301 Shawnee Road

Alexandria, VA 22312

NTIS http://www.ntis.gov

Phone: 800.553 .6847 or 703.605 .6000

Fax: 703.605.6900

Email: orders@ntis.gov 


\section{Acknowledgments}

We gratefully acknowledge the many people whose efforts contributed to this report. We thank Paul Denholm, Trieu Mai, and Brady Stoll for helping develop methods for better representing PV at high penetration in capacity expansion models. Numerous NREL colleagues reviewed and improved this report, including Sarah Kurtz, Eric Lantz, Mark Mehos, Dave Mooney, Dan Steinberg, and Greg Wilson. We are grateful to Sam Baldwin (DOE), Paul Basore (DOE), Aaron Bergman (DOE), John Bistline (EPRI), Paul Donohoo-Vallet (DOE), Charlie Gay (DOE), Dan Kammen (UC Berkeley), Cara Marcy (EIA), Chris Namovicz (EIA), Rich Tusing (DOE), and Ryan Wiser (LBNL) for providing feedback on this work. We especially thank Rebecca JonesAlbertus for her leadership and insights relating to the work presented in this report. This report was funded by the U.S. Department of Energy (DOE) Solar Energy Technologies Office under contract number DE-AC36-08GO28308. 


$\begin{array}{ll}\text { List of Acronyms and Abbreviations } \\ \text { CEM } & \begin{array}{c}\text { capacity expansion model } \\ \text { CPP }\end{array} \\ \text { CSP } & \text { Clean Power Plan } \\ \text { dGen } & \text { distributed generation model } \\ \text { DOE } & \text { Department of Energy } \\ \text { DPV } & \text { distributed photovoltaics } \\ \text { EERE } & \text { Office of Energy Efficiency \& Renewable Energy } \\ \text { EIA } & \text { Energy Information Administration } \\ \text { ELCC } & \text { effective load carrying capability } \\ \text { GW } & \text { gigawatt } \\ \text { LCOE } & \text { levelized cost of energy } \\ \text { LDC } & \text { load duration curve } \\ \text { LOLP } & \text { loss of load probability } \\ \text { LSC } & \text { low storage costs } \\ \text { NG } & \text { natural gas } \\ \text { NG-CC } & \text { natural gas combined cycle } \\ \text { NG-CT } & \text { natural gas combustion turbine } \\ \text { NLDC } & \text { net load duration curve } \\ \text { NREL } & \text { National Renewable Energy Laboratory } \\ \text { O\&M } & \text { operation and maintenance } \\ \text { OGS } & \text { oil-gas-steam } \\ \text { PV } & \text { photovoltaics } \\ \text { RE } & \text { renewable energy } \\ \text { ReEDS } & \text { Regional Energy Deployment System model } \\ \text { UPV } & \text { utility photovoltaics } \\ \text { VG } & \text { variable generation } \\ \text { yr } & \text { year } \\ \text { WACC } & \text { weighted average cost of capital } \\ & \end{array}$




\section{Executive Summary}

After launching the SunShot Initiative, the U.S. Department of Energy (DOE) published the SunShot Vision Study (DOE 2012), which envisions a future in which solar's levelized cost of energy (LCOE) in 2020 declines to 6 cents per kilowatt-hour $(\phi / \mathrm{kWh})$ for utility-scale systems, $7 \not / \mathrm{kWh}$ for commercial systems, and $9 \notin / \mathrm{kWh}$ for residential systems. In the context of dramatic solar cost reductions and electricity-sector changes that have occurred since 2010, DOE recently set new LCOE goals for PV to achieve by 2030 in order to enable significantly greater PV adoption: $3 \phi / \mathrm{kWh}$ for utility-scale, $4 \phi / \mathrm{kWh}$ for commercial, and $5 \phi / \mathrm{kWh}$ for residential systems (Figure 1).

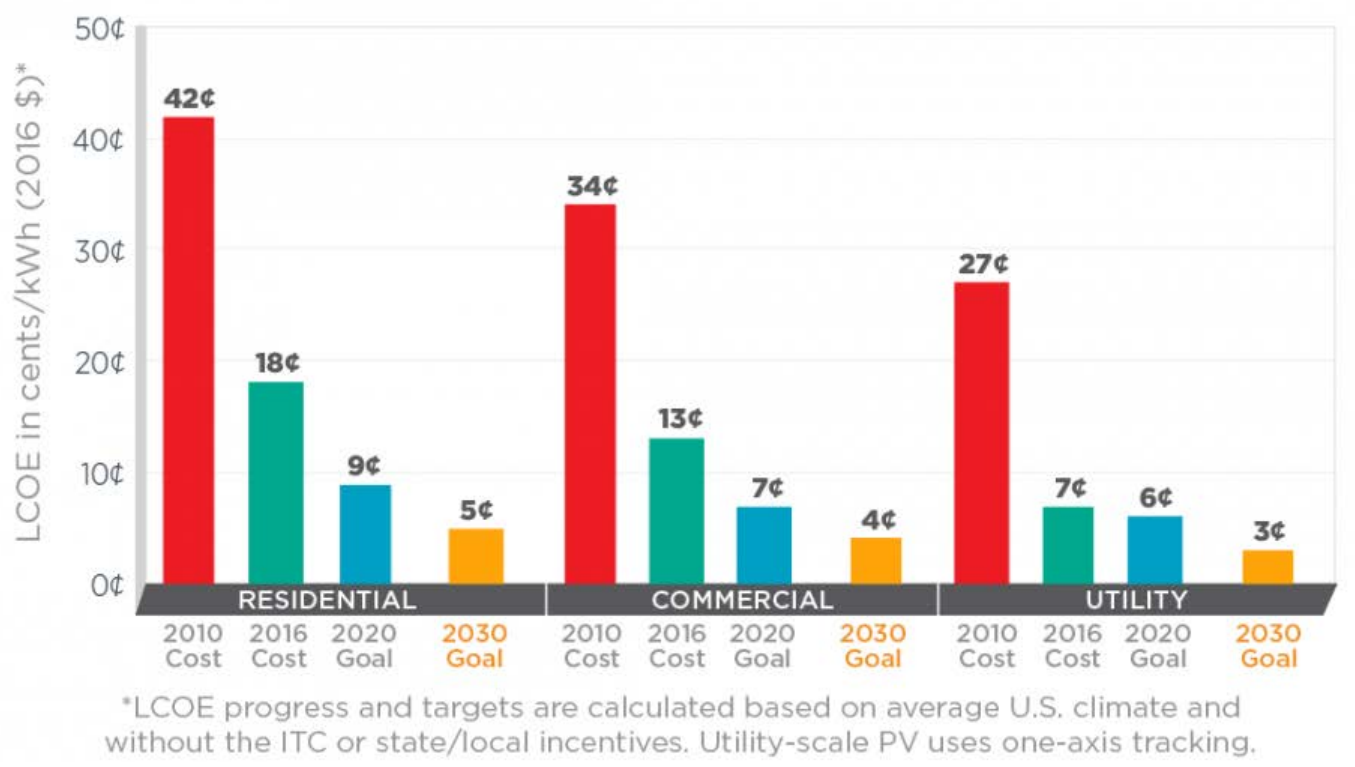

Figure 1. Historical and current PV costs and SunShot 2020 and 2030 goals (DOE 2016b)

This report analyzes the potential impacts of achieving the SunShot 2030 cost targets for the contiguous United States. ${ }^{1}$ In addition, it analyzes the impact of SunShot-level PV costs combined with low-cost energy storage. Specifically, we analyze two SunShot scenarios in comparison with a baseline scenario. Both SunShot scenarios assume that DOE's 2030 LCOE goals are achieved for utility-scale, commercial, and residential PV systems. The two SunShot scenarios differ in that one assumes mid-case storage cost reductions $(\sim \$ 260 / \mathrm{kWh}$ by 2030$)$, whereas the other assumes low storage costs (LSC) are achieved $(\sim 130 / \mathrm{kWh}$ by 2030$)$. The baseline scenario uses the mid-case PV cost values from NREL's 2016 Annual Technology Baseline (ATB), ${ }^{2}$ and it assumes the mid-case storage cost reductions.

\footnotetext{
${ }^{1}$ The post-2030 PV costs continue to decline such that 2050 PV costs are $33 \%$ lower than the 2030 targets. See Appendix D for details on pathways that can achieve these low costs.

${ }^{2}$ The ATB contains current and future cost and performance projections for the U.S. electricity sector technologies (NREL 2016). The mid-case projections from the ATB are used in these scenarios for all non-PV technologies unless otherwise stated. These mid-case projections include anticipated cost declines for all technologies. Additional details are available in Appendix A.
} 
With these assumptions, we project evolution of the contiguous U.S. electricity system using NREL's Regional Energy Deployment System (ReEDS) and Distributed Generation (dGen) models. These models have been specifically designed to represent variable renewable electricity (e.g., time and locational value of renewable energy, curtailment, and declining capacity value) in the U.S. power system. Figure 2 shows the modeled results for PV capacity. Projected PV deployment under the SunShot and SunShot LSC scenarios rapidly outpaces deployment under the baseline ATB Mid scenario, leading to a future grid system that is significantly different from today's system. The SunShot scenario sees annual PV deployment peak in 2030 at just under 55 gigawatts $(\mathrm{GW})$ /year, with post-2030 annual deployment ranging from $20 \mathrm{GW} /$ year to $40 \mathrm{GW} /$ year. The SunShot LSC scenario continues to see growth throughout the model period with average annual PV deployment levels from 2040 to 2050 reaching approximately $65 \mathrm{GW} /$ year. $^{3}$ The projected PV growth is dominated by utility-scale systems, but the actual mix of utility and distributed systems will ultimately vary depending on how policies, system costs, and rate structures evolve. Figure 3 compares the generation mixes among the SunShot, SunShot LSC, and ATB Mid scenarios.

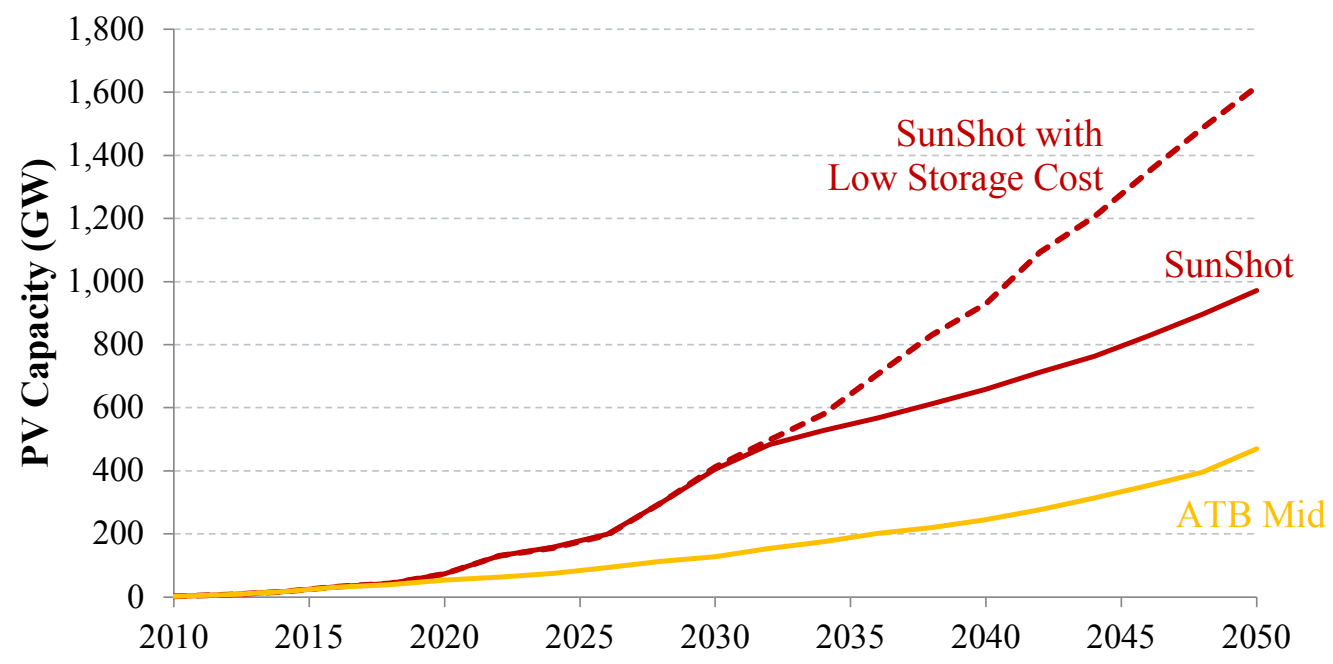

Figure 2. Cumulative PV deployment projections for the SunShot, SunShot LSC, and ATB Mid scenarios for the contiguous United States

\footnotetext{
${ }^{3}$ These annual deployment values reflect new builds only and do not include any repowered or rebuilt capacity.
} 


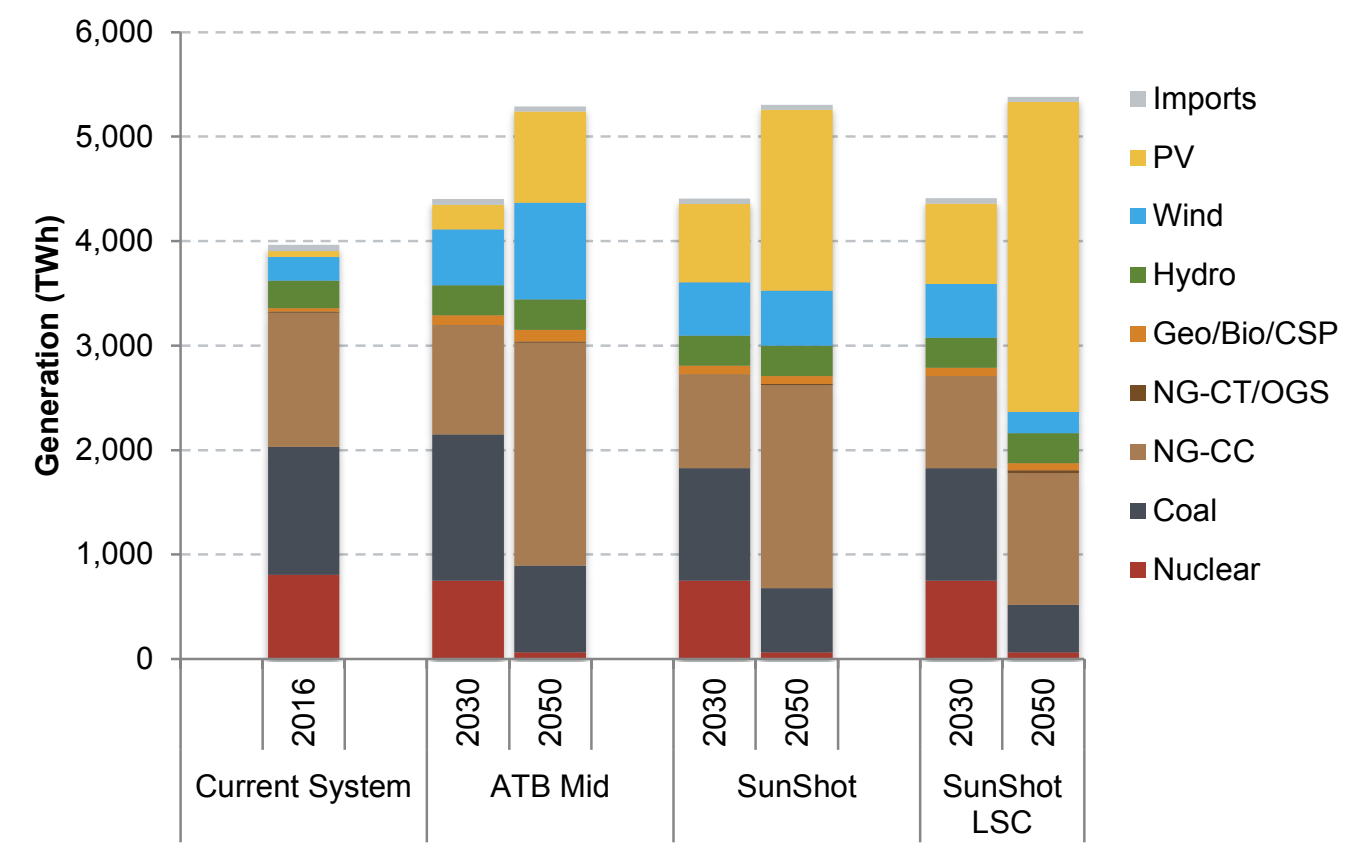

Figure 3. Generation mix in 2016, 2030, and 2050 by technology for the ATB Mid, SunShot, and SunShot LSC scenarios for the contiguous United States

NG-CC is natural gas combined cycle. NG-CT is natural gas combustion turbine. OGS is oil-gas-steam. And, Geo/Bio/CSP is geothermal, biopower, and concentrating solar power technologies. Imports are net electricity imports from Canada and Mexico.

Projected impacts of achieving the SunShot and SunShot LSC scenarios include the following:

- PV deployment increases twofold to threefold. Achieving the SunShot PV cost targets could result in $405 \mathrm{GW}$ of PV capacity in 2030, which would provide $17 \%$ of contiguous U.S. electricity generation. In 2050, deployment could rise to $971 \mathrm{GW}$, which would provide $33 \%$ of generation. With the addition of low-cost storage (i.e., by achieving the SunShot LSC scenario), 1,618 GW of PV capacity could be deployed by 2050, which would provide $55 \%$ of generation. In comparison, the ATB Mid scenario deploys only $127 \mathrm{GW}$ of PV in 2030 (5\% of generation) and $470 \mathrm{GW}$ in 2050 (17\% of generation).

- Electricity prices and electric-system costs decline. In 2030, retail electricity prices are projected to be approximately 2\% lower in the SunShot and SunShot LSC scenarios than they are in the ATB Mid scenario. By 2050 SunShot electricity prices are projected to be $1.8 \%$ lower, while SunShot LSC prices are projected to be $12 \%$ lower. This translates into a residential consumer bill savings of $\$ 2 /$ month per household (SunShot) and $\$ 13 /$ month per household (SunShot LSC). Total system costs are also projected to decline relative to the ATB Mid scenario: the SunShot scenario is projected to save (in net present value) \$194 billion through 2050 (5.1\% lower than ATB Mid), while the SunShot LSC scenario is projected to save (in net present value) \$338 billion through 2050 (9.0\% lower than ATB Mid).

- Water withdrawals and consumption are reduced. Because PV uses far less water than the conventional generators it displaces, the SunShot scenario is projected to reduce cumulative water withdrawals in the power sector by $11 \%$ and consumption by $13 \%$ 
through 2050 compared with the ATB Mid scenario. Adding low-cost storage could produce even greater benefits, potentially reducing water withdrawals by $13 \%$ and consumption by $19 \%$ through 2050 .

- Emissions of carbon dioxide $\left(\mathrm{CO}_{2}\right)$ continue to decline. Under the SunShot scenario, $\mathrm{CO}_{2}$ emissions are projected to be $22 \%$ lower in 2030 and $18 \%$ lower in 2050 compared with the ATB Mid scenario. With the addition of low-cost storage, $\mathrm{CO}_{2}$ emissions are projected to be $22 \%$ lower in 2030 and $42 \%$ lower in 2050 compared with the ATB Mid scenario.

- Relatively little additional transmission is required. In general, the greater the amount of PV deployed, the more transmission is needed to transmit electricity from PV plants to demand centers. However, this is in part mitigated by the abundance of PV energy close to load centers. In the ATB Mid scenario, transmission capacity is projected to increase by $2.5 \%$ in 2030 and $8.3 \%$ in 2050 relative to 2016, while the SunShot scenario transmission capacity is projected to increase by $3.0 \%$ in 2030 and $9.6 \%$ by 2050 . The SunShot LSC scenario requires a slightly greater level of transmission build-out, with transmission capacity projected to increase by $3.1 \%$ in 2030 and $11.9 \%$ in 2050 . These levels of transmission build-out are the same or lower than historical transmission buildout rates.

- Energy storage capacity increases dramatically when low-cost storage is available. The projected storage capacity installed in 2050 in the SunShot LSC scenario reaches $323 \mathrm{GW}$, which is roughly 6 times greater than in the SunShot scenario and 11 times greater than in the ATB Mid scenario. This dramatic increase in projected storage deployment indicates the synergistic value of low-cost flexibility in a low-cost PV future.

- Curtailment rates rise without low-cost storage, and storage losses rise with low-cost storage. In general, more PV leads to more curtailment, although low-cost storage mitigates this effect. In 2030, the curtailment rates are $2.8 \%$ in the SunShot scenario and $2.1 \%$ in the SunShot LSC scenario. In 2050, the spread is similar: 3.7\% in the SunShot scenario and $2.9 \%$ in the SunShot LSC scenario. These results compare with curtailment rates of $1.2 \%$ in 2030 and $0.7 \%$ in 2050 under the ATB Mid scenario. However, storage systems incur losses during their charge and discharge cycles. In the SunShot LSC scenario, losses due to storage are nearly the same as the losses from curtailment.

We analyze the sensitivity of the SunShot and SunShot LSC scenarios to various market assumptions, including lower and higher electricity demand growth, lower and higher natural gas prices, accelerated and extended conventional generator lifetimes, and lower and higher non-PV renewable energy technology costs. We also consider scenarios where we include cost penalties for rapid growth in PV deployment in order to represent potential supply chain constraints. These analyses provide a range of plausible projections for PV deployment when the SunShot 2030 LCOE goals are achieved (Figure 4). ${ }^{4}$ In these sensitivity scenarios PV deployment in 2030 ranges from $307 \mathrm{GW}$ (13\% of electricity supplied by PV) to $435 \mathrm{GW}(18 \%)$, and deployment in 2050 ranges from $850 \mathrm{GW}(28 \%)$ to $1,923 \mathrm{GW}(64 \%)$. The availability of low-cost storage has

\footnotetext{
${ }^{4}$ Here and throughout the report we use LCOE as a summary indicator, but the ReEDS and dGen models do not use LCOE for model decision-making.
} 
the largest impact on projected SunShot deployment, followed by natural gas prices and electricity demand.

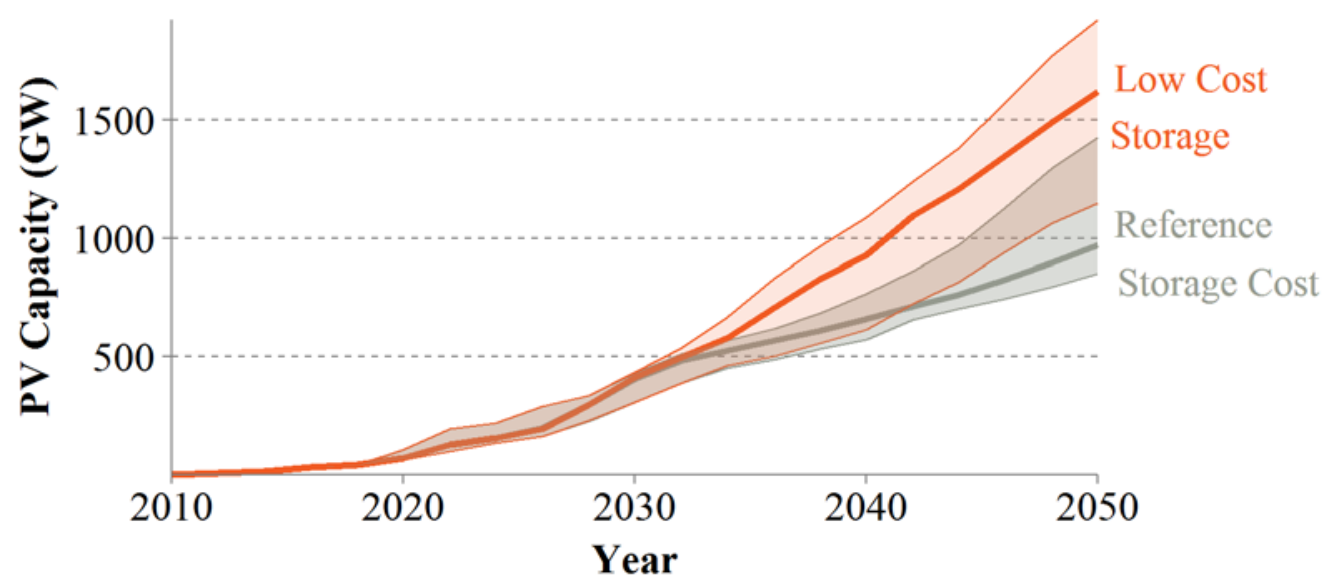

Figure 4. Cumulative PV capacity ranges for SunShot (gray) and SunShot LSC (orange) sensitivity scenarios for the contiguous United States

Bold lines show the SunShot and SunShot LSC core scenario projections. 


\section{Table of Contents}

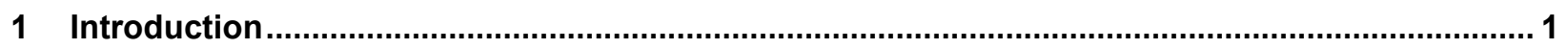

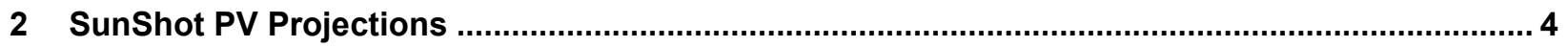

2.1 Sensitivity of SunShot Deployment Projections to Market Assumptions .................................. 13

3 Impacts of SunShot Compared with other PV Cost Scenarios …............................................... 17

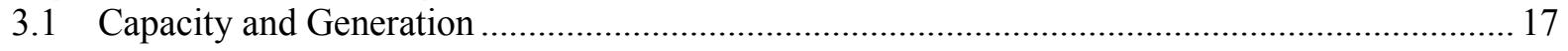

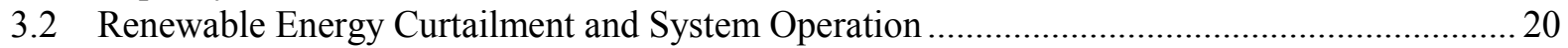

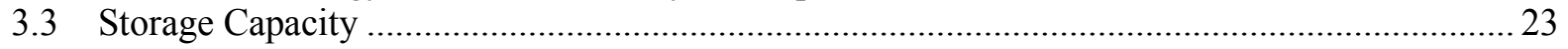

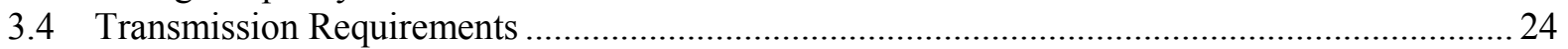

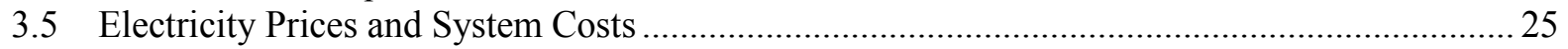

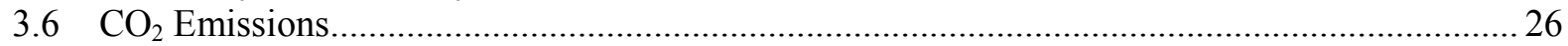

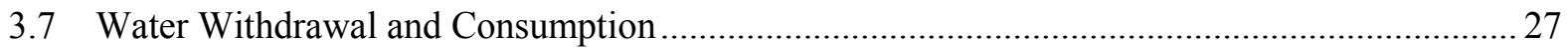

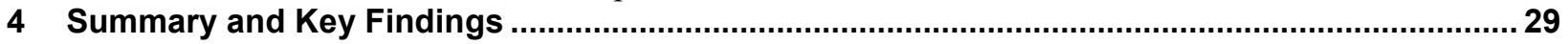

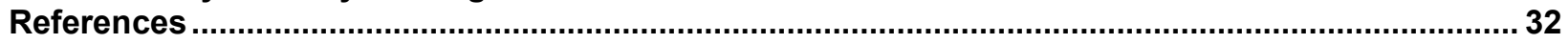

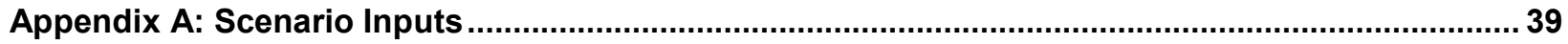

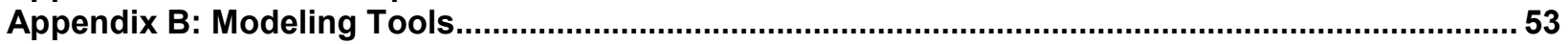

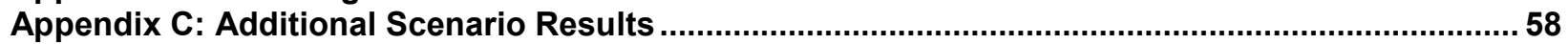

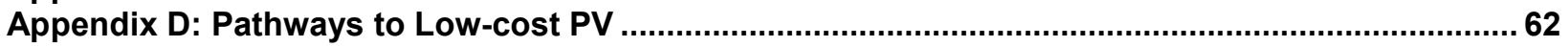

Appendix E: 8760-Based Method for Representing Variable Generation Capacity Value ................ 63 


\section{List of Figures}

Figure 1. Historical and current PV costs and SunShot 2020 and 2030 goals (DOE 2016b) .................... V Figure 2. Cumulative PV deployment projections for the SunShot, SunShot LSC, and ATB Mid scenarios for the contiguous United States ...................................................................................... vi

Figure 3. Generation mix in 2016, 2030, and 2050 by technology for the ATB Mid, SunShot, and SunShot LSC scenarios for the contiguous United States................................................... vii

Figure 4. Cumulative PV capacity ranges for SunShot (gray) and SunShot LSC (orange) sensitivity scenarios for the contiguous United States ........................................................................ ix

Figure 5. Historical and current PV costs and SunShot 2020 and 2030 goals (DOE 2016b) ..................... 1

Figure 6. Total PV deployment and UPV system price in the United States, 2009-2016....................... 2

Figure 7. Cumulative PV deployment projections for SunShot, SunShot LSC, and ATB Mid scenarios.... 6

Figure 8. Annual PV deployments for the SunShot and SunShot LSC scenarios (for new builds only,

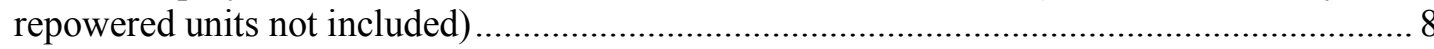

Figure 9. Cumulative PV capacity by state in 2050, SunShot scenario (left) and SunShot LSC scenario

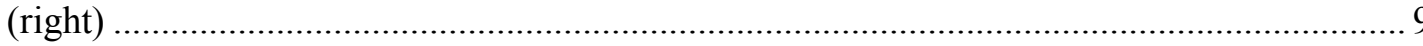

Figure 10. PV penetration (fraction of state generation supplied by PV) by state in 2050, SunShot scenario (left) and SunShot LSC scenario (right) ............................................................... 9

Figure 11. Nationwide cumulative capacity by technology and year for SunShot scenario..................... 10

Figure 12. Nationwide annual generation by technology and year for SunShot scenario ......................... 10

Figure 13. Nationwide cumulative capacity by technology and year for SunShot LSC scenario ............. 11

Figure 14. Nationwide annual generation by technology and year for SunShot LSC scenario ................. 11

Figure 15. Nationwide cumulative capacity in 2016, 2030, and 2050 by technology for the ATB Mid, SunShot, and SunShot LSC scenarios............................................................................. 12

Figure 16. Nationwide generation in 2016, 2030, and 2050 by technology for the ATB Mid, SunShot, and

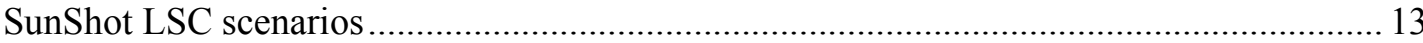

Figure 17. Wind, PV, and total RE generation (left) and capacity (right) in select RE technology sensitivities

Figure 18. Nationwide cumulative PV capacity ranges for SunShot (gray) and SunShot LSC (orange) sensitivity scenarios

Figure 19. Impact of the specified sensitivity on 2050 PV deployment relative to the SunShot and SunShot LSC reference scenarios.

Figure 20. Nationwide cumulative PV capacity by year for PV cost scenarios with and without low storage costs

Figure 21. Nationwide cumulative capacity in 2030 and 2050 by technology for PV cost scenarios with and without low storage costs

Figure 22. Nationwide generation in 2030 and 2050 by technology for PV cost scenarios with and without low storage costs

Figure 23. Nationwide cumulative DPV capacity by year for PV cost scenarios without low storage costs20

Figure 24. Total annual curtailment rate for PV cost scenarios with and without low storage costs..........21

Figure 25. Dispatch stack for four representative days (in 2050) in the SunShot scenario, showing peak generation from non-renewable energy technologies occurring during the evening .............. 22

Figure 26. Dispatch stack for four representative days (in 2050) in the SunShot LSC scenario, showing storage charging from PV during the day and discharging during the evening and night ..... 22

Figure 27. Nationwide cumulative utility-scale storage capacity for PV cost scenarios with and without low storage costs....

Figure 28. Transmission builds as a function of PV penetration (fraction of generation supplied by PV) for PV cost scenarios with and without low storage costs ............................................... 24

Figure 29. Normalized national average retail electricity prices for PV cost scenarios with and without

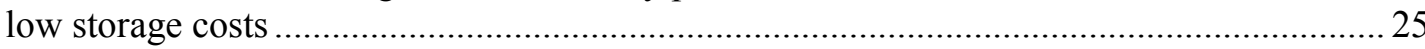

Figure 30. Total present value of system costs from 2016 to 2050 for PV cost scenarios ........................ 26 
Figure 31. Nationwide electric-sector $\mathrm{CO}_{2}$ emissions for PV cost scenarios with and without low storage costs.

Figure 32. Cumulative electric-sector water withdrawals (left) and consumption (right), 2016-2050 _.... 28

Figure 33. Utility-scale PV capital cost assumptions.......................................................................... 42

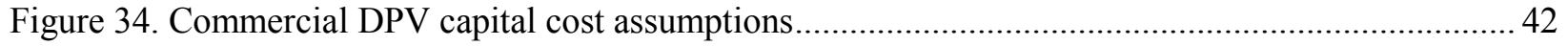

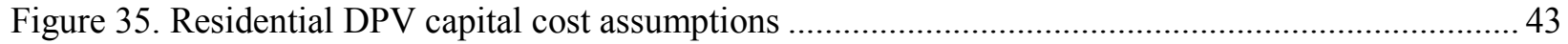

Figure 36. Capital cost projections for utility-scale battery storage systems.......................................... 47

Figure 37. Capital cost projections for commercial behind-the-meter battery systems ........................... 47

Figure 38. Capital cost projections for residential behind-the-meter battery systems ............................. 48

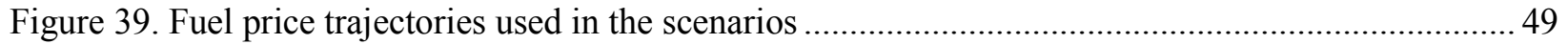

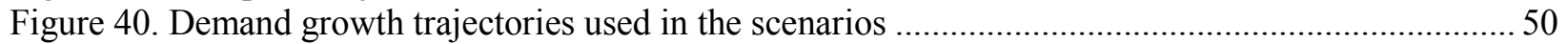

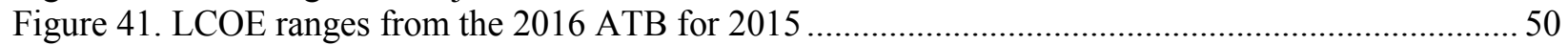

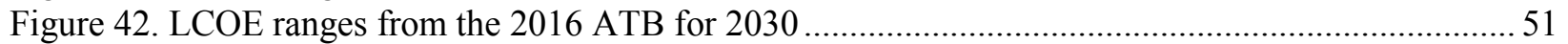

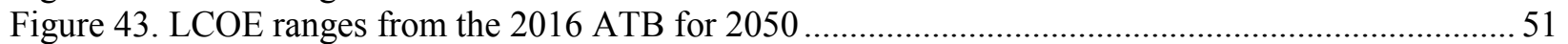

Figure 44. Map of ReEDS 134 "balancing area" regions and 18 "RTOs" ............................................ 54

Figure 45. Cumulative installed capacity in 2030 and 2050 for all reference storage cost scenarios.........59

Figure 46. Cumulative installed capacity in 2030 and 2050 for all low storage cost (LSC) scenarios....... 59

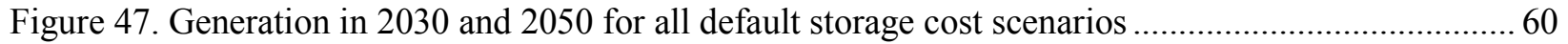

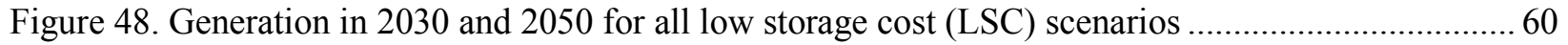

Figure 49. Six categories of LCOE input parameters and overall results under a range of assumptions... 62

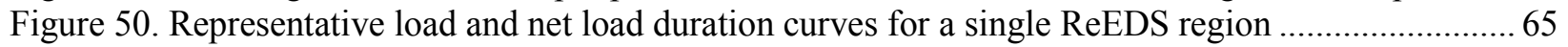

Figure 51. Load duration curve (LDC) based approach to calculating CV ............................................6 66

Figure 52. Marginal PV CV outputs from ReEDS and manual calculation with fixed minimum generation of $7.5 \mathrm{GW}$

Figure 53. Incremental PV CV in the Austin, Texas, region using the existing and new ReEDS method. 68 Figure 54. Incremental PV CV in the southern California region using the existing and

new ReEDS method 


\section{List of Tables}

Table 1. PV Cost Inputs for SunShot and Baseline Scenarios........................................................... 4

Table 2. Storage Cost Inputs used in the SunShot and Baseline Scenarios ................................................ 5

Table 3. Cumulative PV Projections for SunShot, SunShot LSC, and ATB Mid Scenarios ....................... 7

Table 4. PV Deployment in 2030 and 2050 across Sensitivity Scenarios .............................................. 15

Table 5. Cumulative PV Projections for PV Cost Scenarios with and without LSC ............................... 18

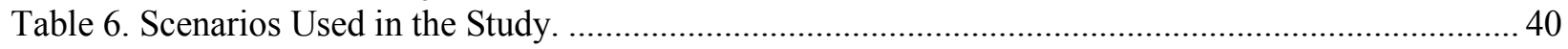

Table 7. Utility-Scale PV Operational Costs (2015\$), Performance, and Lifetime Parameters

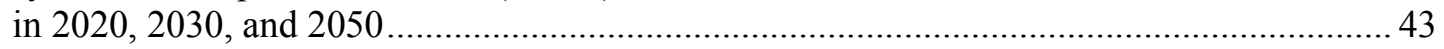

Table 8. DPV Operational Costs (2015\$), Degradation, and Lifetime Parameters

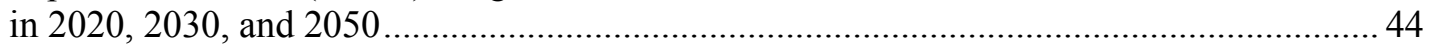

Table 9. Example of Financing Assumptions to Reach the Utility-Scale PV SunShot 2030 Target......... 46

Table 10. Example of Financing Assumptions to Reach the Residential and Commercial PV SunShot

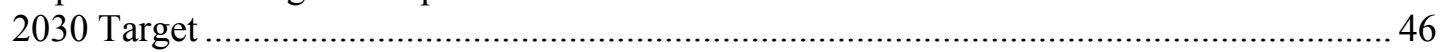

Table 11. Summary PV Deployment and Penetration in 2030 and 2050 among the 25 Scenarios Included

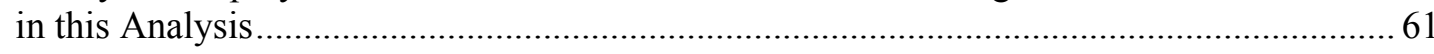




\section{Introduction}

The U.S. Department of Energy (DOE) launched the SunShot Initiative in January 2011 with the goal of making solar electricity cost competitive with conventionally generated electricity by 2020. At the time, this meant reducing photovoltaic (PV) and concentrating solar power (CSP) prices by approximately $75 \%$ - relative to 2010 costs - across the residential, commercial, and utility-scale sectors. For utility-scale solar, this target translated into an average levelized-cost of energy (LCOE) target of $\$ 0.06 / \mathrm{kWh}$ by $2020 .{ }^{5}$ To examine the implications of achieving this goal, DOE's Solar Energy Technologies Office published the SunShot Vision Study in 2012, which projected that achieving the SunShot 2020 targets could lead to solar penetration levels of $14 \%$ by 2030 and $27 \%$ by 2050 (DOE 2012). These projected penetration levels were realized through a combination of PV and CSP and would lead to a variety of benefits (DOE 2016a; Wiser, Millstein, et al. 2016).

As Figure 5 shows, today's typical utility-scale PV (UPV) prices are already approaching the original SunShot 2020 target (Bolinger and Seel 2016; Fu et al. 2016; Wesoff 2017), and distributed PV (DPV) costs have declined substantially (Barbose and Darghouth 2016). Current deployment levels of PV (Figure 6) exceed those projected in the SunShot Vision Study. This rapid progress has presented an opportunity to envision even more ambitious PV goals.

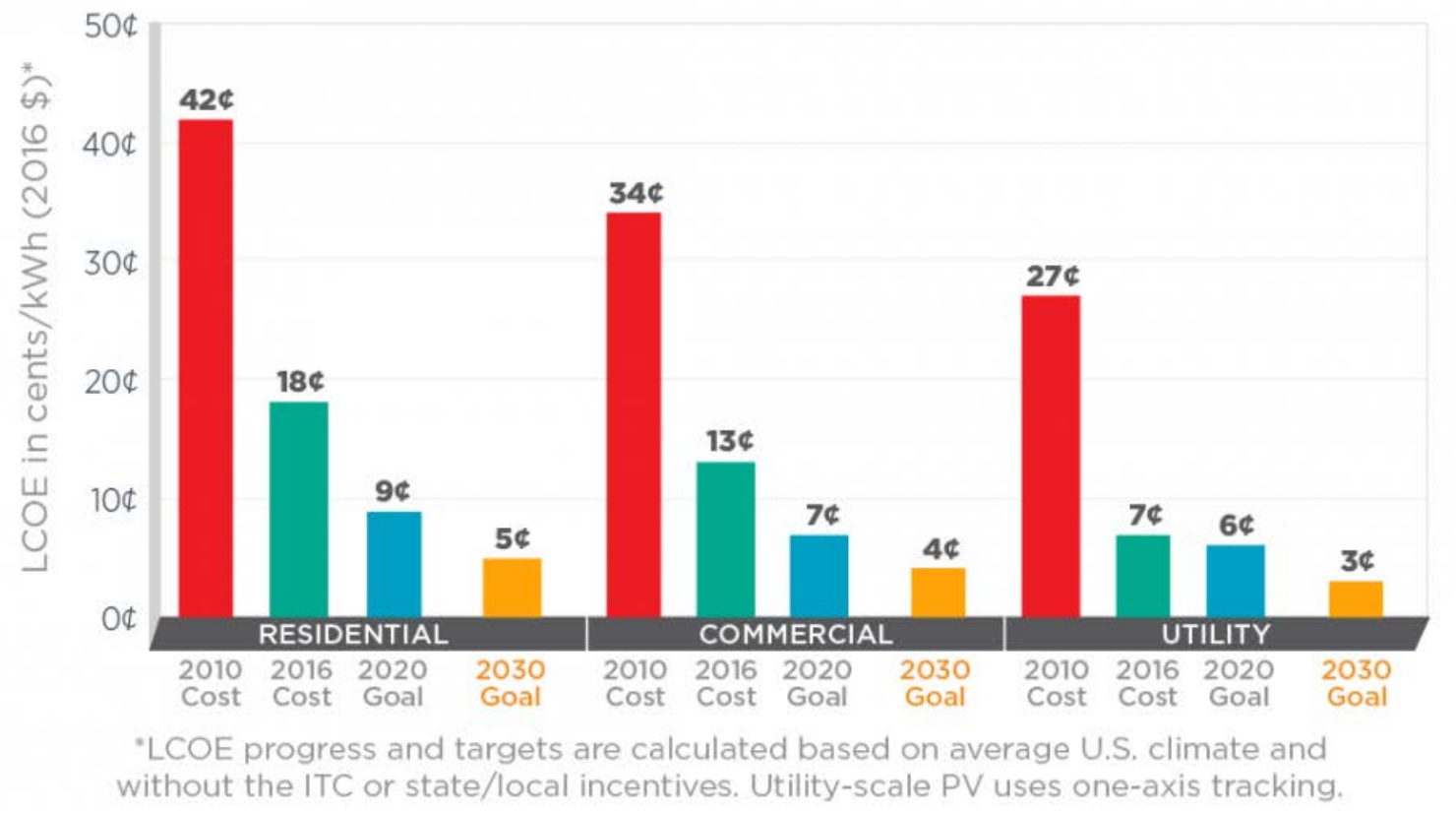

Figure 5. Historical and current PV costs and SunShot 2020 and 2030 goals (DOE 2016b)

\footnotetext{
${ }^{5}$ The LCOE is the total cost of installing and operating a generator, expressed in dollars per kilowatt-hour of electricity generated by the system over its life. It accounts for installation costs, financing costs, taxes, O\&M costs, salvage value, incentives, revenue requirements (for utility financing options), and quantity of electricity generated over the system's lifetime. The LCOEs reported in this work do not include the investment tax credit, so an LCOE goal of $\$ 0.06 / \mathrm{kWh}$ is before the investment tax credit is applied.
} 


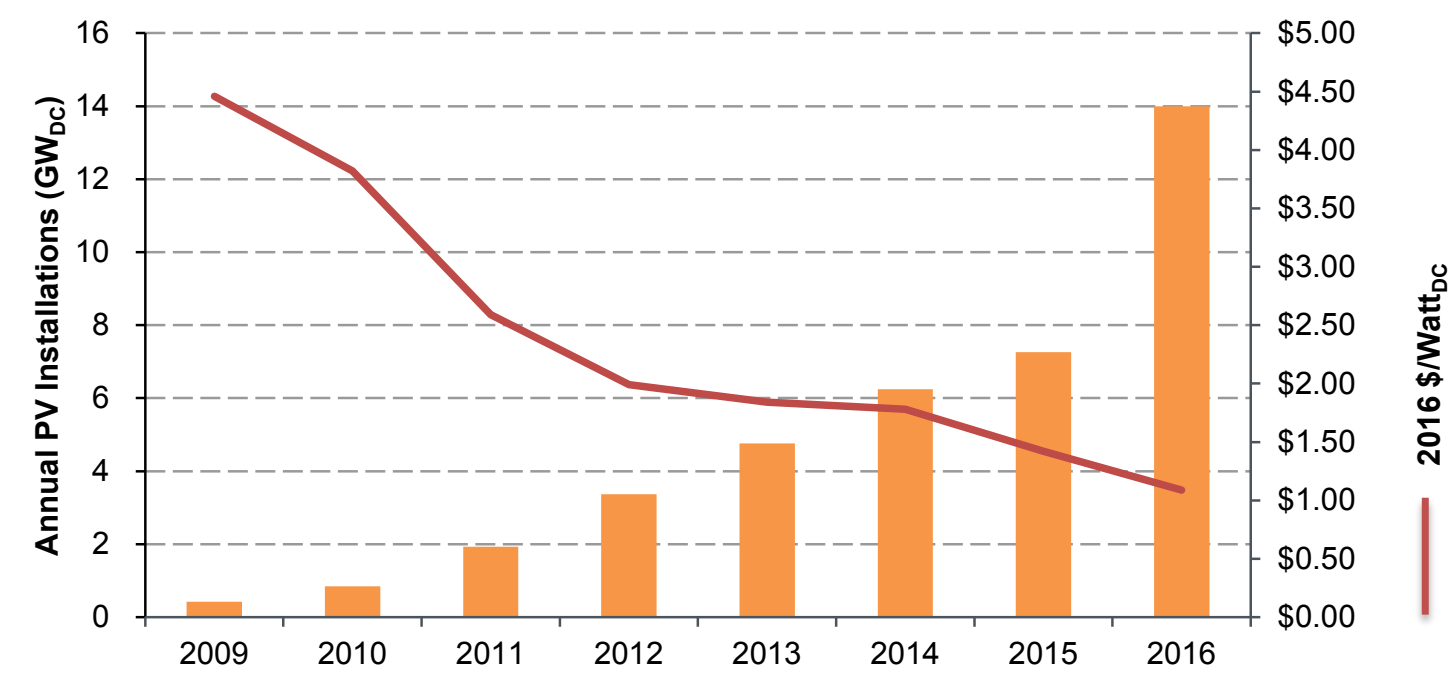

Figure 6. Total PV deployment and UPV system price in the United States, 2009-2016

Sources: Fu et al. (2016) and GTM/SEIA (2016)

At the same time, changes in the broader U.S. electricity sector suggest a need for updated PV deployment projections. Abundant low-cost natural gas made available by the shale gas revolution has driven down projected natural gas prices since the original SunShot Vision Study was published (Cole, Mai, et al. 2016). Electricity demand growth projections have slowed owing to the lingering effects of the recession as well as investments in energy efficiency. Projected wind energy costs have declined (Wiser, Jenni, et al. 2016; NREL 2016). Finally, policy changes have included updated renewable portfolio standards and extended schedules for the federal production and investment tax credits.

Within this new context, DOE recently set LCOE goals for PV to achieve by $2030: \$ 0.03 / \mathrm{kWh}$ for utility-scale, $\$ 0.04 / \mathrm{kWh}$ for commercial, and $\$ 0.05 / \mathrm{kWh}$ for residential systems. ${ }^{6}$ These SunShot 2030 goals are shown in Figure 5.

Achieving such very-low-cost PV could dramatically shift how electricity is produced and used. Considering only LCOEs, PV would outcompete many other generating technologies and undergo very rapid deployment. However, without changes to generation, transmission, and distribution systems - and to how electricity is sold to the end consumer - the value of PV will decline substantially as PV penetration increases (Mills and Wiser 2013; Denholm et al. 2016). This decline in PV value could ultimately limit the penetration of PV by reducing the economics of PV systems. The extent of that decline, however, depends on the relative costs of PV versus other generator types and on the cost of flexibility options, such as demand response and storage, which can be used to integrate PV more cost-effectively.

Previous analysis has demonstrated that grid flexibility options that have been deployed, or are in the process of being deployed, can help maintain the energy and capacity value of PV above what it costs to build, thereby increasing PV deployment. However, existing grid-flexibility options have potential limitations, and the current high cost of implementing certain

\footnotetext{
${ }^{6}$ Updated CSP targets were not announced with the SunShot 2030 targets for PV.
} 
technologies, such as energy storage, could limit how much PV can be deployed (Denholm and Margolis 2016; Denholm, Clark, and O'Connell 2016).

Reducing the costs of PV and grid-flexibility options simultaneously could spur a breakthrough, as low-cost PV makes combining PV with grid-flexibility options more affordable, and low-cost flexibility enables greater PV deployment. For this reason, DOE is incorporating grid-flexibility cost considerations with its PV cost goals. One important grid-flexibility option is energy storage, which can store PV-generated energy during the day and then discharge it when there is little or no PV resource; this capability becomes more valuable as PV deployment increases and the peak net load ${ }^{7}$ period moves from the afternoon into the evening.

In this report we project the PV deployment and associated impacts due to achieving the SunShot 2030 targets, using updated inputs and assumptions for the U.S. electricity sector. Other technologies also hold potential for large cost reductions, and these could affect grid evolution significantly (Donohoo-Vallett et al. 2017). However, because PV is the focus of this report, we include only limited analysis of varying other renewable energy costs.

We also analyze the impacts of low-cost energy storage in conjunction with low-cost PV. However, storage is only one of numerous grid-flexibility options, which also include strategies such as demand response, increased conventional generator flexibility, and expanded electricity transmission (Denholm et al. 2016). In that sense, the energy storage analysis reported here could represent other flexibility options that provide similar services at similar costs.

The remainder of this report is organized as follows. Section 2 analyzes two SunShot scenarios (one with and one without low-cost storage) in comparison with a baseline scenario, providing results in terms of projected deployment of PV and other generating technologies. Section 2 also shows the sensitivity of the SunShot scenarios to various market assumptions. Section 3 presents the impacts of the SunShot scenarios on projected renewable energy curtailment and system operation, storage capacity, transmission requirements, electricity prices and system costs, carbon dioxide $\left(\mathrm{CO}_{2}\right)$ emissions, and water withdrawal and consumption. It also compares these impacts with the impacts of six other scenarios that vary based on PV and storage costs. Finally, Section 4 offers conclusions and suggestions for future research. A set of appendices provide additional detail about the underlying assumptions, modeling tools, analysis, and results.

\footnotetext{
${ }^{7}$ Net load is load minus variable renewable energy generation.
} 


\section{SunShot PV Projections}

We analyze two SunShot scenarios in comparison to a baseline scenario. Both SunShot scenarios assume that DOE's 2030 LCOE goals are achieved for utility-scale, commercial, and residential PV systems and that costs continue to decline after $2030 .{ }^{8}$ One SunShot scenario assumes midcase storage cost declines, and the other assumes low storage costs (LSC), with both storage cost decline trajectories coming from Cole, Marcy, et al. (2016). ${ }^{9}$ The baseline scenario assumes the NREL Annual Technology Baseline (ATB) mid-case PV costs are achieved, and it assumes the mid-case storage cost declines. These scenarios represent current regulations such as renewable portfolio standards and the investment and production tax credits, but they do not include the Clean Power Plan. Non-solar generator cost and performance assumptions are taken from the 2016 ATB (NREL 2016) and fuel cost and demand projections are taken from the Annual Energy Outlook 2016 Reference Scenario (EIA 2016). For distributed PV, retail rates and net metering policies are based on current rates and policies as of spring 2017, and retail rate structures are assumed unchanged over time (e.g., we do not introduce time-of-use rates for residential customers who are currently on flat rates). Details on specific scenario inputs are provided in Appendix A, and the modeling structure and assumptions are included in Appendix B. Table 1 and Table 2 summarize the SunShot and baseline scenario PV and storage cost inputs.

Table 1. PV Cost Inputs for SunShot and Baseline Scenarios.

See Appendix A for more details on these assumptions.

\begin{tabular}{|c|c|c|c|c|c|}
\hline \multirow[b]{2}{*}{ Market Sector } & \multirow[b]{2}{*}{$\begin{array}{c}\text { Benchmark } 2016 \\
(\phi / k W h)^{\mathrm{a}}\end{array}$} & \multicolumn{2}{|c|}{2030 PV LCOE $(\phi / k W h)^{a}$} & \multicolumn{2}{|c|}{2050 PV LCOE $(\phi / k W h)^{a}$} \\
\hline & & ATB Mid & SunShot & ATB Mid & SunShot \\
\hline Utility-scale & 7 & 5.7 & 3 & 4.7 & 2 \\
\hline Commercial rooftop & 13 & 9.1 & 4 & 7 & 2.7 \\
\hline Residential rooftop & 18 & 10.2 & 5 & 8.3 & 3.3 \\
\hline
\end{tabular}

a The LCOE in the table is calculated using an "average" capacity factor, which is represented by the capacity factor that would be seen in Kansas City, Missouri. $\phi / \mathrm{kWh}=$ cents per kilowatt-hour

\footnotetext{
${ }^{8}$ Appendix D includes details on pathways that can lead to these low-cost PV targets.

${ }^{9}$ Although ReEDS also includes pumped-hydro and compressed air energy storage, the mid and low storage cost projections refer just to battery storage. Pumped-hydro and compressed air energy storage do not have assumed cost declines. These battery cost projections assume a 15 -year battery life at $\sim 1$ cycle per day and a $90 \%$ roundtrip efficiency.
} 
Table 2. Storage Cost Inputs used in the SunShot and Baseline Scenarios

See Appendix A for more details on these assumptions.

\begin{tabular}{|l|c|c|c|c|c|}
\hline \multicolumn{2}{|c|}{} & \multicolumn{2}{|c|}{$\begin{array}{c}2030 \text { Energy Storage Cost } \\
\text { (\$/kWh) }\end{array}$} & \multicolumn{2}{c|}{$\begin{array}{c}\text { 2050 Energy Storage Cost } \\
\text { (\$/kWh) }\end{array}$} \\
\hline Market Sector & $\begin{array}{c}\text { Benchmark 2016 } \\
\text { (\$/kWh) }\end{array}$ & Reference & LSC & Reference & LSC \\
\hline $\begin{array}{l}\text { Utility-scale, } \\
\text { eight hours }\end{array}$ & 479 & 264 & 131 & 220 & 97 \\
\hline $\begin{array}{l}\text { Commercial, } \\
\text { three hours }\end{array}$ & 1,034 & 663 & 450 & 537 & 300 \\
\hline $\begin{array}{l}\text { Residential, } \\
\text { three hours }\end{array}$ & 1,854 & 1,189 & 807 & 962 & 539 \\
\hline
\end{tabular}

With these assumptions, we project evolution of the contiguous U.S. electricity system using two models developed by the National Renewable Energy Laboratory. Our primary tool is the Regional Energy Deployment System (ReEDS) capacity expansion model, which relies on system-wide least-cost optimization to estimate the type and location of future generation and transmission capacity (Eurek et al. 2016). ReEDS accounts for the locational and temporal variations in variable renewable technologies, including impacts on curtailment, need for new transmission, declining capacity value, and the need to hold operating reserves to account for uncertainty in short-term renewable energy forecasts. Because ReEDS does not explicitly model distributed generation, we also use the Distributed Generation (dGen) consumer-adoption model, ${ }^{10}$ which projects adoption of U.S. rooftop PV and battery storage in the industrial, commercial, and residential sectors. This joint modeling captures the dynamic balances between growth in electricity consumption, plant retirements, competing generation options, policies, and the projected deployment and operation of behind-the-meter technologies - all of which affect the demand for new PV and storage resources. These models have been used extensively for U.S. electricity-sector analysis, especially with respect to renewable energy technologies. ${ }^{11}$ Appendix B provides details about both models, including caveats and limitations.

As shown in Figure 7, projected PV deployment under the SunShot and SunShot LSC scenarios rapidly outpaces deployment under the baseline ATB Mid scenario. In 2030, both SunShot scenarios result in just over 400 gigawatts $(\mathrm{GW})$ deployed, which is more than three times as much as in the ATB Mid scenario. By 2050, the SunShot scenario has deployed more than twice as much PV $(971 \mathrm{GW})$ as the ATB Mid scenario $(470 \mathrm{GW}),{ }^{12}$ and the SunShot LSC scenario has

\footnotetext{
${ }^{10}$ The dGen model is a rewrite of the original PVDS model (Denholm, Margolis, and Drury 2009) used in the original SunShot Vision Study.

${ }^{11}$ For related publications, see www.nrel.gov/analysis/reeds/related pubs.html (ReEDS) and www.nrel.gov/analysis/dgen/related pubs.html (dGen).

${ }_{12}$ The original SunShot Vision Study (DOE 2012) reported a 2050 PV penetration level of 27\% when achieving a $\$ 0.06 / \mathrm{kWh}$ utility-scale PV cost target using a combination of $8 \%$ CSP and 19\% PV. The lower natural gas price and wind cost projections in particular make both CSP and PV less competitive in the scenarios presented here relative to the original scenarios employed in the SunShot Vision Study. Thus, this report's SunShot scenario,
} 
deployed more than three times as much $(1,618 \mathrm{GW})$. Table 3 shows the results in terms of generation and percentage of contiguous U.S. electricity supplied by PV. These PV penetration levels in 2030, while substantially higher than current levels, are in line with what integration studies have evaluated to date (Ahlstrom et al. 2015; Brinkman et al. 2016). However, 2050 penetration levels are beyond what most integration studies have considered. ${ }^{13}$ Although system changes would need to be implemented to accommodate this higher level of PV energy, the long evaluation period does provide some opportunity to continue to increase system flexibility through increased cooperation, transmission expansion, demand response, storage, and other enabling technologies and institutional solutions.

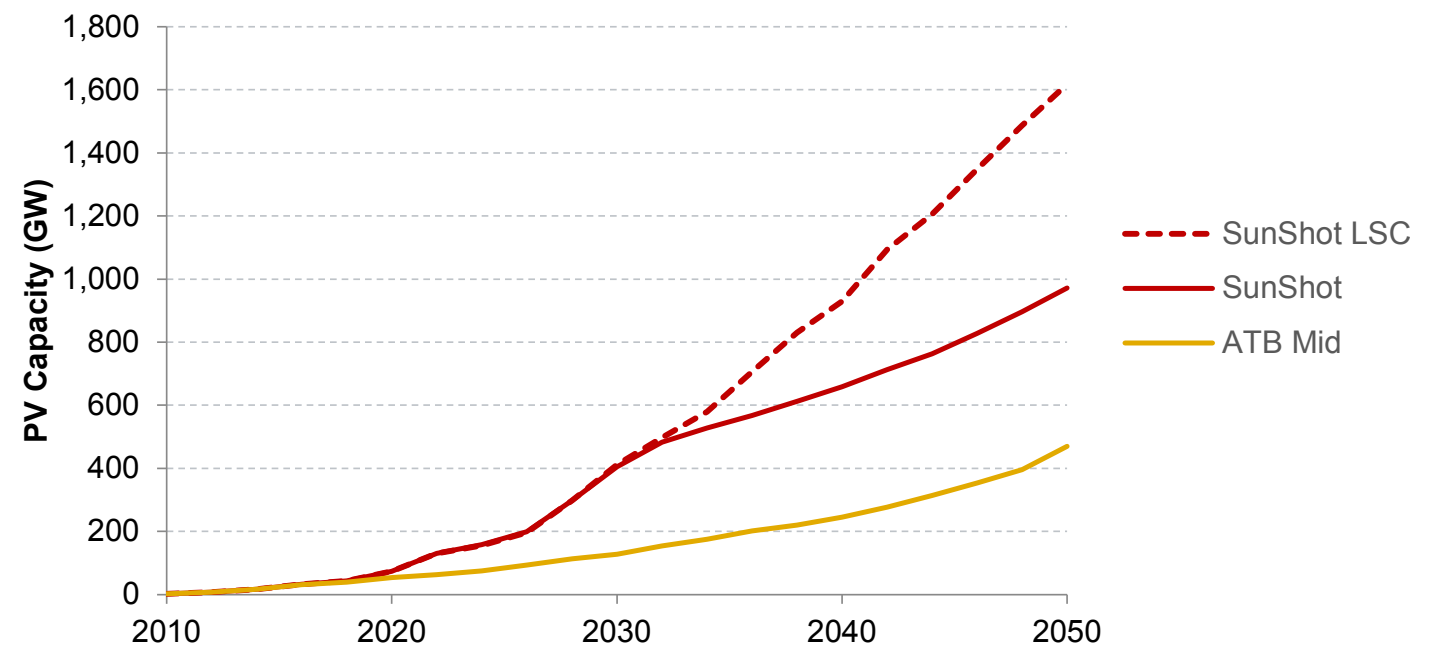

Figure 7. Cumulative PV deployment projections for SunShot, SunShot LSC, and ATB Mid scenarios

All capacity numbers presented in this section are in AC. We used an inverter loading ratio of 1.1 in the ReEDS and dGen models, so the PV capacity numbers in AC can be converted to DC by multiplying by 1.1 .

which achieves the $\$ 0.03 / \mathrm{kWh}$ utility-scale PV target in 2030, now reaches roughly the same overall level of PV penetration, but the PV mix achieving that penetration level is almost entirely PV (see Table 3).

${ }^{13}$ Some studies have looked at higher levels of renewable penetration (Mai et al. 2012; Jacobson et al. 2015; Brinkman et al. 2016), but most have not (Ahlstrom et al. 2015). 
Table 3. Cumulative PV Projections for SunShot, SunShot LSC, and ATB Mid Scenarios

\begin{tabular}{|c|c|c|c|c|}
\hline Year & Scenario & $\begin{array}{l}\text { Installed Capacity } \\
\text { (GW) }\end{array}$ & $\begin{array}{c}\text { Electricity } \\
\text { Generation (TWh) }^{\mathrm{a}}\end{array}$ & $\begin{array}{l}\text { PV Penetration (\% of } \\
\text { Electricity Supplied) }\end{array}$ \\
\hline & SunShot & 405 & 749 & $17.0 \%$ \\
\hline \multirow[t]{3}{*}{2030} & SunShot LSC & 412 & 770 & $17.5 \%$ \\
\hline & ATB Mid & 127 & 235 & $5.3 \%$ \\
\hline & SunShot & 971 & 1,729 & $32.6 \%$ \\
\hline \multirow[t]{2}{*}{2050} & SunShot LSC & 1,618 & 2,968 & $55.2 \%$ \\
\hline & ATB Mid & 470 & 872 & $16.5 \%$ \\
\hline
\end{tabular}

${ }^{\mathrm{a}} \mathrm{TWh}=$ terawatt-hour

Figure 8 shows results in terms of annual PV deployment. In both the SunShot and SunShot LSC scenarios, the impact of the investment tax credit (ITC) can be seen in the early 2020s, which leads to rapid near-term deployment follow by a short period of lower deployment rates as the ITC is stepped down. The SunShot scenario deployment peaks in 2030 at just under $55 \mathrm{GW} /$ year, with post-2030 annual deployment ranging from 20 to $40 \mathrm{GW} /$ year. Annual PV deployment in the SunShot LSC scenario generally continues to grow through 2050, with average annual deployment from 2040 to 2050 reaching about $65 \mathrm{GW} /$ year. The rapid increase in deployment that begins in the late 2020s occurs because that is when the LCOE of PV begins to drop below the marginal cost of most existing generators, meaning that is cheaper to build a new PV system than to operate an existing plant. That high level of deployment then falls in the SunShot scenario as PV curtailment increases and PV capacity value declines, but is largely maintained in the SunShot LSC scenario because storage is able to mitigate the declining value of PV. In contrast to the SunShot scenarios, the ATB Mid scenario does not reach $20 \mathrm{GW} /$ year of PV deployment until the late 2040s. 


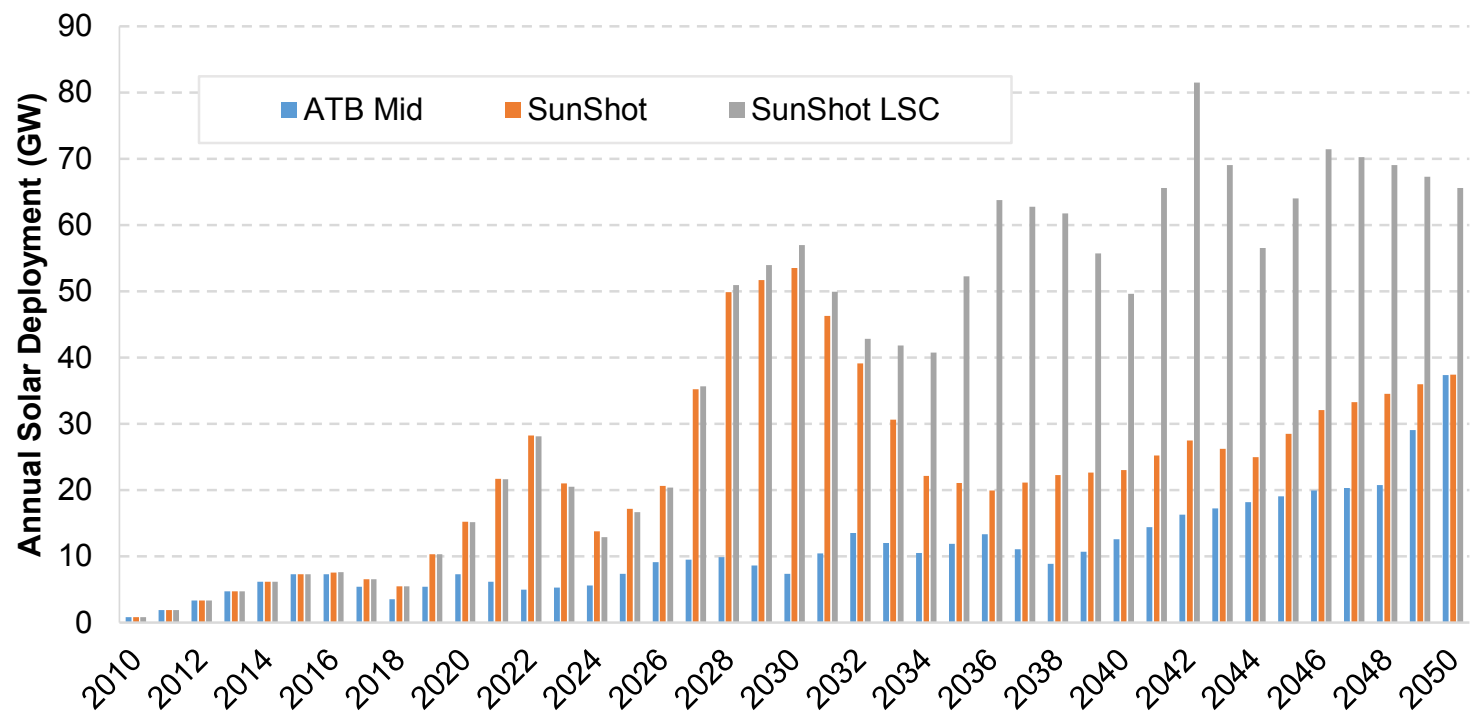

Figure 8. Annual PV deployments for the SunShot and SunShot LSC scenarios (for new builds only, repowered units not included)

ReEDS has limited foresight, so it does not do any smoothing of deployment in order to avoid ramp ups or down in deployment (e.g., ReEDS does not reduce deployment in year X so that deployment does not decrease significantly in year $\mathrm{X}+2$ ).

State-level deployment is shown in Figure 9 (cumulative capacity in 2050) and Figure 10 (fraction of state generation supplied by PV in 2050). State-level PV penetration exhibits substantial variation, ranging from 3\% to $62 \%$ in the SunShot scenario and from $13 \%$ to $81 \%$ in the SunShot LSC scenario. ${ }^{14}$ The PV capacity is not simply deployed in the best resource locations. Rather, the capacity is optimally sited based on regional capital cost difference, regional natural gas price differences, transmission needs and constraints, need for new capacity (due to load growth and retirements), and local policy differences (e.g., the presence or absence of renewable portfolio standards). In addition, value is added by smoothing out resource variability via the spreading of $\mathrm{PV}$ across a wider geographic area. ${ }^{15}$ Because of these considerations, ReEDS interprets some states as especially favorable for PV deployment. For example, Virginia's high deployment results from a relatively high PV resource, lower regional capital costs than surrounding states, high levels of power plant retirements, the state's ability to export into higher-cost regions, and a relatively poor wind resource.

\footnotetext{
${ }^{14}$ The high PV penetration values can be achieved by states exporting their electricity to neighboring regions.

${ }^{15}$ Because of the greater geographic dispersion, clouds and other localized weather effects have a lesser impact on overall system performance.
} 

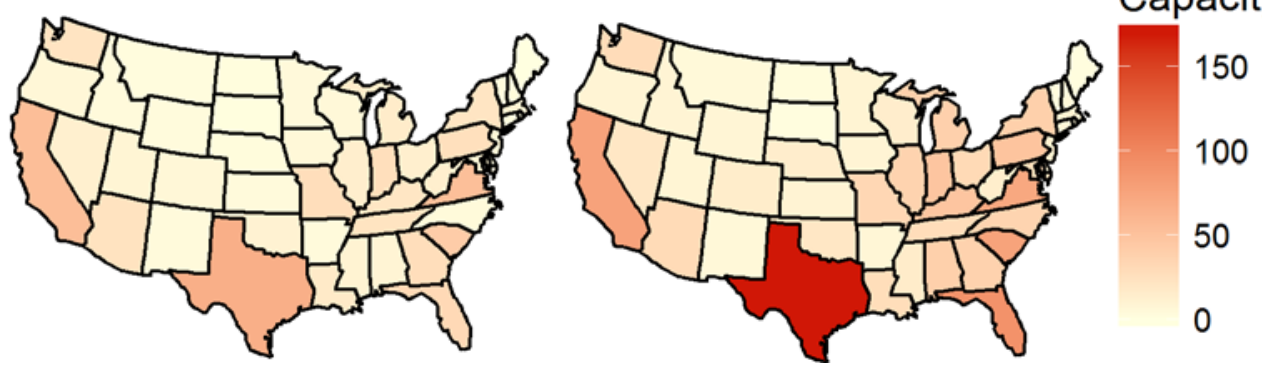

Capacity (GW)

Figure 9. Cumulative PV capacity by state in 2050, SunShot scenario (left) and SunShot LSC scenario (right)
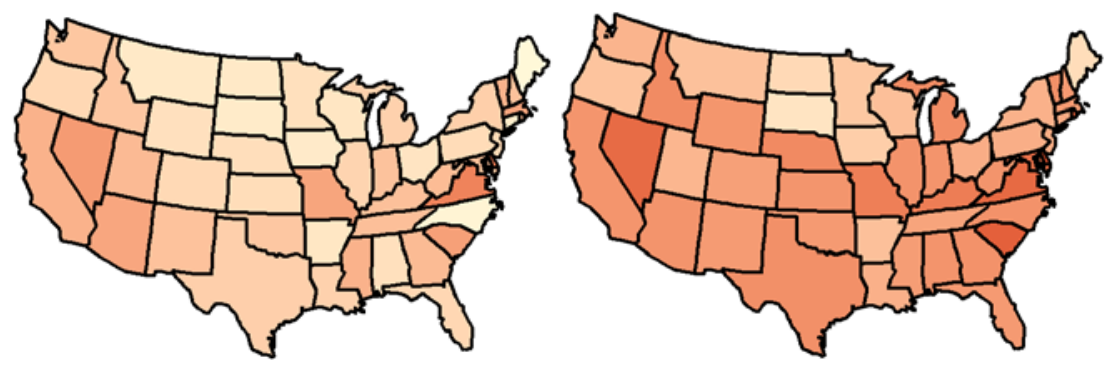

Penetration

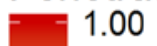

0.75

0.50

0.25

0.00

Figure 10. PV penetration (fraction of state generation supplied by PV) by state in 2050, SunShot scenario (left) and SunShot LSC scenario (right)

In the SunShot scenarios, total projected U.S. electricity-system capacity essentially doubles between today and 2050. The impact of SunShot deployment on this grid mix is shown in Figure 11 (capacity) and Figure 12 (generation), and the impact of SunShot LSC deployment is shown in Figure 13 (capacity) and Figure 14 (generation). On a capacity basis, PV grows more than any other generation type in both scenarios. Although the growth in PV generation is also dramatic, it is less pronounced than the capacity growth, owing to PV's relatively low capacity factor. By 2050 , system-wide PV capacity factors average about $20 \%$, because significant amounts of PV are deployed in lower-resource locations, and because PV curtailment increases. ${ }^{16}$

\footnotetext{
${ }^{16}$ Current PV capacity factors are around 26\% (Bolinger and Seel 2016).
} 


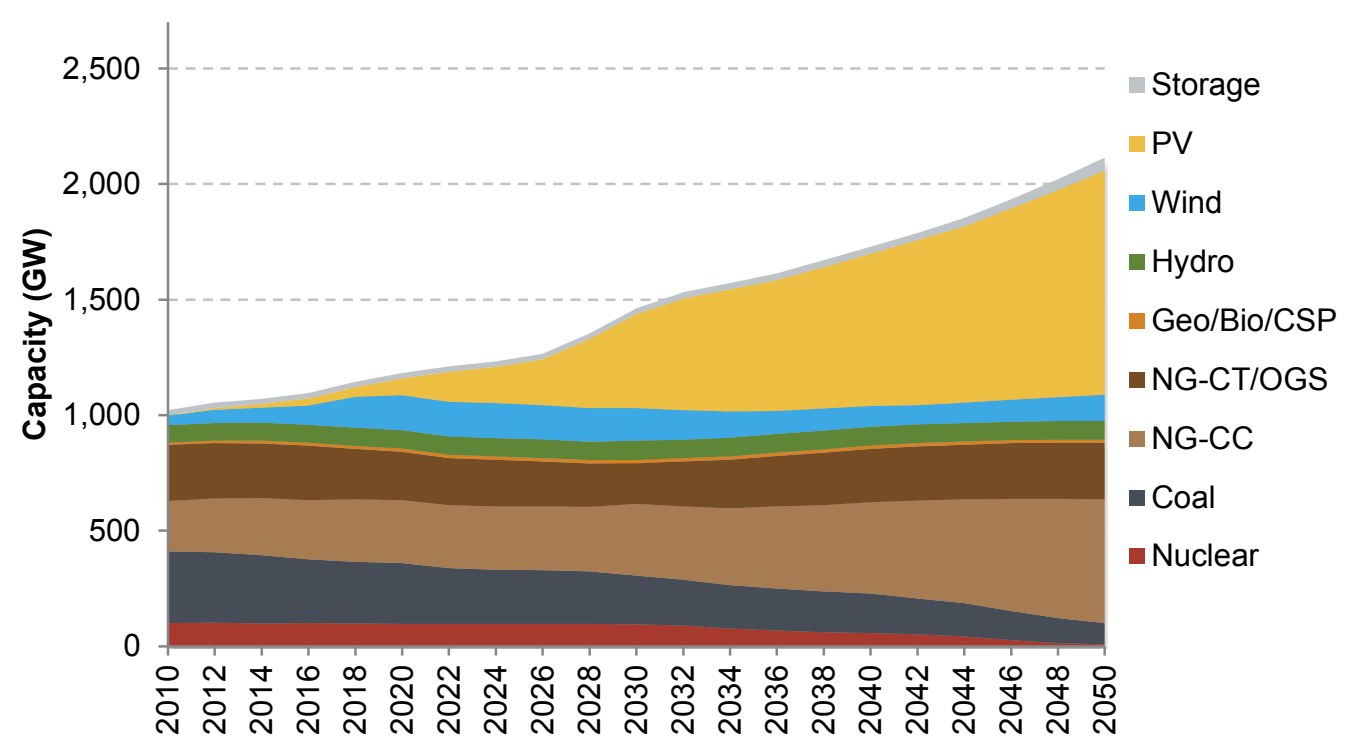

Figure 11. Nationwide cumulative capacity by technology and year for SunShot scenario NG-CC is natural gas combined cycle. NG-CT is natural gas combustion turbine. OGS is oil-gas-steam. And, and Geo/Bio/CSP is geothermal, biopower, and concentrating solar power technologies. Imports are net electricity imports from Canada and Mexico.

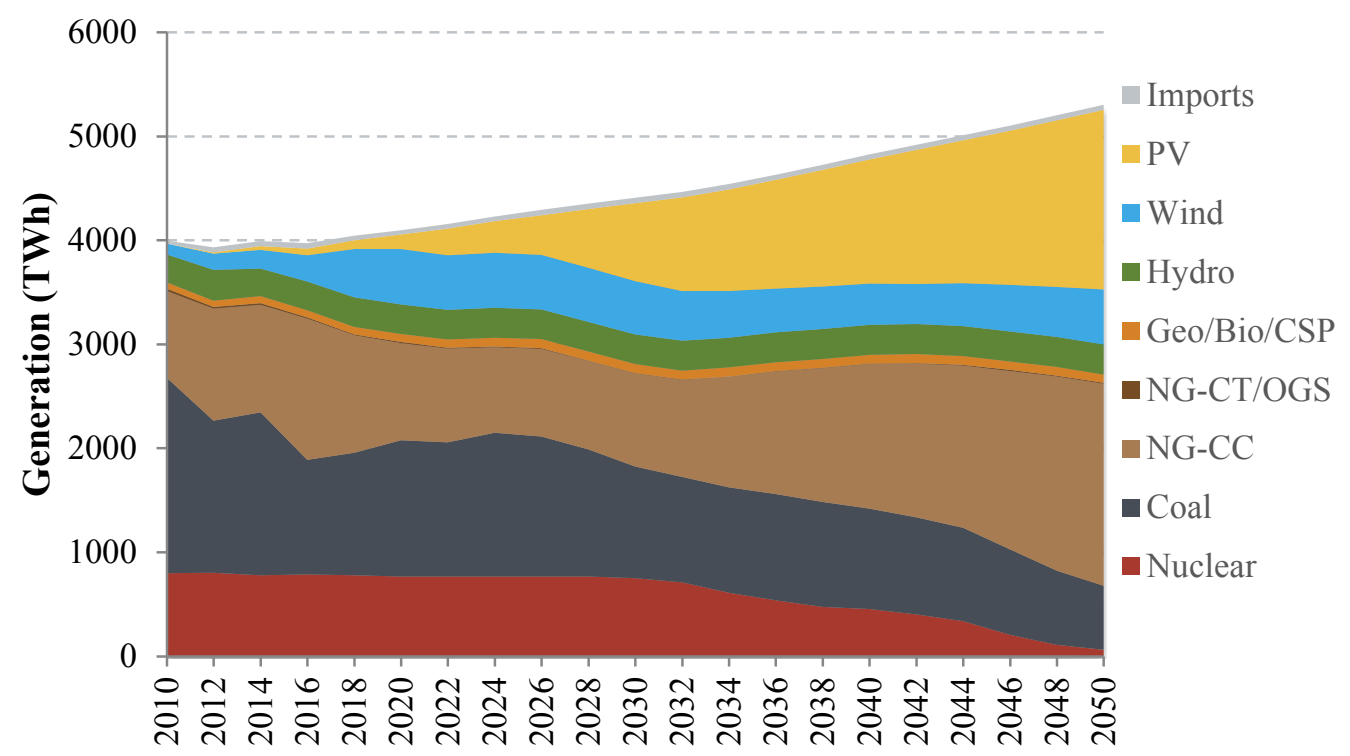

Figure 12. Nationwide annual generation by technology and year for SunShot scenario 


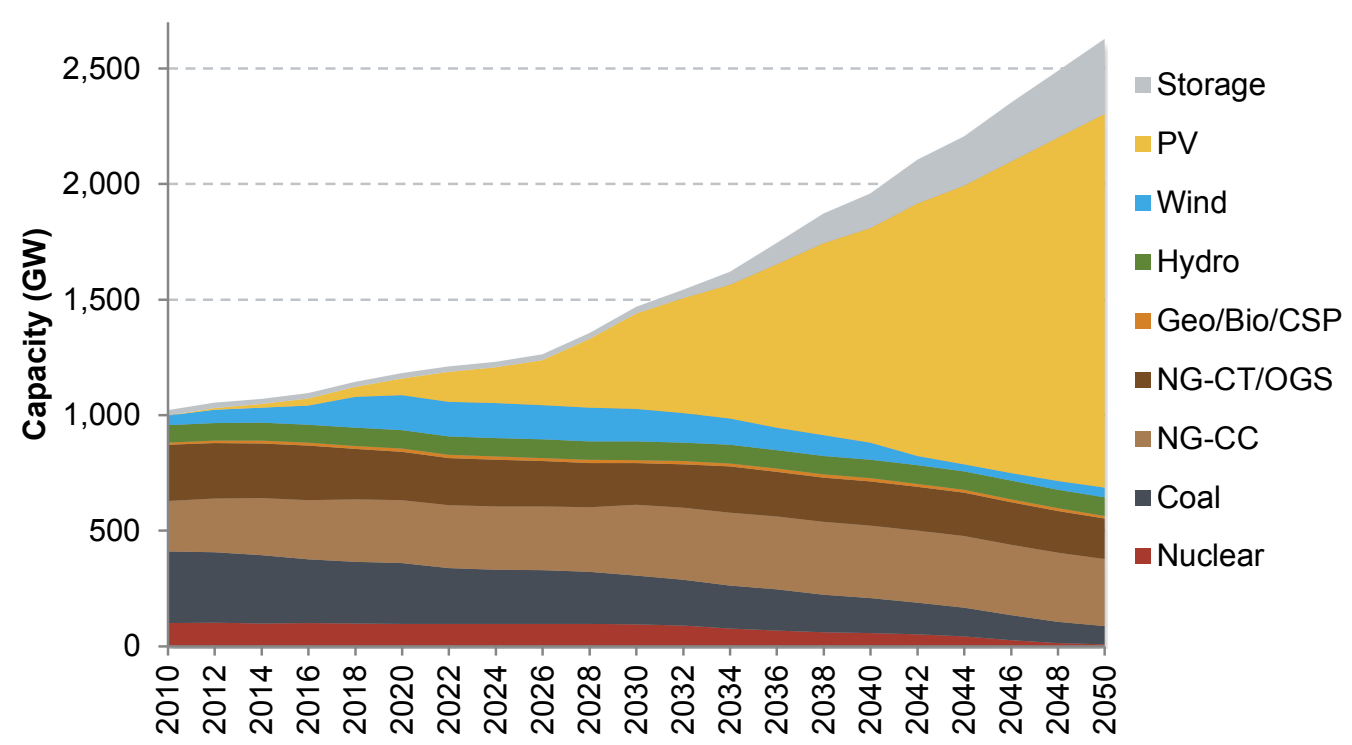

Figure 13. Nationwide cumulative capacity by technology and year for SunShot LSC scenario

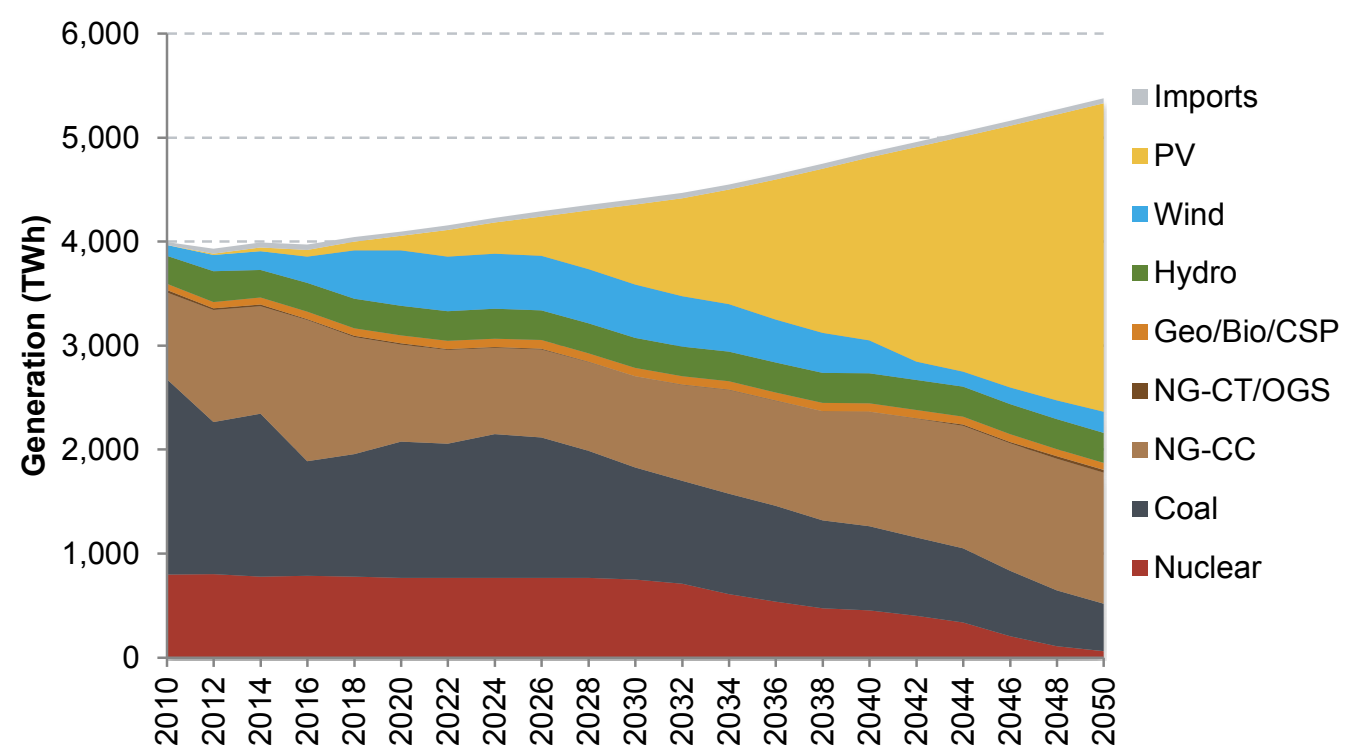

Figure 14. Nationwide annual generation by technology and year for SunShot LSC scenario

Figure 15 and Figure 16 compare the capacity and generation mixes among the SunShot, SunShot LSC, and ATB Mid scenarios. Although all the SunShot scenarios have significantly more PV capacity than the ATB Mid scenario, only the SunShot LSC scenario in 2050 has considerably less conventional capacity than its ATB Mid counterpart, with the reductions primarily coming from natural gas units. The impacts of PV deployment on the use of natural gas plants are more pronounced in the generation mixes (Figure 16). In particular, the low-cost energy storage in the SunShot LSC scenario replaces natural gas combustion turbines - because batteries function as peaking and fast-ramping units - and storage provides already-stored PV energy when PV power is unavailable, which displaces combined-cycle natural gas generation. 
Also seen in these figures is the impact of strong PV growth on wind and coal deployment. Wind capacity and generation are squeezed by the competition from low-cost PV. Coal capacity is not influenced as much as natural gas and wind, but the generation share of coal is. By the 2030s, existing coal units typically have a lower marginal cost than new or existing natural gas units, so additional energy provided by PV more often offsets natural gas generation instead of coal generation. Also, because nuclear capacity begins to retire in the 2030s (owing to the assumed 60-year lifetime for nuclear plants), coal units can fill in that baseload capacity while still ramping down during the day to accommodate more low-cost PV energy (see Section 3.2 for additional discussion of system operation).

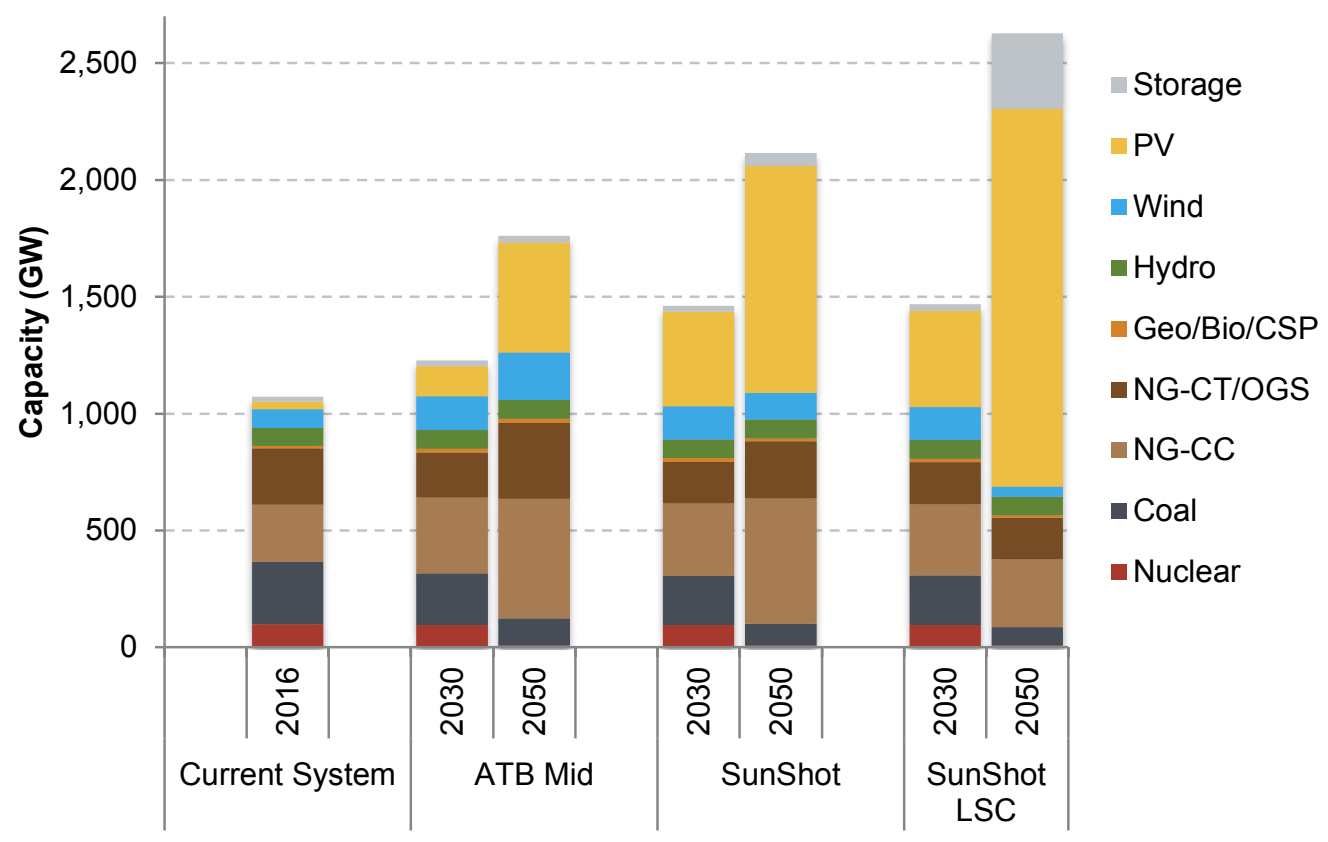

Figure 15. Nationwide cumulative capacity in 2016, 2030, and 2050 by technology for the ATB Mid, SunShot, and SunShot LSC scenarios 


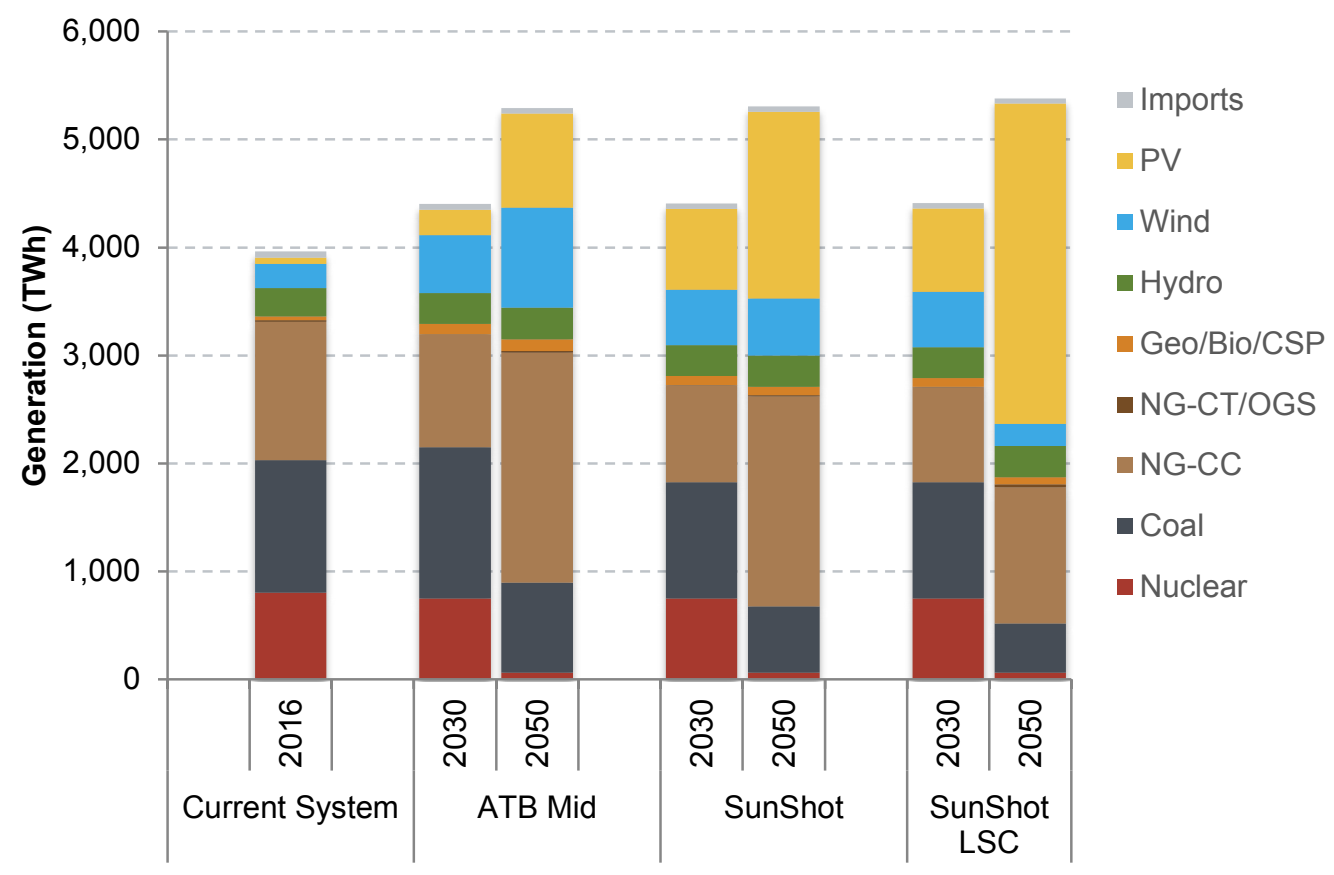

Figure 16. Nationwide generation in 2016, 2030, and 2050 by technology for the ATB Mid, SunShot, and SunShot LSC scenarios

\subsection{Sensitivity of SunShot Deployment Projections to Market Assumptions}

We analyze the sensitivity of the SunShot and SunShot LSC scenarios to various market assumptions, including lower and higher electricity demand growth, lower and higher natural gas prices, accelerated and extended conventional generator lifetimes, and lower and higher non-PV renewable energy technology costs. The scenario definitions are taken from the suite of 2016 Standard Scenarios (Cole, Mai, et al. 2016). We also include a scenario that includes growth penalties on utility-scale PV. See Appendix A for details on how the sensitivity scenario inputs are defined.

These analyses provide a range of plausible projections for the SunShot and SunShot LSC scenarios. As shown in Figure 18 and Table 4, 2030 PV deployment ranges from $307 \mathrm{GW}$ (13\% of electricity demand met by PV) to $435 \mathrm{GW}(18 \%),{ }^{17}$ and 2050 deployment ranges from $850 \mathrm{GW}(28 \%)$ to $1,923 \mathrm{GW}(64 \%)$. A more complete set of result for the sensitivity scenarios are presented in Appendix C. Text Box 1 presents a special sensitivity case in which both PV and wind achieve their new goals.

\footnotetext{
${ }^{17}$ Nearly all of the PV capacity is from PV, because no new CSP is built by the model except in the ATB Mid and High NG Price scenarios.
} 


\section{Text Box 1. Wind Atmosphere to Electrons (A2e) Initiative Sensitivity}

This analysis focuses on the impacts of PV technology advancements under a range of future market conditions, including a range of non-wind renewable energy (RE) technology costs. However, this range does not encompass all possibilities and it excludes DOE's recently announced Atmosphere to Electrons (A2e) initiative (Dykes et al. 2017; Mai et al. forthcoming), where wind technology cost reductions exceed those in the lowest cost projections modeled in our market sensitivity scenarios (i.e., Low RE Cost scenario). In this text box, we show RE capacity and generation results assuming successes in both PV and wind technologies by using SunShot 2030 and A2e projections, respectively. These results are compared to the SunShot scenario. Both scenarios use the SunShot assumptions for all settings except for the wind costs.

The dotted lines in Figure 17 show annual generation and capacity results from the SunShot $+\mathrm{A} 2 \mathrm{e}$ scenario in which RE generation grows consistently over time and is projected to serve a large majority of total generation needs by 2050. In 2050, wind and solar generation together comprise $90 \%$ of all RE generation. Installed capacity results follow similar trends with total RE capacity exceeding $1,300 \mathrm{GW}$ by 2050 , including over 500 GW from wind and over $700 \mathrm{GW}$ from PV technologies.

The solid lines in the figure show results for the SunShot scenario which has more-modest wind technology advancements. As would be expected, wind penetration and deployment are lower in this scenario and PV growth is greater than in the SunShot + A2e scenario. However, we find that aggregate RE generation and capacity are higher when both wind and PV achieve their greatest technology advancements, demonstrating that successful technology innovations in both would yield even greater system benefits than success in any single individual technology.
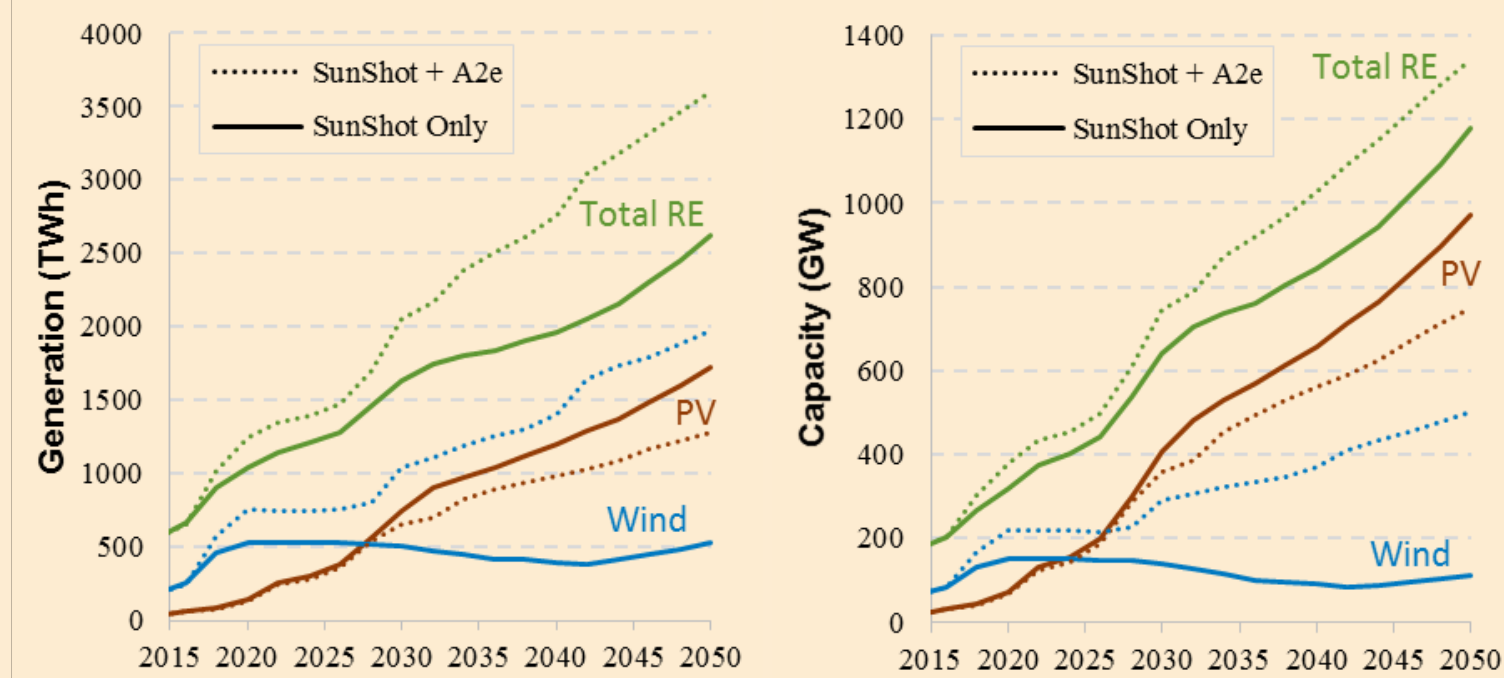

Figure 17. Wind, PV, and total RE generation (left) and capacity (right) in select RE technology sensitivities 


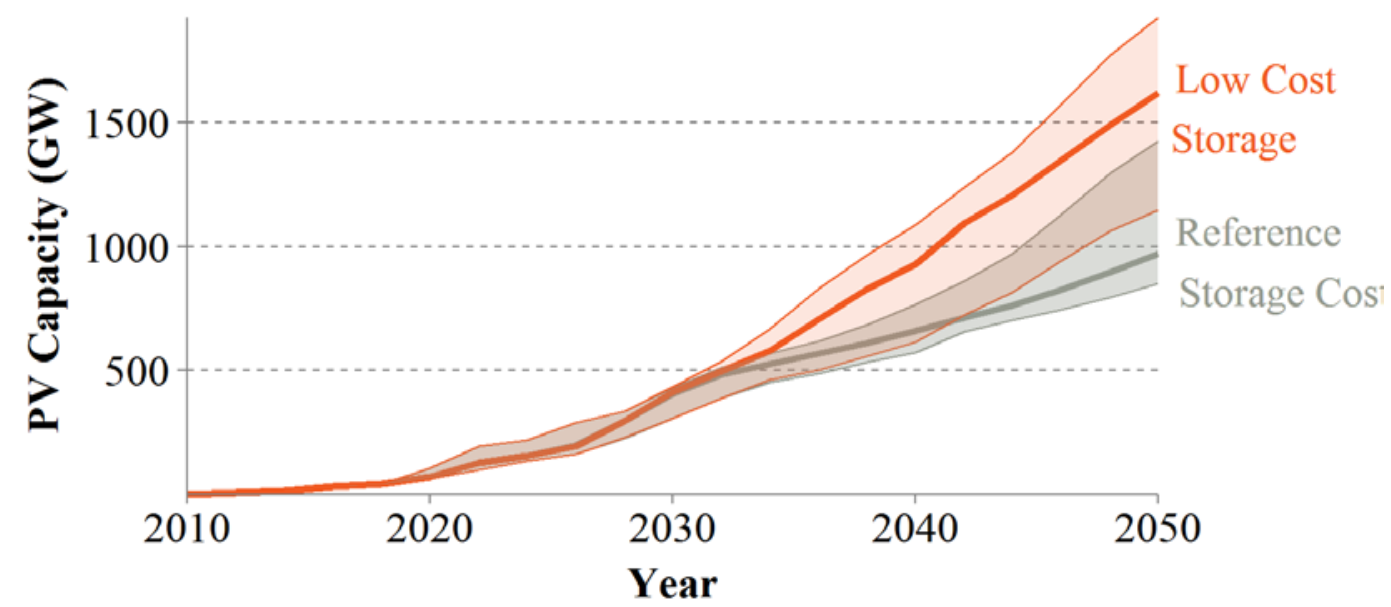

Figure 18. Nationwide cumulative PV capacity ranges for SunShot (gray) and SunShot LSC (orange) sensitivity scenarios

Bold lines show the SunShot and SunShot LSC core scenario projections.

Table 4. PV Deployment in 2030 and 2050 across Sensitivity Scenarios

\begin{tabular}{lcccc}
\hline & \multicolumn{2}{c}{ PV Capacity (GW) } & \multicolumn{2}{c}{$\begin{array}{c}\text { PV Penetration (\% of } \\
\text { Electricity Supplied) }\end{array}$} \\
Scenario Set & $\mathbf{2 0 3 0}$ & $\mathbf{2 0 5 0}$ & $\mathbf{2 0 3 0}$ & $\mathbf{2 0 5 0}$ \\
\hline SunShot-reference storage cost & $307-431$ & $850-1,426$ & $13 \%-18 \%$ & $28 \%-46 \%$ \\
SunShot LSC -low storage cost & $307-435$ & $1,148-1,923$ & $13 \%-18 \%$ & $41 \%-64 \%$ \\
\hline
\end{tabular}

The sensitivity scenarios also quantify which factors produce the largest impact on projected PV deployment. Clearly, from Figure 18 and Table 4, the availability of low-cost storage has the largest impact on projected deployment. Assuming low-cost storage instead of reference-cost storage increases $2050 \mathrm{PV}$ capacity by an average of more than $50 \%$ across the sensitivity scenarios. Among the other factors considered, natural gas prices and electricity demand have the next-largest impacts on PV capacity (see Figure 19). Natural gas is projected to be a costeffective technology well into the future (Cole, Mai, et al. 2016), but deviations in expected natural gas prices can yield much greater or lesser deployment of natural gas technologies. Increasing or decreasing demand directly impacts the need for new capacity, including PV capacity. In addition, extending the lifetime of the nuclear fleet by 20 years (low retirements) decreases PV deployment substantially by reducing the need for new capacity and - because nuclear generation is highly inflexible - making it more challenging to integrate larger quantities of variable renewable energy. 


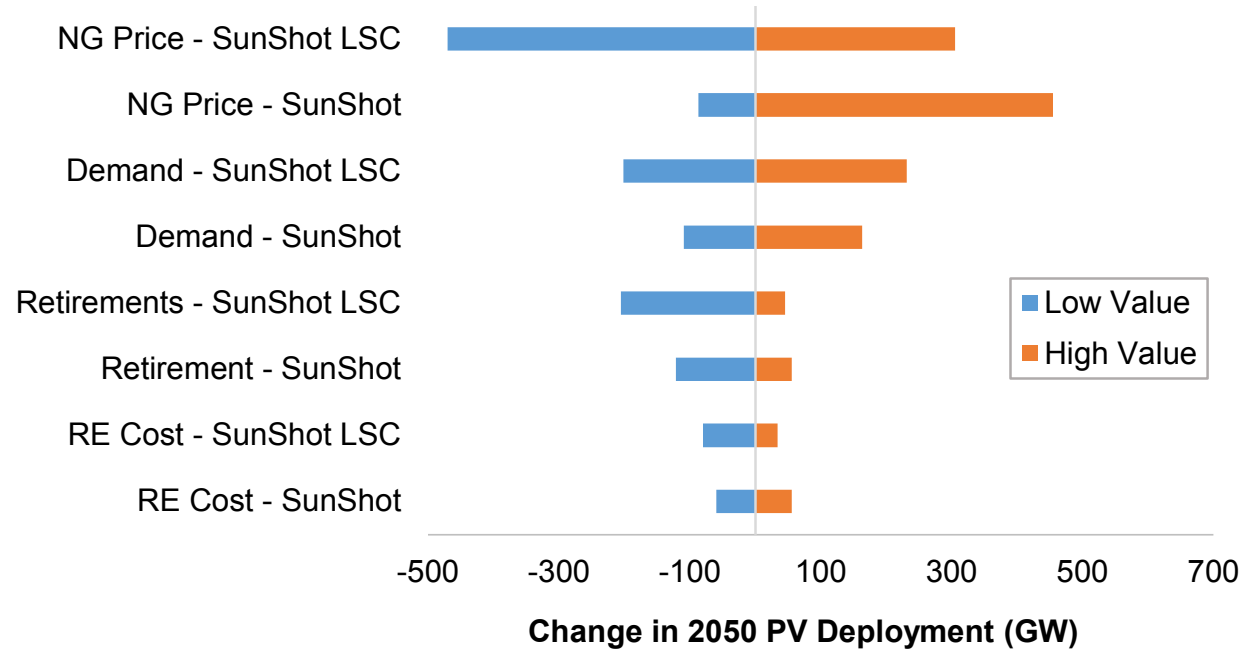

Figure 19. Impact of the specified sensitivity on 2050 PV deployment relative to the SunShot and SunShot LSC reference scenarios

Details of the sensitivities are provided in Appendix A, but a summary of the magnitudes is provided here. The natural gas price scenarios represent changes in 2050 natural gas prices of $-40 \%$ and $+70 \%$. The demand scenarios have changes of $-33 \%$ and $+40 \%$ in the average growth rate. The high retirements shorten coal plant lifetimes by 10 years and the low retirements increase nuclear lifetimes by 20 years. And, the RE costs scenarios change costs by $-34 \%$ to $+58 \%$, depending on the technology. 


\section{Impacts of SunShot Compared with other PV Cost Scenarios}

This section compares the impacts of the SunShot and SunShot LSC scenarios-which assume PV LCOEs of $3 \phi / \mathrm{kWh}$ (utility-scale), $4 \phi / \mathrm{kWh}$ (commercial), and $5 \phi / \mathrm{kWh}$ (residential) in 2030 - with the impacts of scenarios that underachieve or overachieve with respect to those SunShot LCOE goals. The overachieving scenarios assume the PV LCOEs reach 33\% below the SunShot LCOE in 2030 (i.e., utility PV reaches $2 \notin / \mathrm{kWh}$ in 2030), with one scenario that uses reference storage costs and another that uses low storage costs (LSC). These scenarios are named $33 \%$ Below and 33\% Below LSC. ${ }^{18}$ A similar pair of scenarios-named 33\% Above and 33\% Above LSC - assumes PV LCOEs are 33\% higher than the SunShot targets in 2030 (i.e., utility PV reaches $4 \phi / \mathrm{kWh}$ in 2030). We also include additional ATB mid-case scenarios, one with LSC and another (which we only use for comparing $\mathrm{CO}_{2}$ emissions projections) that includes the U.S. Environmental Protection Agency's Clean Power Plan (CPP). Impacts considered include PV capacity and generation (Section 3.1), renewable energy curtailment and system operation (3.2), storage capacity (3.3), transmission requirements (3.4), electricity prices and system costs (3.5), $\mathrm{CO}_{2}$ emissions (3.6), and water withdrawal and consumption (3.7).

We chose to represent the impacts listed above using cost sensitivities because of the large uncertainty related to projections that extend decades into the future (see Section 2.1). The higher and lower cost scenarios lead to higher and lower amounts of PV deployment, so in showing the impact across these cost sensitivity scenarios we can at least approximately capture the impact of over or underestimating the amount of PV that might be deployed in the types of low-cost PV futures envisioned in this work.

\subsection{Capacity and Generation}

Figure 20 shows the PV capacity projections for each scenario. Total PV deployment is a function of PV costs and storage costs. The lower storage costs let the growth that occurs prior to 2035 continue into the 2040 s rather than slow down. In the most optimistic cost scenario, the PV penetration reaches $62 \%$ by 2050 (Table 5 ).

\footnotetext{
${ }^{18}$ Appendix D includes details for how these cost pathways might be achieved.
} 


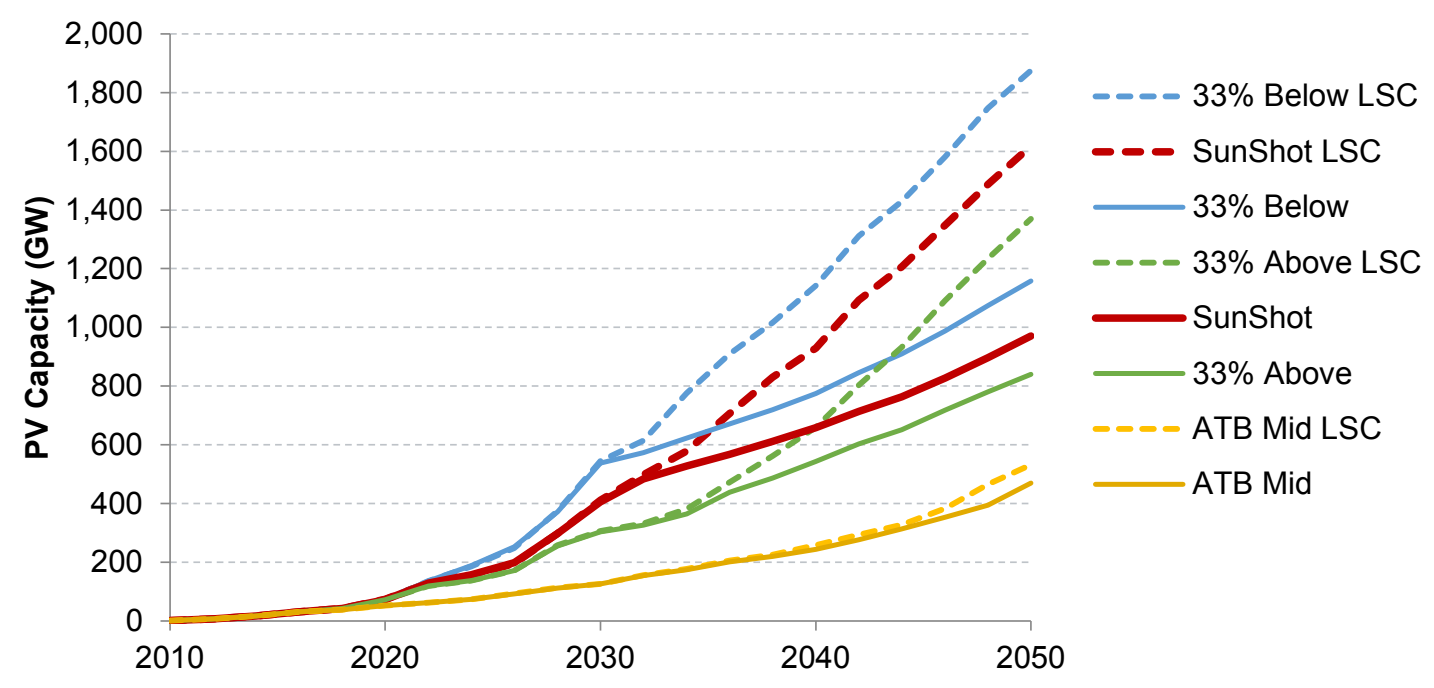

Figure 20. Nationwide cumulative PV capacity by year for PV cost scenarios with and without low storage costs

Table 5. Cumulative PV Projections for PV Cost Scenarios with and without LSC

\begin{tabular}{lcccc}
\hline & \multicolumn{2}{c}{ PV Capacity (GW) } & \multicolumn{2}{c}{$\begin{array}{c}\text { PV Penetration (\% of } \\
\text { Electricity Supplied) }\end{array}$} \\
Scenario & $\mathbf{2 0 3 0}$ & $\mathbf{2 0 5 0}$ & $\mathbf{2 0 3 0}$ & $\mathbf{2 0 5 0}$ \\
\hline 33\% Below & 537 & 1,158 & $22.5 \%$ & $38.0 \%$ \\
\hline SunShot & 405 & 971 & $17.0 \%$ & $32.6 \%$ \\
\hline 33\% Above & 303 & 840 & $13.0 \%$ & $28.8 \%$ \\
ATB Mid & 127 & 470 & $5.3 \%$ & $16.5 \%$ \\
\hline $33 \%$ Below LSC & 545 & 1,875 & $23.0 \%$ & $61.8 \%$ \\
\hline SunShot LSC & 412 & 1,618 & $17.5 \%$ & $55.2 \%$ \\
\hline 33\% Above LSC & 306 & 1,370 & $13.2 \%$ & $48.2 \%$ \\
\hline ATB Mid LSC & 127 & 532 & $5.3 \%$ & $19.1 \%$ \\
\hline
\end{tabular}

Figure 21 and Figure 22 show the capacity and generation mixes for each cost scenario in 2030 and 2050. The capacities of the conventional plants (nuclear, gas, and coal-fired plants) do not have large differences among the scenarios without low-cost storage. With low-cost storage, however, conventional capacities decrease as PV costs decrease. Figure 22 demonstrates that additional PV generation has the largest impact on coal in 2030 and on wind in 2050. With LSC, $\mathrm{PV}$ primarily offsets coal generation in 2030 and natural gas generation in 2050, though wind is also largely impacted in 2050 . 


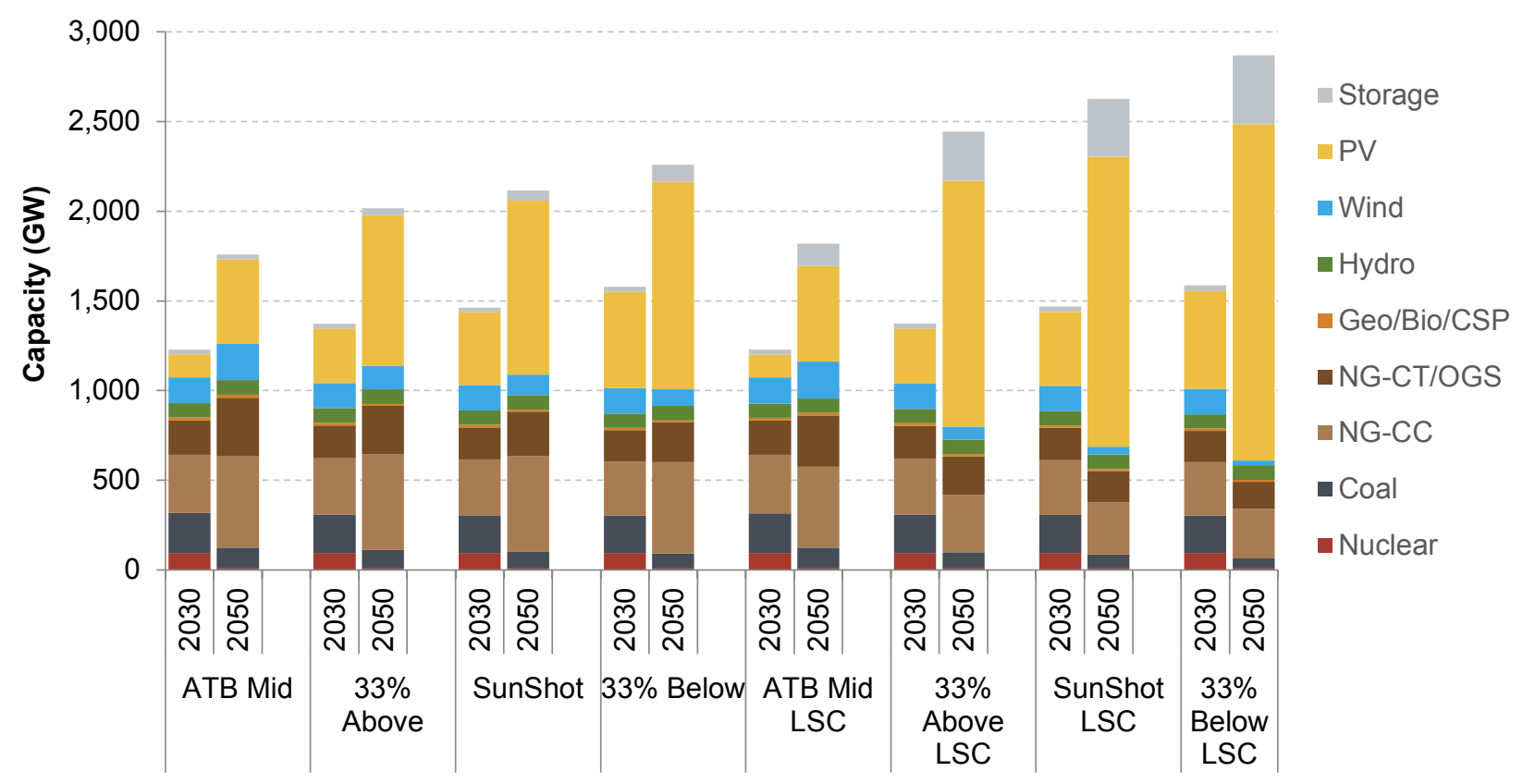

Figure 21. Nationwide cumulative capacity in 2030 and 2050 by technology for PV cost scenarios with and without low storage costs

NG-CC is natural gas combined cycle. NG-CT is natural gas combustion turbine. OGS is oil-gas-steam. And, Geo/Bio is geothermal and biopower technologies.

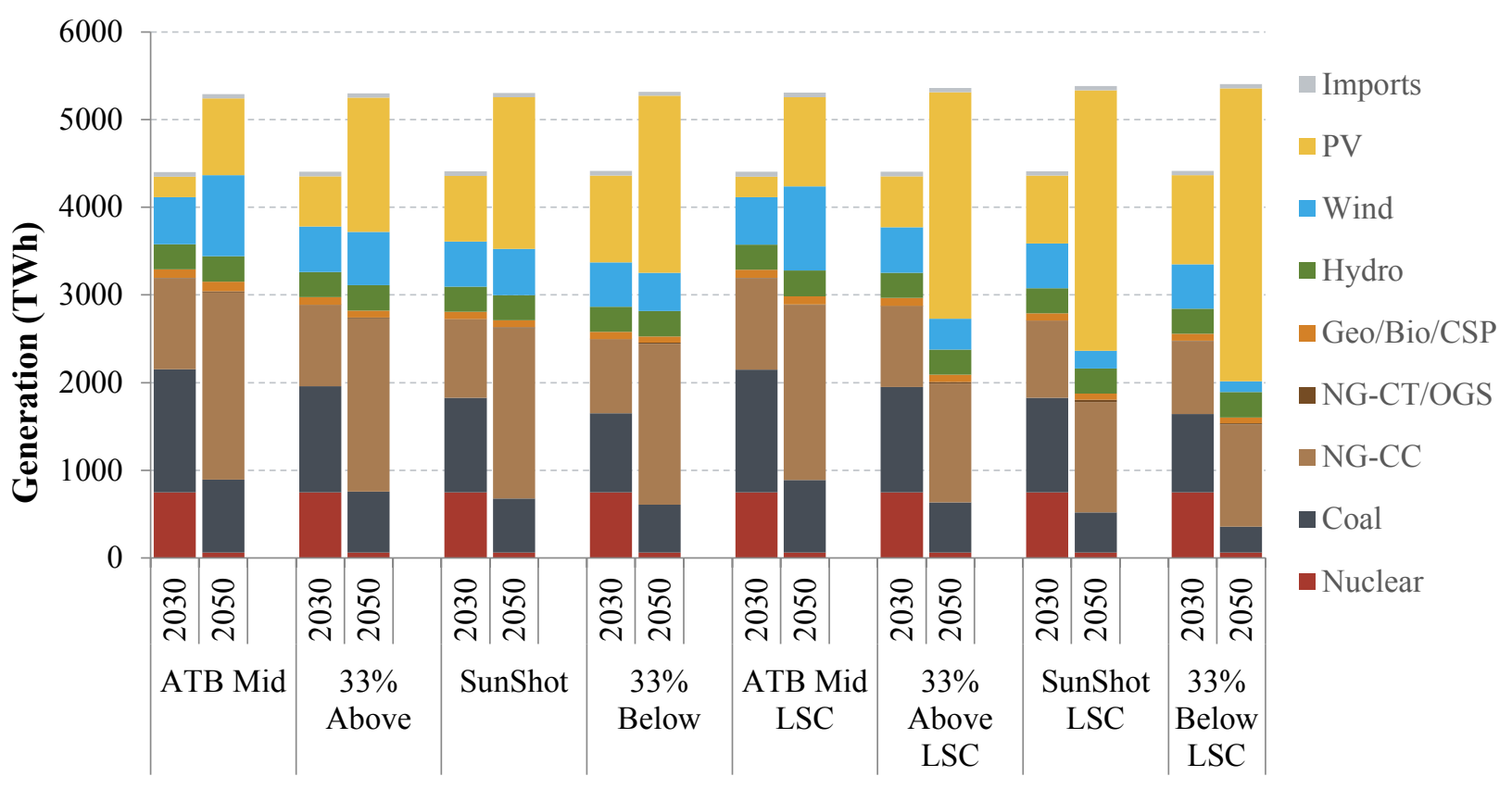

Figure 22. Nationwide generation in 2030 and 2050 by technology for PV cost scenarios with and without low storage costs 
Figure 23 shows projected DPV capacity across the PV cost scenarios with reference storage costs. ${ }^{19}$ DPV adoption is a somewhat less sensitive to PV costs than is utility PV deployment (Figure 20). For example, utility PV capacity under the SunShot scenario is $115 \%$ more than the ATB Mid value in 2050 with reference storage costs, whereas DPV adoption is $88 \%$ higher. This is largely driven by the difference in revenue streams between DPV and UPV. Because DPV obtains revenue by offsetting retail tariffs, it is an attractive investment for many potential customers in all scenarios, and adoption is largely driven by the rate at which DPV spreads through the public. Lower PV costs can unlock new DPV markets and accelerate adoption but not to the same degree observed in the utility-scale sector. In addition, because DPV deployment is a function of consumers' willingness to adopt, other factors - such as financing and the availability of alternative business models like third-party ownership — can impact the rate of adoption. ${ }^{20}$

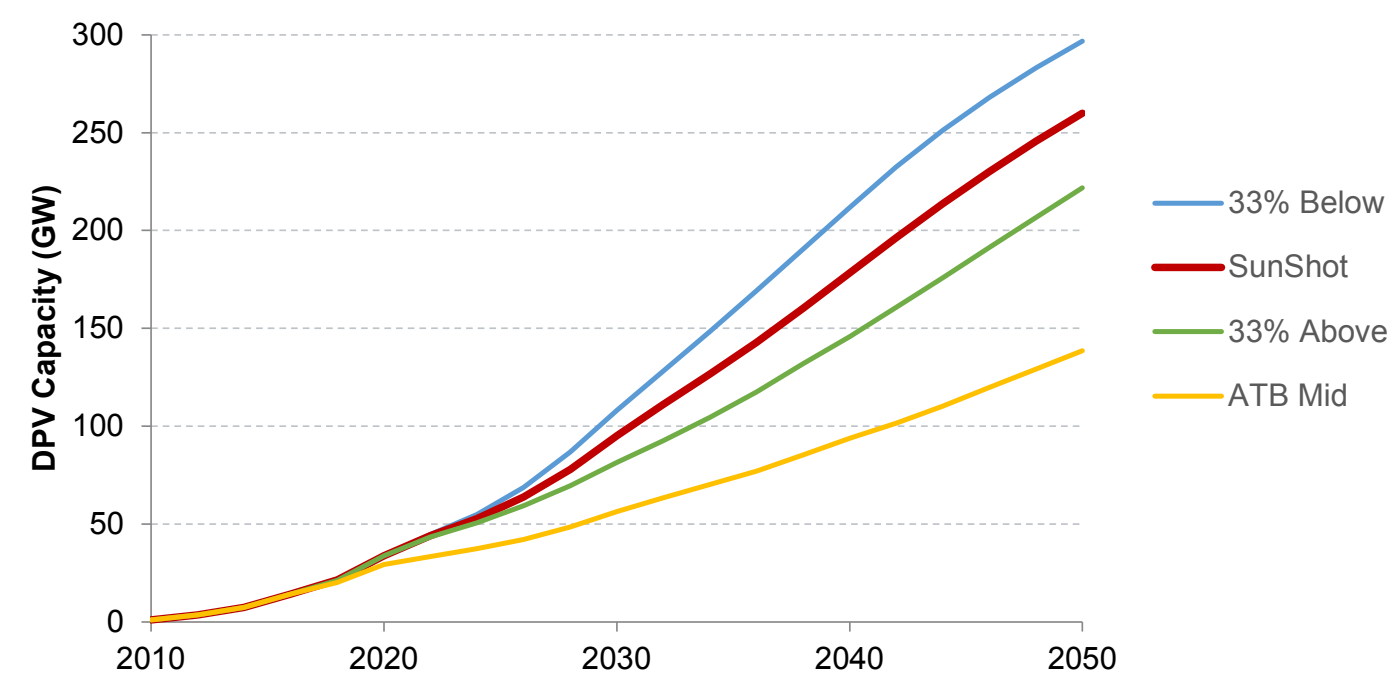

Figure 23. Nationwide cumulative DPV capacity by year for PV cost scenarios without low storage costs

\subsection{Renewable Energy Curtailment and System Operation}

The impact of PV and storage cost assumptions on curtailment rate is summarized in Figure $24 .^{21}$ The curtailment rate is defined as curtailment divided by variable renewable energy generation. As expected, the curtailment rate is higher in the lower-cost PV scenarios. As PV becomes more competitive, the system is able to "throw away" more energy cost-effectively via curtailment. Figure 24 also demonstrates one of the primary value streams of low-cost storage; it reduces

\footnotetext{
${ }^{19}$ These scenarios do not include any assumptions about the evolution of retail tariffs as the penetration of PV increases. The DPV adoption projections included here assume that the rate structures that existed in 2016 across the United States continue through 2050.

${ }^{20}$ It is expected that low-cost storage will influence DPV adoption through three primary factors: increased financial performance of co-deployed PV-plus-storage systems, reduced total cost of electricity, and changed retail tariff structures. Because dGen's is currently unable to model the changes in retail tariff structures, the influence of lowcost storage on DPV adoption is omitted from this analysis.

${ }^{21}$ The hump in curtailment in the early 2020s does not persist because of increased deployment of new transmission capacity (see Figure 28).
} 
curtailment, which in turn allows more PV to be deployed cost-effectively. In 2050, curtailment ranges from $2.5 \%$ to $5.4 \%$ in the non-ATB-Mid scenarios without low storage costs and from $1.2 \%$ to $5.1 \%$ in the scenarios with low storage costs. Marginal curtailment rates are much higher. For example, in the SunShot scenario in 2050, the average marginal curtailment rate for a UPV system is $31 \%$, with some regions seeing annual marginal curtailment rates of up to $53 \%{ }^{22}$ In addition to curtailment, storage systems incur losses, such that in the low-cost storage scenarios, losses due to storage more than double the losses from curtailment. If storage losses are counted as curtailment, the 2050 curtailment rates would be $3.2 \%-8.6 \%$ in the SunShot scenarios and $2.0 \%-8.4 \%$ in the SunShot LSC scenarios.

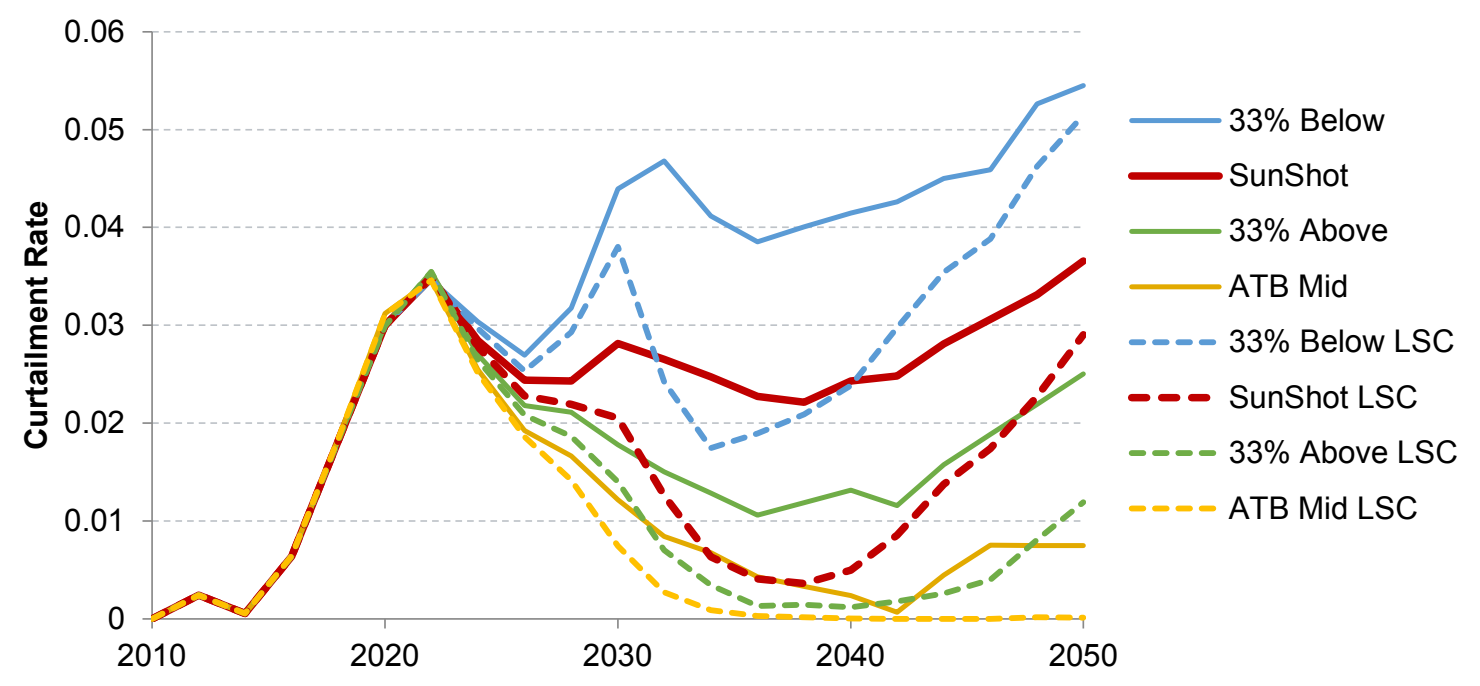

\section{Figure 24. Total annual curtailment rate for PV cost scenarios with and without low storage costs $^{23}$}

One of the reasons that curtailment rates remain fairly low even at these very high PV penetrations is that by 2050 many of the less-flexible generators (i.e., coal and nuclear) have retired (see Figure 21). With fewer must-run generators online, PV can more easily be integrated because non-PV generation can be turned down to very low levels during daytime hours. Sensitivity scenarios that keep must-run generators online longer result in lower PV deployment (see Figure 19 and Appendix C).

Figure 25 shows the operation of the system in 2050 in the SunShot scenario, and Figure 26 shows the operation in the SunShot LSC scenario. PV is the primary energy supplier during daytime hours, with additional limited generation during the evening. Coal generators still

\footnotetext{
${ }^{22}$ Some regions are so saturated with PV that large portions of the output from a new PV plant would be unusable. However, ReEDS can do things to mitigate a high curtailment rate. For example, it can turn down must-run generators or add storage in order to recover that curtailed energy, which creates a lower effective marginal curtailment rate. Most often, however, ReEDS simply chooses to build new PV in regions that have lower marginal curtailment rates and avoid those regions with high curtailment rates.

${ }^{23}$ The reason for the "hump" in curtailment rate in 2022 is that 2022 is the first year that new, unannounced transmission is allowed to be built in ReEDS. It also corresponds with the end of new wind builds that receive the PTC, so wind builds also slow considerably after 2022.
} 
operate in a typical baseload fashion in summer and winter, but they ramp down during spring and fall afternoons to their minimum generation levels to reduce PV curtailment. The natural gas combined-cycle plants are very flexible and are used to match load while minimizing renewable energy curtailment. Storage in these scenarios is used in a manner that is opposite to how it is typically employed today, with charging occurring overnight and discharging occurring in the afternoon. In these high-PV scenarios, storage charges during the day, when there is excess PV energy, and then discharges in the evening and overnight periods. During daytime periods, storage and curtailment are both employed to address PV overgeneration.

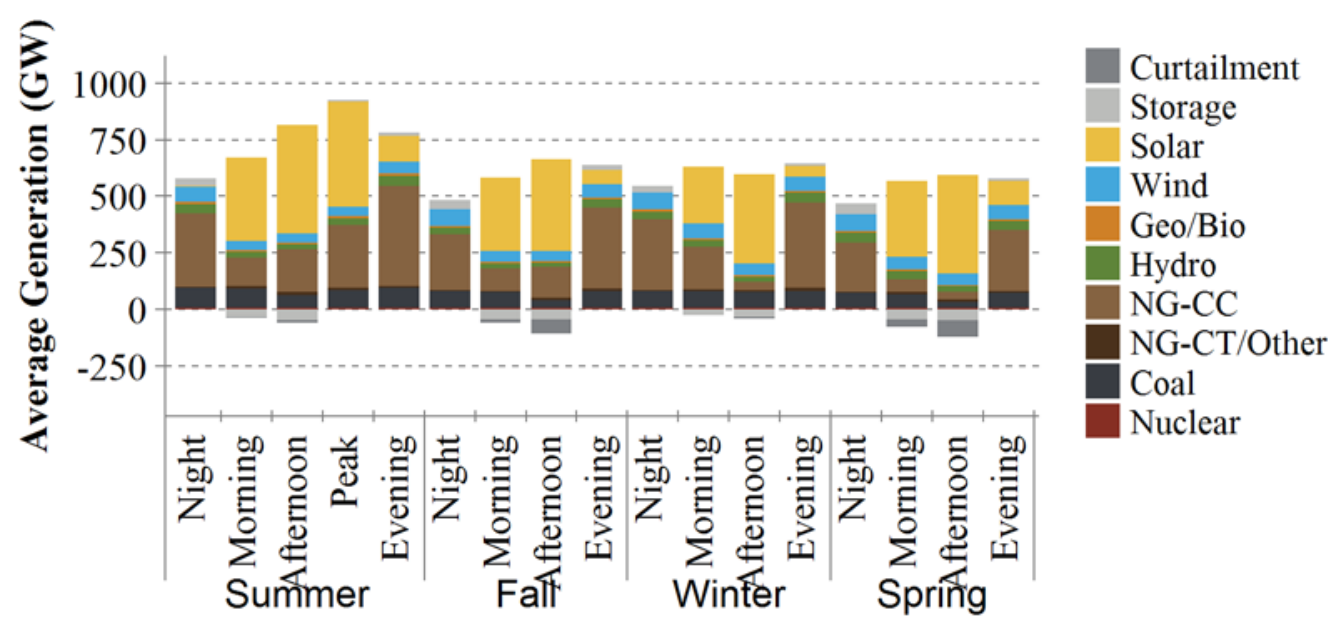

Time Slice

Figure 25. Dispatch stack for four representative days (in 2050) in the SunShot scenario, showing peak generation from non-renewable energy technologies occurring during the evening

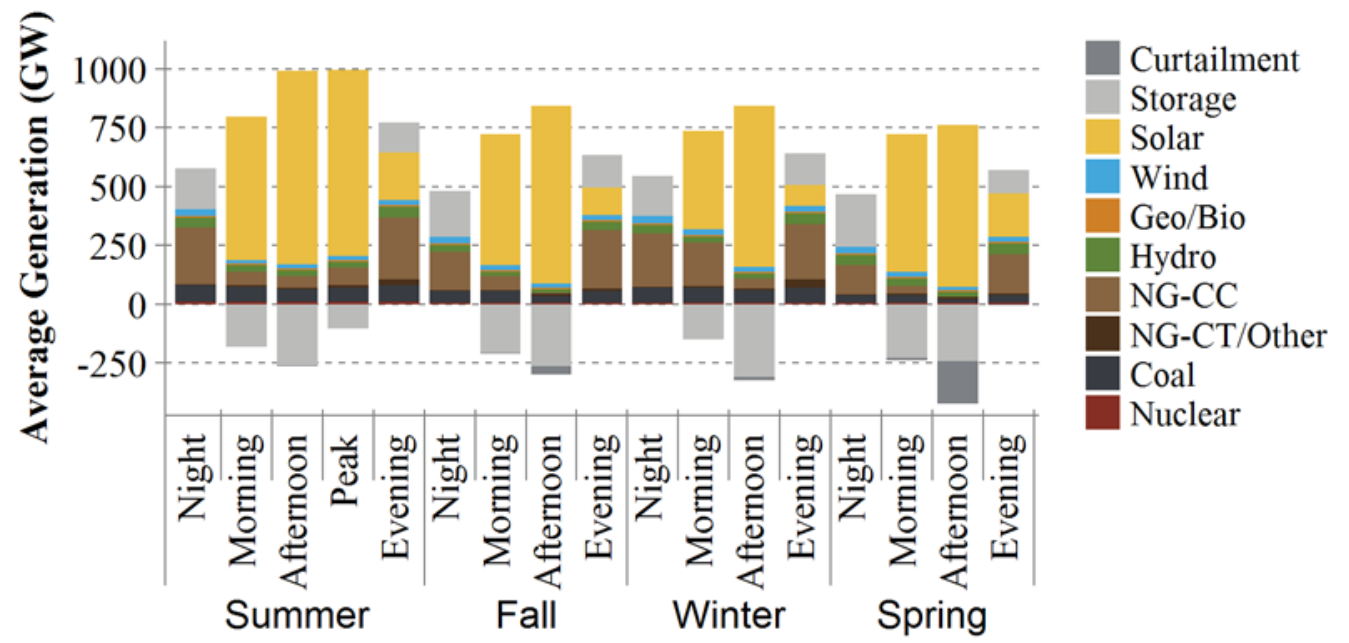

Time Slice

Figure 26. Dispatch stack for four representative days (in 2050) in the SunShot LSC scenario, showing storage charging from PV during the day and discharging during the evening and night 


\subsection{Storage Capacity}

The impact of PV and storage cost assumptions on total utility-scale storage capacity deployed is summarized in Figure $27 .{ }^{24}$ Not surprisingly, scenarios with lower-cost storage result in greater capacity. Cumulative storage capacity in 2050 is roughly an order of magnitude greater in the low-storage-cost scenarios that it is in their reference-storage-cost counterparts. This trend is amplified in scenarios that achieve greater reductions in PV costs to support correspondingly larger PV deployment. The scenarios with reference storage costs still see a small amount of storage deployed. The storage deployment under the reference-case battery cost assumptions is a mix of battery, compressed air, and pumped-hydro energy storage.

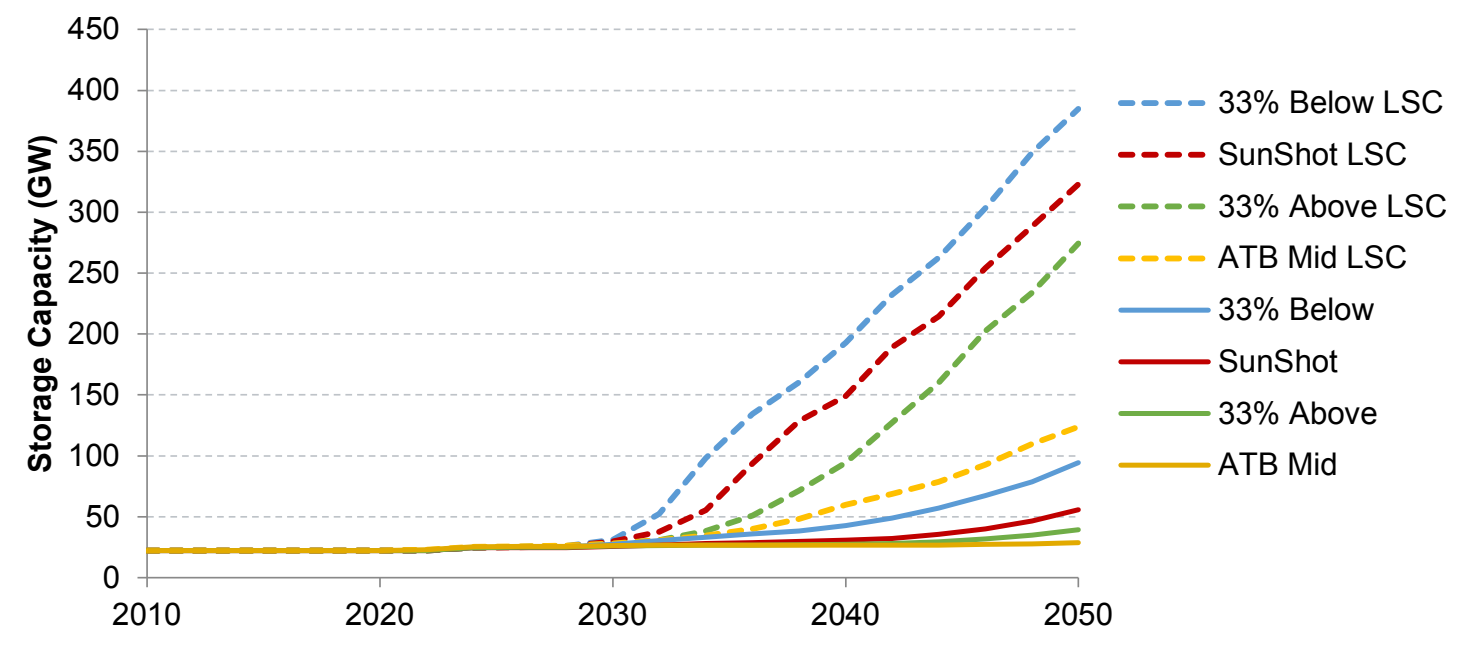
Figure 27. Nationwide cumulative utility-scale storage capacity for PV cost scenarios
with and without low storage costs

ReEDS does not build new storage in any scenarios until the latter 2020s. The model cannot capture localized value for storage such as voltage support or specific participation in ancillary service markets, but rather it accounts for the system-wide benefits of storage such as curtailment reduction, contribution toward reserve margin requirements, and contribution toward quick-start and spinning reserve requirements. Thus, the ReEDS projections are more likely to underestimate rather than overestimate the deployment potential for utility-scale storage in the near-term. Also, because of the relatively low penetration of renewables and the relatively small need for new capacity before 2030, ReEDS does not find significant value with storage until the 2030 timeframe.

Adoption of behind-the-meter storage is projected to be much lower than utility-scale storage deployment. For example, behind-the-meter storage deployment is just over $6 \mathrm{GW}$ in 2050 in the SunShot LSC scenario, compared with $323 \mathrm{GW}$ of utility-scale storage. This disparity results from the higher costs of behind-the-meter storage as well as dGen's assumptions that current tariff structures do not evolve and existing PV systems cannot be retrofitted with storage. Behind-the-meter storage deployment is based solely on revenue from bill reductions under current tariff structures. An evolution of tariff structures, or continued development of alternative

\footnotetext{
${ }^{24}$ The initial storage capacity is the $22 \mathrm{GW}$ of existing pumped-hydro energy storage.
} 
revenue models beyond monthly bill reduction, could drive the adoption of significantly more behind-the-meter storage.

\subsection{Transmission Requirements}

The impact of PV and storage cost assumptions on transmission capacity additions ${ }^{25}$ is summarized in Figure 28. ${ }^{26}$ The lower-cost PV scenarios lead to greater amounts of PV deployment, which results in more transmission builds so PV generation can be transported to demand centers. However, the availability of low-cost storage reduces the need for new transmission builds for the same PV penetration level. When storage is available, PV can often be constructed and used near where the electricity is consumed. Thus, an increase in PV deployment does not necessarily signify a need to build new long-distance transmission capacity. Because PV resources are so abundant in the United States, the option of installing PV closer to load centers becomes increasingly cost effective, especially when low-cost storage is available. The transmission builds projected in these scenarios is in line with or smaller than historical transmission investment rates (DOE 2015a).

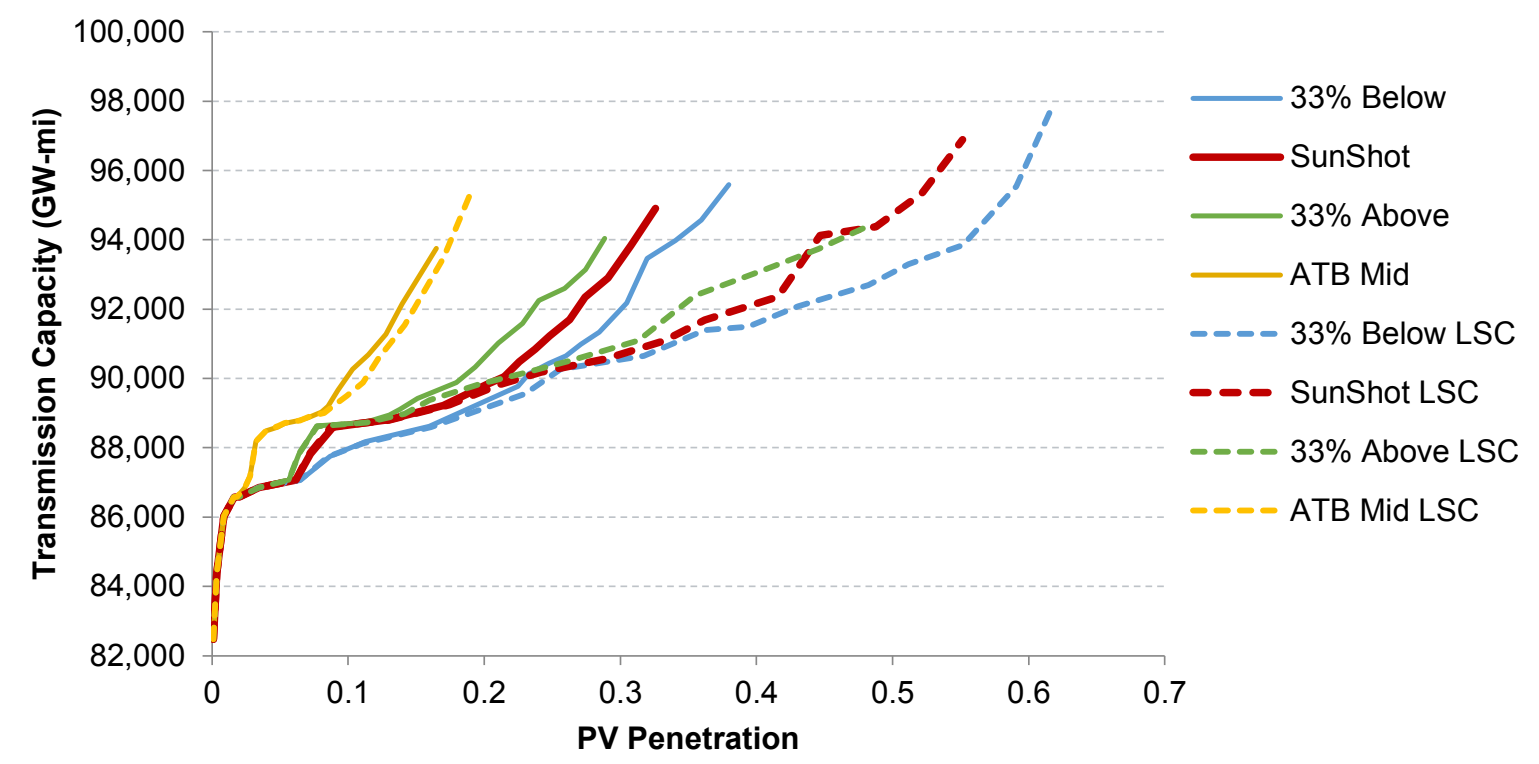

Figure 28. Transmission builds as a function of PV penetration (fraction of generation supplied by PV) for PV cost scenarios with and without low storage costs

\footnotetext{
${ }^{25}$ In this section, transmission capacity refers to high-voltage bulk power system transmission. It does not include the spur lines built to connect remote sites to the high-voltage transmission system or any distributionlevel transmission.

${ }^{26}$ The rapid increases in transmission capacity at very low PV penetration levels are primarily spurred by nearterm wind growth driven by the production tax credit.
} 


\subsection{Electricity Prices and System Costs}

The impact of PV and storage cost assumptions on modeled cost-of-service electricity prices is shown in Figure 29. In 2030, lower cost PV leads to decreases in electricity prices of $1.4 \%-2.5 \%$ relative to their respective ATB Mid scenarios. ${ }^{27}$ By 2050, the electricity prices are again slightly lower $(1.1 \%-2.0 \%)$ in the 33\% Below, SunShot, and 33\% Above scenarios than they are in the ATB Mid scenario. Adding low-cost storage, however, leads to substantial reductions in electricity prices. For example, in 2050, the SunShot scenario's electricity price is $1.8 \%$ lower that the ATB Mid scenario's price, and the SunShot LSC scenario's price is 9.8\% lower than the ATB Mid LSC scenario's price. This electricity savings translates into a residential consumer bill savings of \$2/month per household (savings for SunShot over ATB Mid) and \$13/month per household (savings for SunShot LSC over ATB Mid).

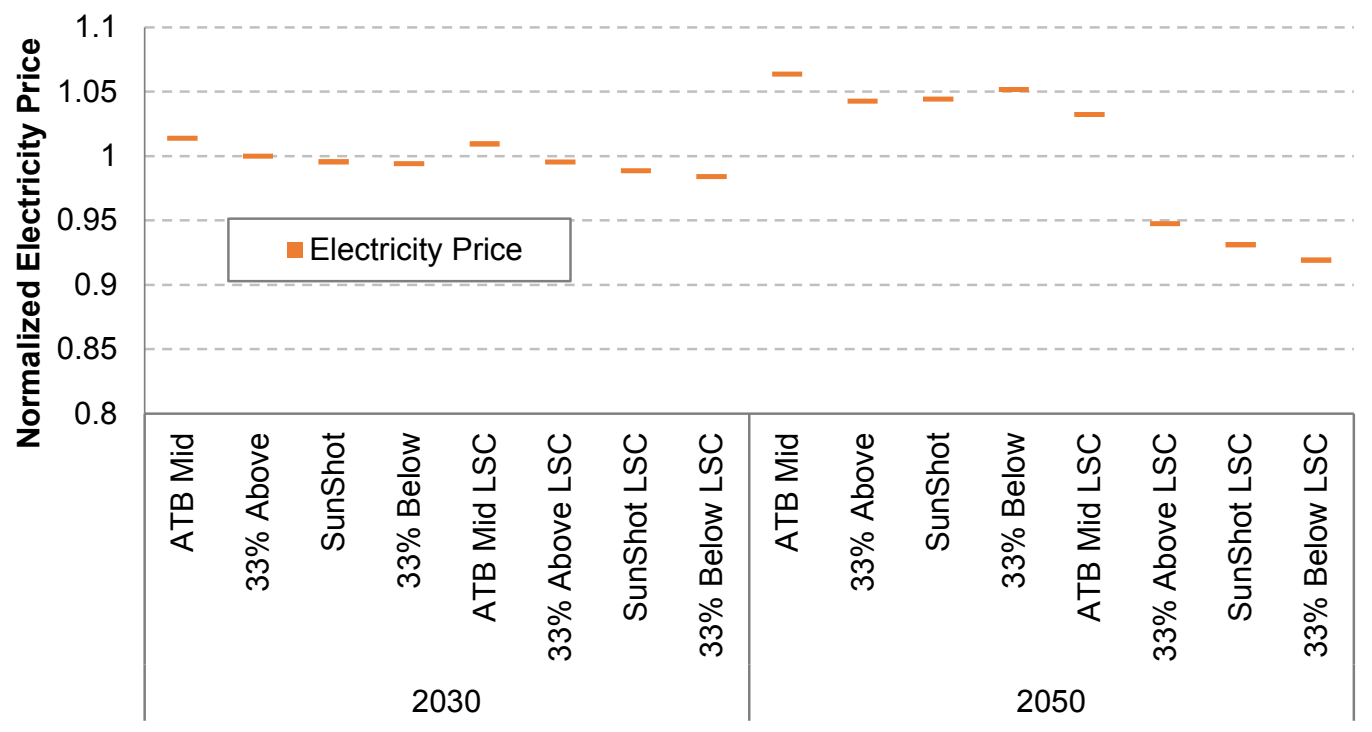

Figure 29. Normalized national average retail electricity prices for PV cost scenarios with and without low storage costs ${ }^{28}$

The present value of total system costs ${ }^{29}$ from 2016 to 2050 is shown in Figure 30. The lower PV cost scenarios reduce total system costs primarily by reducing conventional fuel and O\&M costs. The low-cost storage scenarios provide further cost reductions by reducing conventional capital costs. Storage increases PV generation (which has no fuel cost and little O\&M cost) and reduces the need for peaking units; this dual use of storage creates a cost-efficient system. For example, the SunShot scenario's system cost is $\$ 194$ billion lower than the ATB Mid scenario's system cost, and the SunShot LSC scenario's system cost is $\$ 310$ billion less than the ATB Mid LSC scenario's system cost.

\footnotetext{
${ }^{27}$ ReEDS only captures costs associated with the build-out of the bulk power system when calculating an electricity price. It assumes that other costs such as distribution system costs and billing costs remain at historical levels.

${ }^{28}$ The electricity prices have been normalized to their 2016 values such that a value of 1.1 means the value is 1.1 times the 2016 value.

${ }^{29}$ Total system costs include all utility-scale investments made by the ReEDS model to construct and operate power plants and long-distance transmission. For details, see Eurek et al. (2016).
} 


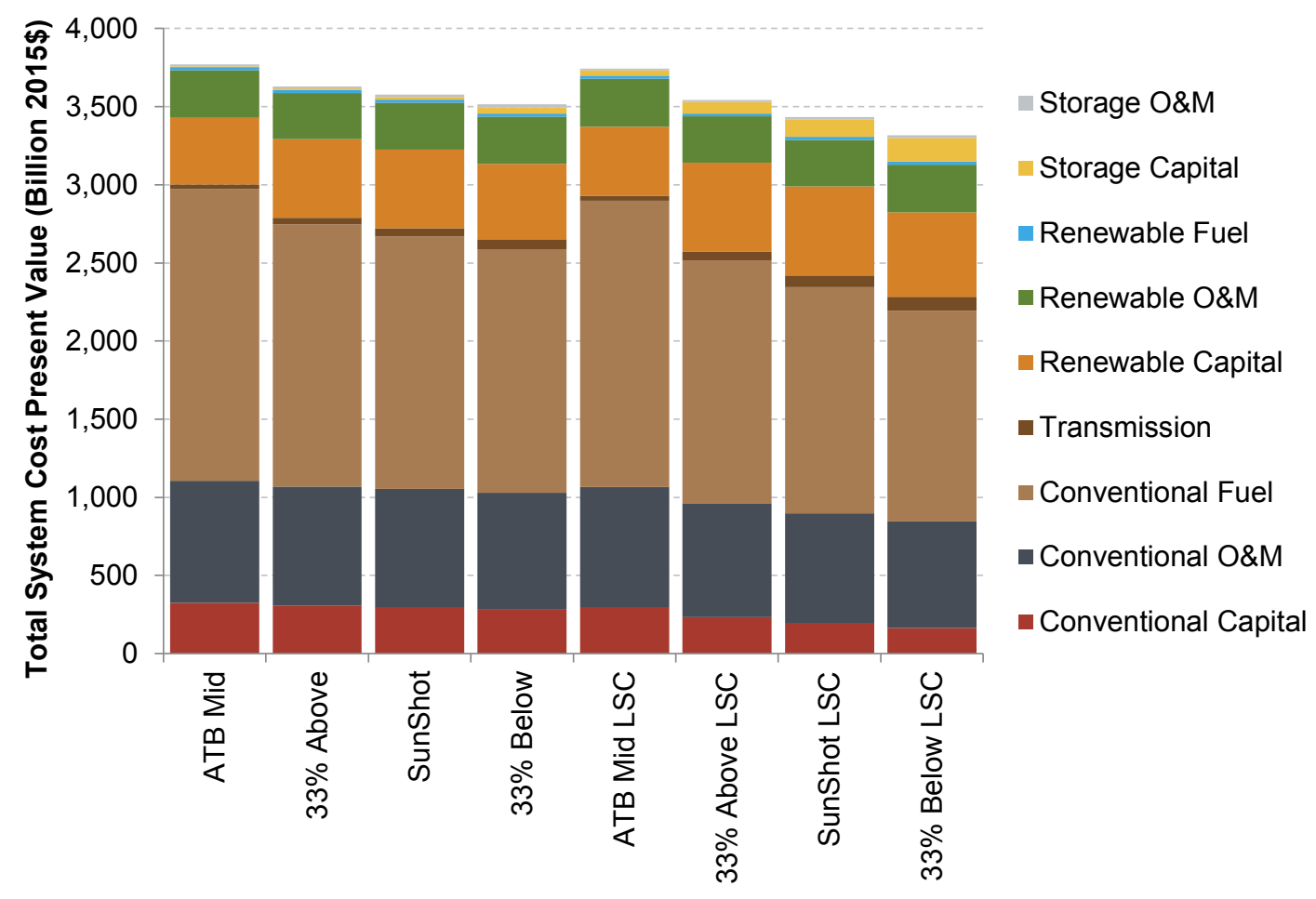

Figure 30. Total present value of system costs from 2016 to 2050 for PV cost scenarios

\section{6 $\mathrm{CO}_{2}$ Emissions}

The impact of PV and storage cost assumptions on total nationwide $\mathrm{CO}_{2}$ emissions is shown in Figure 31 for the PV cost scenarios. ${ }^{30}$ The three ATB Mid scenarios demonstrate the baseline for current expectations of electric-sector emissions over time. In the ATB Mid cases without the CPP, emissions rise in the 2020s and 2030s as natural gas prices increase slightly, nuclear plants retire, and demand grows, which leads to more dispatch of existing coal generators as well as additional natural gas generation. In the ATB Mid CPP scenario, the CPP in effect imposes a ceiling on electric-sector $\mathrm{CO}_{2}$ emissions resulting in the flat emissions trajectory that is somewhat higher than the emissions in the SunShot scenario, while the SunShot LSC scenario's emissions are lower than emissions in both of those scenarios and continue to decline in the 2030s. Compared with 2005 levels, 2050 emissions are 44\% lower in the SunShot scenario and $60 \%$ lower in the SunShot LSC scenario. Emissions in the 33\% Below and 33\% Below LSC scenarios are lower than emissions in the ATB Mid CPP scenario, with the 33\% Below LSC scenario achieving a $68 \%$ reduction in $2050 \mathrm{CO}_{2}$ emissions relative to 2005 levels.

\footnotetext{
${ }^{30}$ The CPP is only included in the ATB Mid CPP scenario. None of the other scenarios represents implementation of the CPP.
} 


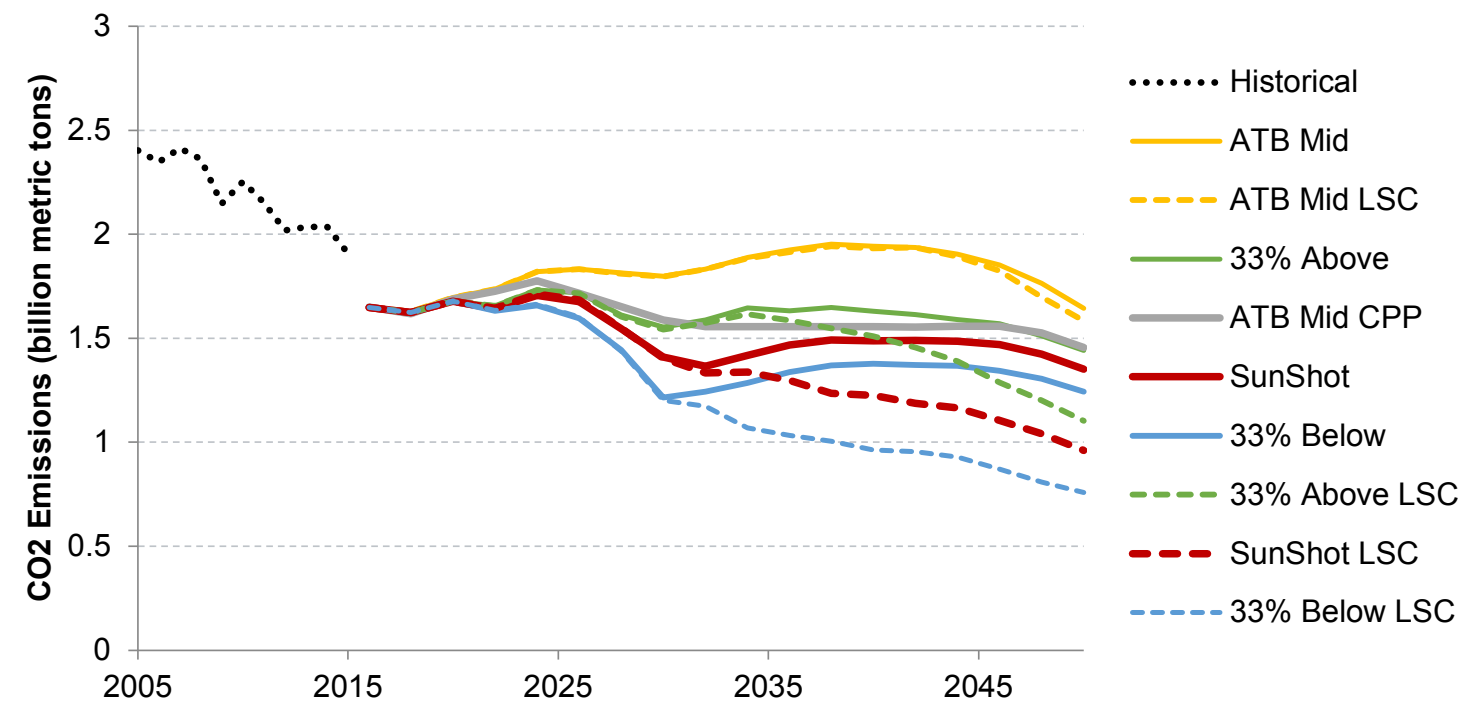

Figure 31. Nationwide electric-sector $\mathrm{CO}_{2}$ emissions for PV cost scenarios with and without low storage costs

\subsection{Water Withdrawal and Consumption}

ReEDS models electric-sector water withdrawal (water removed for cooling but then returned at a higher temperature) and consumption (water for cooling that is lost via evaporation). Operation of nearly all natural gas combined-cycle plants, coal plants, and nuclear plants requires some water withdrawal and consumption-whereas PV technologies require little or no water during operation. Because generation from conventional technologies is offset by additional PV deployment in our low-cost PV scenarios, these scenarios use less water than the ATB Mid scenarios (Figure 32). For example, relative to the ATB Mid scenario, the SunShot scenario reduces cumulative water withdrawals by $11 \%$ and consumption by $13 \%$. Relative to the ATB Mid LSC scenario, the SunShot LSC scenario reduces cumulative water withdrawals by $13 \%$ and consumption by $19 \%$. 

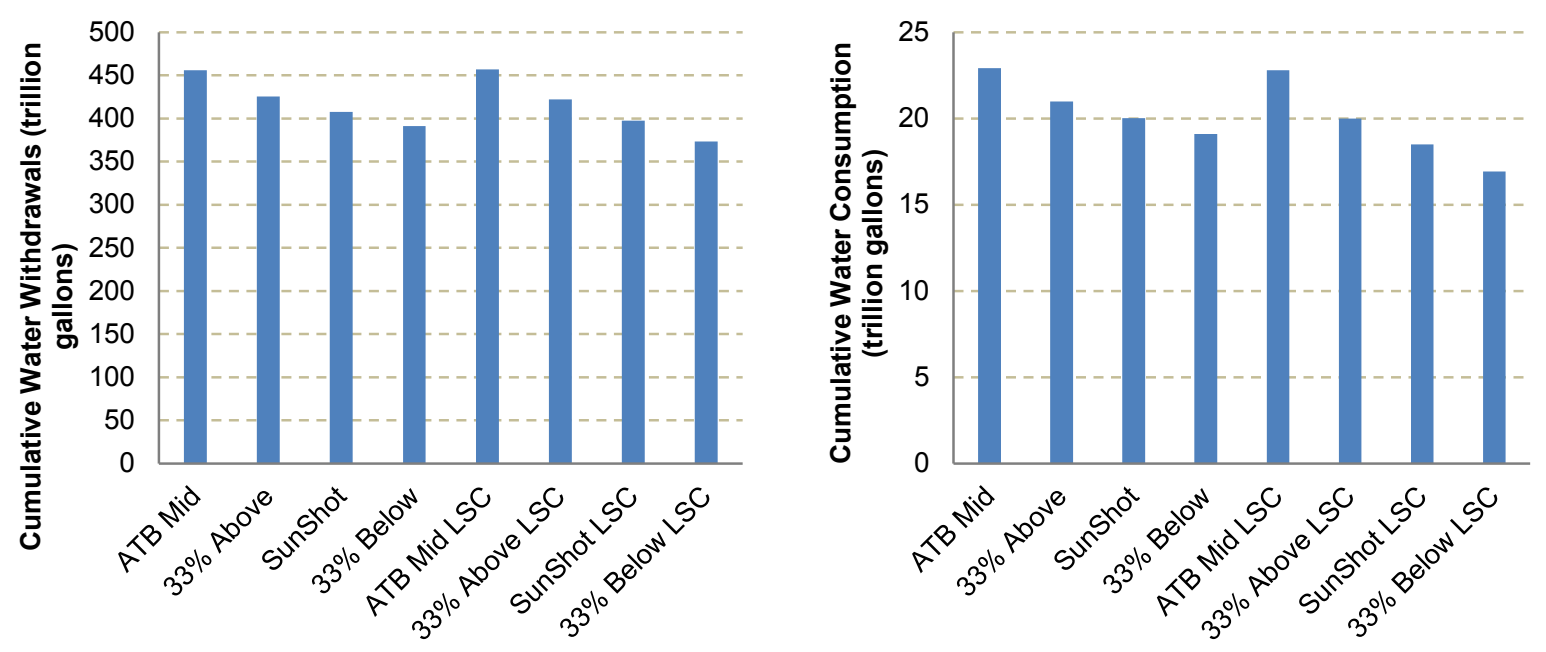

Figure 32. Cumulative electric-sector water withdrawals (left) and consumption (right), 2016-2050 


\section{Summary and Key Findings}

In this report, we project the impacts of achieving the SunShot LCOE targets of $\$ 0.03 / \mathrm{kWh}$ for utility-scale PV, $\$ 0.04 / \mathrm{kWh}$ for commercial PV, and $\$ 0.05 / \mathrm{kWh}$ for residential PV by 2030. We also project the impacts of achieving the SunShot PV cost targets in conjunction with lowcost energy storage - in our SunShot LSC scenario. Here we summarize the impacts of those SunShot scenarios compared with the impacts under the baseline ATB Mid scenario, which represents potential future conditions with more modest PV cost and reductions as well as reference-case storage cost assumptions.

- PV deployment increases two- to threefold. Achieving the SunShot PV cost targets could result in $405 \mathrm{GW}$ of PV capacity in 2030 , which would provide $17 \%$ of contiguous U.S. electricity generation. In 2050, deployment could rise to $971 \mathrm{GW}$, which would provide $33 \%$ of generation. With the addition of low-cost storage (i.e., by achieving the SunShot LSC scenario), 1,618 GW of PV capacity could be deployed by 2050 , which would provide $55 \%$ of generation. In comparison, the ATB Mid scenario deploys only $127 \mathrm{GW}$ of PV in 2030 (5\% of generation) and $470 \mathrm{GW}$ in 2050 (17\% of generation).

- Electricity prices and electric-system costs decline. In 2030, retail electricity prices are projected to be approximately 2\% lower in the SunShot and SunShot LSC scenarios than they are in the ATB Mid scenario. By 2050, SunShot electricity prices are projected to be $1.8 \%$ lower, while SunShot LSC prices are projected to be $12 \%$ lower. This translates to residential consumer bill savings of $\$ 2 /$ month per household (SunShot) and \$13/month per household (SunShot LSC). Total system costs are also projected to decline relative to the ATB Mid scenario; the SunShot scenario is projected to save (in net present value) \$194 billion through 2050 (5.1\% lower than ATB Mid), while the SunShot LSC scenario is projected to save (in net present value) $\$ 338$ billion through 2050 (9.0\% lower than ATB Mid).

- Water withdrawals and consumption are reduced. Because PV uses far less water than the conventional generators it displaces, the SunShot scenario is projected to reduce cumulative water withdrawals by $11 \%$ and consumption by $13 \%$ through 2050 compared with the ATB Mid scenario. Adding low-cost storage could produce even greater benefits, potentially reducing water withdrawals by $13 \%$ and consumption by $19 \%$ through 2050.

- Emissions of $\mathrm{CO}_{2}$ continue to decline. Under the SunShot scenario, $\mathrm{CO}_{2}$ emissions are projected to be $22 \%$ lower in 2030 and $18 \%$ lower in 2050 than they are with the ATB Mid scenario. With the addition of low-cost storage, $\mathrm{CO}_{2}$ emissions are projected to be $22 \%$ lower in 2030 and $42 \%$ lower in 2050 than they are with the ATB Mid scenario.

- Little additional transmission is required. In general, the greater the amount of PV deployed, the more transmission is needed to transmit electricity from PV plants to demand centers. However, this is in part mitigated by the abundance of PV energy close to load centers. In the ATB Mid scenario, transmission capacity is projected to increase by $2.5 \%$ in 2030 and $8.3 \%$ in 2050 relative to 2016, while the SunShot scenario transmission capacity is projected to increase by $3.0 \%$ in 2030 and $9.6 \%$ in 2050 . The SunShot LSC scenario requires a slightly reduced level of transmission build-out, with transmission capacity projected to increase by $3.1 \%$ in 2030 and $11.9 \%$ in 2050 . These 
levels of transmission build-out are the same or lower than historical transmission buildout rates.

- Energy storage capacity increases when low-cost storage is available. The projected storage capacity installed in 2050 in the SunShot LSC scenario is roughly 6 times greater than in the SunShot scenario and 11 times greater than in the ATB Mid scenario. This dramatic increase in projected storage deployment indicates the high value of low-cost flexibility in a low-cost PV future.

- Curtailment rates rise without low-cost storage, and storage losses rise with low-cost storage. In general, more PV leads to more curtailment, although low-cost storage mitigates this effect. In 2030, the curtailment rates are $2.8 \%$ in the SunShot scenario and $2.1 \%$ in the SunShot LSC scenario. In 2050, the spread is similar: $3.7 \%$ in the SunShot scenario and $2.9 \%$ in the SunShot LSC scenario. These results compare with curtailment rates of $1.2 \%$ in 2030 and $0.7 \%$ in 2050 under the ATB Mid scenario. However, storage systems incur losses during their charge and discharge cycles. In the SunShot LSC scenario, losses due to storage are nearly the same as the losses from curtailment.

We analyze the sensitivity of the SunShot and SunShot LSC scenarios to various market assumptions, including lower and higher electricity demand growth, lower and higher natural gas prices, accelerated and extended conventional generator lifetimes, and lower and higher non-PV renewable energy technology costs. We also consider scenarios where we include cost penalties for rapid growth in PV deployment. These analyses provide a range of plausible projections for PV deployment when the SunShot 2030 LCOE goals are achieved. PV deployment in 2030 ranges from $307 \mathrm{GW}$ (13\% of electricity supplied by PV) to $435 \mathrm{GW}(18 \%)$, and deployment in 2050 ranges from $850 \mathrm{GW}(28 \%)$ to $1,923 \mathrm{GW}(64 \%)$. The availability of low-cost storage has the largest impact on projected SunShot deployment; it is followed by natural gas prices and electricity demand.

We also compare the impacts of the SunShot and SunShot LSC scenarios with the impacts of six other scenarios that vary PV costs up and down from the SunShot 2030 LCOE goals. Two scenarios - one with reference storage costs and one with low storage costs - assume PV LCOEs are $33 \%$ below the SunShot target in 2030 (i.e., utility-scale PV LCOE is $2 \propto / \mathrm{kWh}$ in 2030). A similar pair of scenarios assumes PV LCOEs are 33\% above the SunShot target in 2030 (i.e., utility PV LCOE is $4 \phi / \mathrm{kWh}$ in 2030). We also include additional ATB mid-case scenarios: one with low storage costs and another that includes the U.S. Environmental Protection Agency's Clean Power Plan. Across all these scenarios, PV deployment ranges from $127 \mathrm{GW}$ to $545 \mathrm{GW}$ (5\%-23\% of demand met by PV) in 2030, and it ranges from $470 \mathrm{GW}$ to $1,875 \mathrm{GW}(17 \%-62 \%)$ in 2050. The scenario results are grouped relatively tightly in 2030, but by 2050 the $33 \%$ Below SunShot scenario with low-cost storage deploys the most PV, and the ATB Mid scenario deploys the least.

Utility-scale PV accounts for most of the PV deployment in our scenarios. However, the actual mix of utility-scale and distributed PV deployed likely will be influenced significantly by the evolution of policies and rate structures that impact distributed PV systems. We do not analyze this topic in detail, and it merits further exploration. 
Overall, continued analysis is needed to better understand and quantify the impacts of a high-PV, and potentially high-storage future in which the electricity generation system operates in a fundamentally different manner than today's system. Specific areas for future work include the following:

- Impacts on the Distribution Grid. We do not represent any of the costs or benefits of integrating large amounts of PV with distributions systems. Those costs and benefits are location specific and will depend on how the distribution network and PV systems evolve.

- Utility Business Models. As PV penetration increases, the value of energy and capacity during different parts of the day will shift. That shift might put pressure on some existing rate structures and utility business models, including DPV valuation (e.g., net metering). This work does not represent changes to rate structures (e.g., shifting to time-of-use rates) or changes to current net metering policies.

- Impacts on Electricity Consumption. As PV penetration increases, the number of hours that have zero or negative marginal costs for electricity are likely to increase. Electricity consumer might change behavior (e.g., charge an electric vehicle during the afternoon rather than overnight) or otherwise create opportunities (e.g., hydrogen electrolyzers, economy-wide electrification) to use this low-cost energy, which could in turn have an impact on load shapes and total electricity demand. Additionally, low-cost energy storage would reduce the cost of electric vehicles, which could in turn increase their adoption and drive up overall electricity consumption.

- Grid-Integration Challenges. The PV penetration levels envisioned in this work far exceed current penetration levels. The higher penetration likely would require changes in utility and grid operator practices and techniques (e.g., improved PV forecasting, increased system cooperation, and more frequent dispatch periods).

- Land-Use Requirements and Impacts. ReEDS and dGen screen out land areas and rooftops that are unsuitable or are otherwise unavailable for PV deployment (e.g., national parks), but detailed land-use impacts go far beyond this initial screening.

- Supply Chain Impacts. Our scenarios see high levels of PV deployment relative to today's levels. PV supply chains would need to be scaled to accommodate that growth, and that scaling is not considered in this work beyond simple growth penalties included in the model.

- Job Impacts. The evolution of the electricity sector described in this work would increase job opportunities in PV while impacting job opportunities across the other electricity-generating sectors.

- The Role of CSP. This work focuses only on a future in which PV reaches $\$ 0.03 / \mathrm{kWh}$ but does not consider additional possible reductions in the cost of CSP beyond the original SunShot 2020 targets. Future work that specifically considers the potential role of CSP is forthcoming. 


\section{References}

ABB. 2016a. "ABB Velocity Suite.” http://new.abb.com/enterprise-software/energy-portfoliomanagement/market-intelligence-services/velocity-suite.

_ 2016b. "e7 Capacity Expansion: Long-Term Resource Planning for Resource Planners and Portfolio Managers." http://new.abb.com/docs/librariesprovider139/default-documentlibrary/epm_capacity-expansion_jul16_web.pdf?sfvrsn=2.

Ahlstrom, M., C. Smith, D. Piwko, D. Lew, A. Bloom, Trieu Mai, K. Clark, and M. Milligan. 2015. "Relevant Studies for NERC's Analysis of EPA's Clean Power Plan 111(d) Compliance." NREL/TP-5D00-63979. Golden, CO: National Renewable Energy Laboratory. http://www.nrel.gov/docs/fy15osti/63979.pdf.

Ardani, Kristen, Eric O'Shaughnessy, Ran Fu, Chris McClurg, Robert Margolis, and Joshua Honeycutt. 2016. "Installed Costs and Deployment Barriers for Residential Solar Photovoltaics (PV) with Energy Storage: Q1 2016.” NREL/TP-6A20-67474. Golden, CO: National Renewable Energy Laboratory. http://www.nrel.gov/docs/fy17osti/67474.pdf.

Barbose, Galen, and Naim Darghouth. 2016. "Tracking the Sun IX: The Installed Price of Residential and Non-Residential Photovoltaic Systems in the United States." LBNL-1006036. Berkeley, CA: Lawrence Berkeley National Laboratory. https://emp.lbl.gov/sites/all/files/tracking_the_sun_ix_report.pdf.

Bird, Lori, Debra Lew, Michael Milligan, E. Maria Carlini, Ana Estanqueiro, Damian Flynn, Emilio Gomez-Lazaro, et al. 2016. "Wind and Solar Energy Curtailment: A Review of International Experience." Renewable and Sustainable Energy Reviews 65 (November): 577-86. doi:10.1016/j.rser.2016.06.082.

Blanford, Geoffrey J., James H. Merrick, and David Young. 2014. "A Clean Energy Standard Analysis with the US-REGEN Model." The Energy Journal 35 (1). doi:10.5547/01956574 .35.SI1.8.

Bolinger, Mark. 2014. "An Analysis of the Costs, Benefits, and Implications of Different Approaches to Capturing the Value of Renewable Energy Tax Incentives." LBNL-6610E. Ernest Orlando Lawrence Berkeley National Laboratory, Berkeley, CA (US). https://www.osti.gov/scitech/biblio/1134230.

Bolinger, Mark, and Joachim Seel. 2016. "Utility-Scale Solar 2015: An Empirical Analysis of Project Cost, Performance, and Pricing Trends in the United States." LBNL-1006037. Berkeley, CA: Lawrence Berkeley National Laboratory. https://emp.lbl.gov/sites/all/files/lbnl1006037_report.pdf.

Brinkman, Gregory, Jennie Jorgenson, Ali Ehlen, and James Caldwell. 2016. "Low Carbon Grid Study: Analysis of a 50\% Emission Reduction in California." NREL/TP-6A20-64884. Golden, CO: National Renewable Energy Laboratory. http://www.nrel.gov/docs/fy16osti/64884.pdf.

Cole, Wesley, Trieu Mai, Kelly Eurek, Daniel C. Steinberg, and Robert Margolis. 2015. "Considering the Role of Solar Generation under Rate-Based Targets in the EPA's Proposed Clean Power Plan.” The Electricity Journal 28 (8): 20-28. doi:10.1016/j.tej.2015.09.002. 
Cole, Wesley, Trieu Mai, Jeffrey Logan, Daniel Steinberg, James McCall, James Richards, Benjamin Sigrin, and Gian Porro. 2016. "2016 Standard Scenarios Report: A U.S. Electricity Sector Outlook." NREL/TP-6A20-66939. Golden, CO: National Renewable Energy Laboratory. http://www.nrel.gov/docs/fy17osti/66939.pdf.

Cole, Wesley, Cara Marcy, Venkat Krishnan, and Robert Margolis. 2016. "Utility-Scale Lithium-Ion Storage Cost Projections for Use in Capacity Expansion Models." In 2016 North American Power Symposium (NAPS), 1-6. Denver, CO. doi:10.1109/NAPS.2016.7747866.

Cole, Wesley, Kenneth B. Medlock III, and Aditya Jani. 2016. "A View to the Future of Natural Gas and Electricity: An Integrated Modeling Approach." Energy Economics. Accessed April 1. doi:10.1016/j.eneco.2016.03.005.

D'Annunzio, C., and S. Santoso. 2008. "Noniterative Method to Approximate the Effective Load Carrying Capability of a Wind Plant." IEEE Transactions on Energy Conversion 23 (2): 544-50. doi:10.1109/TEC.2008.918597.

Denholm, Paul, Kara Clark, and Matt O’Connell. 2016. “On the Path to SunShot: Emerging Issues and Challenges in Integrating High Levels of Solar into the Electrical Generation and Transmission System." Golden, CO: National Renewable Energy Laboratory. http://www.osti.gov/scitech/biblio/1253978.

Denholm, Paul, and Robert Margolis. 2016. "Energy Storage Requirements for Achieving 50\% Solar Photovoltaic Energy Penetration in California." NREL/TP-6A20-66595. Golden, CO: National Renewable Energy Laboratory. http://www.nrel.gov/docs/fy16osti/66595.pdf.

Denholm, Paul, Robert Mark Margolis, and Easan Drury. 2009. "The Solar Deployment System (SolarDS) Model: Documentation and Sample Results." NREL/TP-6A2-45832. Golden, CO: National Renewable Energy Laboratory. http://www.nrel.gov/docs/fy10osti/45832.pdf.

Denholm, Paul, Joshua Novacheck, Jennie Jorgenson, and Matthew O'Connell. 2016. Impact of Flexibility Options on Grid Economic Carrying Capacity of Solar and Wind: Three Case Studies. Golden, CO: National Renewable Energy Laboratory. Denholm, Paul, and Robert Margolis. http://www.nrel.gov/docs/fy17osti/66854.pdf.

DOE (U.S. Department of Energy). 2012. "Sunshot Vision Study." DOE/GO-102012-3037. Washington, D.C.: U. S. Department of Energy. http://www.nrel.gov/docs/fy12osti/47927.pdf.

—. 2015a. "Quadrennial Energy Review: Energy Transmission, Storage, and Distribution Infrastructure." Department of Energy.
. 2015b. "Wind Vision: A New Era for Wind Power in the United States." DOE/GO- 102015-4557. Washington, D.C.: U. S. Department of Energy.
http://energy.gov/sites/prod/files/2015/03/f20/wv_full_report.pdf.

\footnotetext{
_ 2016a. "On the Path to SunShot: Executive Summary." DOE/EE 1412. Washington, D.C.: U.S. Department of Energy. https://energy.gov/sites/prod/files/2016/05/f31/OTPSS\%20\%20Executive\%20Summary-508.pdf.

_.2016b. "SunShot 2030 | Department of Energy."

https://energy.gov/eere/sunshot/sunshot-2030.
} 
Donohoo-Vallett, Paul, Trieu Mai, Matthew Mowers, and Gian Porro. 2017. "Impact of Clean Energy R\&D on the U.S. Power Sector.” NREL/TP-6A20-67691. Golden, CO: National Renewable Energy Laboratory. https://www.osti.gov/scitech/biblio/1340173.

Dragoon, K., and V. Dvortsov. 2006. "Z-Method for Power System Resource Adequacy Applications.” IEEE Transactions on Power Systems 21 (2): 982-88. doi:10.1109/TPWRS.2006.873417.

Duignan, R., C. J. Dent, A. Mills, N. Samaan, M. Milligan, A. Keane, and M. O’Malley. 2012. "Capacity Value of Solar Power." In 2012 IEEE Power and Energy Society General Meeting, 16. doi:10.1109/PESGM.2012.6345429.

Dykes, Katherine, Maureen Hand, Tyler Stehly, Paul Veers, Mike Robinson, Eric Lantz, and Richard Tusing. 2017 "Enabling the SMART Wind Power Plant of the Future Through ScienceBased Innovation.” NREL/TP-6A20-68123. Golden, CO: National Renewable Energy Laboratory. https://www.nrel.gov/docs/fy17osti/68123.pdf.

EIA. 2016. “Annual Energy Outlook 2016.” DOE/EIA-0383(2016). Washington, D.C.: U.S. DOE Energy Information Administration.

Ela, E., M. Milligan, A. Bloom, A. Botterud, A. Townsend, and T. Levin. 2014. "Evolution of Wholesale Electricity Market Design with Increasing Levels of Renewable Generation." NREL/TP-5D00-61765. Golden, CO: National Renewable Energy Laboratory. https://www.osti.gov/scitech/biblio/1159375-evolution-wholesale-electricity-market-designincreasing-levels-renewable-generation.

EPA. 2015. "Carbon Pollution Emission Guidelines for Existing Stationary Sources: Electric Utility Generating Units.” http://www.epa.gov/airquality/cpp/cpp-final-rule.pdf.

EPRI. 2017. “US-REGEN Model Documentation.” EPRI Technical Update \#3002010956. Palo Alto, CA: Electric Power Research Institute.

Eurek, Kelly, Wesley Cole, David A. Bielen, Nate Blair, Stuart Cohen, Bethany Frew, Jonathan Ho, Venkat Krishnan, Trieu Mai, and Daniel Steinberg. 2016. "Regional Energy Deployment System (ReEDS) Model Documentation: Version 2016.” NREL/TP-6A20-67067. Golden, CO: National Renewable Energy Laboratory. http://www.nrel.gov/docs/fy17osti/67067.pdf.

Frew, Bethany, Wesley Cole, Yinong Sun, James Richards, and Trieu Mai. 2017. "8760-Based Method for Representing Variable Generation Capacity Value in Capacity Expansion Models." NREL/CP-6A20-68869. Golden, CO: National Renewable Energy Laboratory. https://www.nrel.gov/docs/fy17osti/68869.pdf.

Fu, Ran, Donald Chung, Travis Lowder, David Feldman, Kristen Ardani, and Robert Margolis. 2016. “U.S. Solar Photovoltaic System Cost Benchmark: Q1 2016.” NREL/PR-6A20-67142. Golden, CO: National Renewable Energy Laboratory. https://www.osti.gov/scitech/biblio/1327216.

Garver, L. L. 1966. "Effective Load Carrying Capability of Generating Units." IEEE Transactions on Power Apparatus and Systems PAS-85 (8): 910-19. doi:10.1109/TPAS.1966.291652. 
GTM/SEIA. 2016. “U.S. Solar Market Insight Report: 2016 Q4.” Greentech Media (GTM) \& Solar Energy Industries Association (SEIA). http://www.seia.org/research-resources/solarmarket-insight-report-2016-q4.

Hale, Elaine, Brady Stoll, and Trieu Mai. 2016. "Capturing the Impact of Storage and Other Flexible Technologies on Electric System Planning." NREL/TP-6A20-65726. Golden, CO: National Renewable Energy Laboratory. http://www.nrel.gov/docs/fy16osti/65726.pdf.

Hasche, B., A. Keane, and M. O’Malley. 2011. "Capacity Value of Wind Power, Calculation, and Data Requirements: The Irish Power System Case." IEEE Transactions on Power Systems 26 (1): 420-30. doi:10.1109/TPWRS.2010.2051341.

Ibanez, E., and M. Milligan. 2012. "Impact of Transmission on Resource Adequacy in Systems with Wind and Solar Power." In 2012 IEEE Power and Energy Society General Meeting, 1-5. doi:10.1109/PESGM.2012.6343955.

Jacobson, Mark Z., Mark A. Delucchi, Guillaume Bazouin, Zack A. F. Bauer, Christa C. Heavey, Emma Fisher, Sean B. Morris, Diniana J. Y. Piekutowski, Taylor A. Vencill, and Tim W. Yeskoo. 2015. “100\% Clean and Renewable Wind, Water, and Sunlight (WWS) All-Sector Energy Roadmaps for the 50 United States." Energy \& Environmental Science 8 (7): 2093-2117. doi:10.1039/C5EE01283J.

Jones-Albertus, Rebecca, David Feldman, Ran Fu, Kelsey Horowitz, and Michael Woodhouse. 2016. "Technology Advances Needed for Photovoltaics to Achieve Widespread Grid Price Parity." Progress in Photovoltaics: Research and Applications 24 (9): 1272-83. doi:10.1002/pip.2755.

Keane, A., M. Milligan, C. J. Dent, B. Hasche, C. D’Annunzio, K. Dragoon, H. Holttinen, N. Samaan, L. Soder, and M. O’Malley. 2011. "Capacity Value of Wind Power." IEEE Transactions on Power Systems 26 (2): 564-72. doi:10.1109/TPWRS.2010.2062543.

Lew, D., G. Brinkman, E. Ibanez, B. M. Hodge, M. Hummon, A. Florita, and M. Heaney. 2013. "The Western Wind and Solar Integration Study Phase 2." NREL/TP-5500-55588. Golden, CO: National Renewable Energy Laboratory. https://www.osti.gov/scitech/biblio/1095399-westernwind-solar-integration-study-phase.

Madaeni, S. H., R. Sioshansi, and P. Denholm. 2013. "Comparing Capacity Value Estimation Techniques for Photovoltaic Solar Power.” IEEE Journal of Photovoltaics 3 (1): 407-15. doi:10.1109/JPHOTOV.2012.2217114.

Mai, Trieu, Clayton Barrows, Anthony Lopez, Elaine Hale, Mark Dyson, and Kelly Eurek. 2015. "Implications of Model Structure and Detail for Utility Planning: Scenario Case Studies Using the Resource Planning Model." NREL/TP-6A20-63972. Golden, CO: National Renewable Energy Laboratory. https://www.osti.gov/scitech/biblio/1334388-implications-model-structuredetail-utility-planning-scenario-case-studies-using-resource-planning-model.

Mai, Trieu, Wesley Cole, Venkat Krishnan, and Mark Bolinger. 2015. "Impact of Federal Tax Policy on Utility-Scale Solar Deployment Given Financing Interactions.” Presentation NREL/PR-6A20-65014. Golden, CO: National Renewable Energy Laboratory. http://www.nrel.gov/docs/fy16osti/65014.pdf. 
Mai, Trieu, Wesley Cole, Eric Lantz, Cara Marcy, and Benjamin Sigrin. 2016. "Impacts of Federal Tax Credit Extensions on Renewable Deployment and Power Sector Emissions." NREL/TP-6A20-65571. Golden, CO: National Renewable Energy Laboratory. http://www.nrel.gov/docs/fy16osti/65571.pdf.

Mai, Trieu, Maureen Hand, Samuel F. Baldwin, Ryan H. Wiser, Greg L. Brinkman, Paul Denholm, Doug J. Arent, Gian Porro, Debra Sandor, Donna J. Hostick, Michael Milligan, Edgar A. DeMeo, Morgan Bazilian. 2014. "Renewable Electricity Futures for the United States." IEEE Transactions on Sustainable Energy 5 (2): 372-78. doi:10.1109/TSTE.2013.2290472.

Mai, Trieu, Eric Lantz, Matthew Mowers, Ryan Wiser. Forthcoming. "The Importance of Wind Technology Innovation: Implications for the wind industry, the power system, electricity consumers, and the environment in the United States." Golden, CO: National Renewable Energy Laboratory.

Mai, Trieu, R. Wiser, D. Sandor, G. Brinkman, G. Heath, P. Denholm, D. J. Hostick, N. Darghouth, A. Schlosser, and K. Strzepek. 2012. "Exploration of High-Penetration Renewable Electricity Futures. Vol. 1 of Renewable Electricity Futures Study.” NREL/TP-6A20-52409-1. Golden, CO: National Renewable Energy Laboratory. http://www.nrel.gov/docs/fy12osti/524091.pdf.

Mai, Trieu, Ryan Wiser, Galen Barbose, Lori Bird, Jenny Heeter, David Keyser, Venkat Krishnan, Jordan Macknick, and Dev Millstein. 2016. "A Prospective Analysis of the Costs, Benefits, and Impacts of U.S. Renewable Portfolio Standards.” NREL/TP-6A20-67455; LBNL1006962. Golden, CO: National Renewable Energy Laboratory. https://www.osti.gov/scitech/ biblio/1337612-prospective-analysis-costs-benefits-impacts-renewable-portfolio-standards.

McLaren, Joyce, Pieter Gagnon, Kate Anderson, Emma Elgqvist, Ran Fu, and Tim Remo. 2016. "Battery Energy Storage Market: Commercial Scale, Lithium-Ion Projects in the U.S." NREL/PR-6A20-67235. Golden, CO: National Renewable Energy Laboratory. http:/www.nrel.gov/docs/fy17osti/67235.pdf.

Miller, N. W., M. Shao, S. Pajic, and R. D’Aquila. 2014. "Western Wind and Solar Integration Study Phase 3 - Frequency Response and Transient Stability.” NREL/SR-5D00-62906. Golden, CO: National Renewable Energy Laboratory; GE Energy Management, Schenectady, NY (United States). https://www.osti.gov/scitech/biblio/1167065-western-wind-solar-integrationstudy-phase-frequency-response-transient-stability.

Milligan, M., and B. Parsons. 1999. "A Comparison and Case Study of Capacity Credit Algorithms for Wind Power Plants. Multi-Science Publishing Co. LTD. Brentwood, Essex, United Kingdom.” Journal of Wind Engineering 23 (3).

Milligan, Michael, Bethany Frew, Eduardo Ibanez, Juha Kiviluoma, Hannele Holttinen, and Lennart Söder. 2017. "Capacity Value Assessments of Wind Power: Capacity Value Assessments of Wind Power." Wiley Interdisciplinary Reviews: Energy and Environment 6 (1): e226. doi:10.1002/wene.226.

Mills, A. D., and R. H. Wiser. 2013. "Changes in the Economic Value of Photovoltaic Generation at High Penetration Levels: A Pilot Case Study of California." IEEE Journal of Photovoltaics 3 (4): 1394-1402. doi:10.1109/JPHOTOV.2013.2263984. 
Munoz, F. D., and A. D. Mills. 2015. "Endogenous Assessment of the Capacity Value of Solar PV in Generation Investment Planning Studies." IEEE Transactions on Sustainable Energy 6 (4): 1574-85. doi:10.1109/TSTE.2015.2456019.

NREL (National Renewable Energy Laboratory). 2016. "2016 Annual Technology Baseline.” Golden, CO: National Renewable Energy Laboratory. http://www.nrel.gov/analysis/data_tech_baseline.html.

Pietzcker, Robert C., Falko Ueckerdt, Samuel Carrara, Harmen Sytze de Boer, Jacques Després, Shinichiro Fujimori, Nils Johnson, Alban Kitous, Yvonne Scholz, Patrick Sullivan, Gunnar Luderer. 2017. "System Integration of Wind and Solar Power in Integrated Assessment Models: A Cross-Model Evaluation of New Approaches." Energy Economics. Accessed January 25, 2017. doi:10.1016/j.eneco.2016.11.018.

Sigrin, B., P. Sullivan, E. Ibanez, and R. Margolis. 2014. "Representation of the Solar Capacity Value in the Reeds Capacity Expansion Model: Preprint." NREL/CP-6A20-62015. Golden, CO: National Renewable Energy Laboratory. https:/www.osti.gov/scitech/biblio/ 1150799-representation-solar-capacity-value-reeds-capacity-expansion-model-preprint.

Sigrin, Benjamin, Michael Gleason, Robert Preus, Ian Baring-Gould, and Robert Margolis. 2016. "The Distributed Generation Market Demand Model (dGen): Documentation." NREL/TP-6A2065231. Golden, CO: National Renewable Energy Laboratory. http://www.nrel.gov/docs/fy16osti/65231.pdf.

Sullivan, P., K. Eurek, and R. Margolis. 2014. "Advanced Methods for Incorporating Solar Energy Technologies into Electric Sector Capacity-Expansion Models: Literature Review and Analysis.” NREL/TP-6A20-61185. Golden, CO: National Renewable Energy Laboratory. http://www.nrel.gov/docs/fy14osti/61185.pdf.

Sullivan, Patrick, Volker Krey, and Keywan Riahi. 2013. "Impacts of Considering Electric Sector Variability and Reliability in the MESSAGE Model." Energy Strategy Reviews, Future Energy Systems and Market Integration of Wind Power, 1 (3): 157-63. doi:10.1016/j.esr.2013.01.001.

Ueckerdt, Falko, Robert Pietzcker, Yvonne Scholz, Daniel Stetter, Anastasis Giannousakis, and Gunnar Luderer. 2017. "Decarbonizing Global Power Supply under Region-Specific Consideration of Challenges and Options of Integrating Variable Renewables in the REMIND Model." Energy Economics. Accessed January 26, 2017. doi:10.1016/j.eneco.2016.05.012.

U.S. Energy Information Administration (EIA). 2014. "The Electricity Market Module of the National Energy Modeling System: Model Documentation 2014.” Washington, D.C. https:/www.eia.gov/outlooks/aeo/nems/documentation/electricity/pdf/m068(2014).pdf.

WECC. 2013. "2013 Interconnection-Wide Plan Tools and Models.”

Wesoff, Eric. 2017. "SunShot \$1 per Watt Solar Cost Goal: Mission Accomplished, Years Ahead of Schedule." Greentech Media. January 25. https://www.greentechmedia.com/articles/ $\mathrm{read} /$ Sunshot-1-Per-Watt-Solar-Cost-Goal-Mission-Accomplished-Years-Ahead-of-S. 
Wiser, Ryan, Karen Jenni, Joachim Seel, Erin Baker, Maureen Hand, Eric Lantz, and Aaron Smith. 2016. "Expert Elicitation Survey on Future Wind Energy Costs." Nature Energy 1 (September): 1-8. doi:10.1038/nenergy.2016.135.

Wiser, Ryan, Dev Millstein, Trieu Mai, Jordan Macknick, Alberta Carpenter, Stuart Cohen, Wesley Cole, Bethany Frew, and Garvin Heath. 2016. "The Environmental and Public Health Benefits of Achieving High Penetrations of Solar Energy in the United States." Energy 113 (October): 472-86. doi:10.1016/j.energy.2016.07.068.

Woodhouse, Michael, Rebecca Jones-Albertus, David Feldman, Ran Fu, Kelsey Horowitz, Donald Chung, Dirk Jordan, and Sarah Kurtz. 2016. "On the Path to SunShot: The Role of Advancements in Solar Photovoltaic Efficiency, Reliability, and Costs." NREL/TP-6A20-65872. Golden, CO: National Renewable Energy Laboratory. http://www.osti.gov/scitech/biblio/1253983. 


\section{Appendix A: Scenario Inputs}

This analysis considers the U.S. power sector deployment and generation trends projected through 2050 based on a variety of economic, technology, and policy assumptions across 25 scenarios. The factors varied in these scenarios include PV costs, battery costs, electricity demand growth, natural gas prices, conventional generator retirements, renewable energy technology costs, and the inclusion of the Environmental Protection Agency's Clean Power Plan (EPA 2015). Table 6 summarizes the 25 scenarios, grouped into four scenario sets:

- SunShot scenarios

- SunShot_-Low Storage Cost scenarios

- PV price sensitivity scenarios

- Baseline scenarios.

These scenarios are designed provide not just a single projection achieving the SunShot 2030 goal but a range of projections based on a variety of uncertainties around major assumptions that shape the evolution of the power sector. The PV price sensitivity scenarios are included to demonstrate the relative impacts of under or over achieving on the SunShot 2030 goal. The baseline scenarios are included as a benchmark for demonstrating the level of change from current reference-case-like scenarios. 
Table 6. Scenarios Used in the Study. Scenarios are generally centered on the SunShot scenario (i.e., the SunShot 2030 goal). Bold values are the reference values. Any blank cells use the reference value from the SunShot scenario. Additional scenario details are provided in Appendix $A$.

$\mathrm{NG}=$ natural gas, $\mathrm{RE}=$ renewable energy, and CPP = Clean Power Plan .

\begin{tabular}{|c|c|c|c|c|c|c|c|}
\hline Scenario Name & $\begin{array}{c}2030 \mathrm{PV} \\
\text { Cost }^{\mathrm{a}}\end{array}$ & $\begin{array}{c}\text { Battery } \\
\text { Cost }\end{array}$ & Electricity & $\begin{array}{l}\text { NG } \\
\text { Price }\end{array}$ & $\begin{array}{l}\text { Retire- } \\
\text { ments }\end{array}$ & $\begin{array}{l}\text { RE } \\
\text { Costs }\end{array}$ & CPP \\
\hline SunShot & $3 \phi$ & Ref & Ref & Ref & Ref & Ref & None \\
\hline Low Demand & & & Low & & & & \\
\hline High Demand & & & High & & & & \\
\hline Low NG Price & & & & Low & & & \\
\hline High NG Price & & & & High & & & \\
\hline Low Retire & & & & & Low & & \\
\hline High Retire & & & & & High & & \\
\hline Low RE Cost & & & & & & Low & \\
\hline High RE Cost & & & & & & High & \\
\hline \multicolumn{8}{|l|}{ W/ Growth Penalty } \\
\hline $\begin{array}{l}\text { SunShot - Low } \\
\text { Storage Cost }\end{array}$ & & Low & & & & & \\
\hline $\begin{array}{l}\text { Low Demand - Low } \\
\text { Storage Cost }\end{array}$ & & Low & Low & & & & \\
\hline $\begin{array}{l}\text { High Demand - Low } \\
\text { Storage Cost }\end{array}$ & & Low & High & & & & \\
\hline $\begin{array}{l}\text { Low NG Price - Low } \\
\text { Storage Cost }\end{array}$ & & Low & & Low & & & \\
\hline $\begin{array}{l}\text { High NG Price - Low } \\
\text { Storage Cost }\end{array}$ & & Low & & High & & & \\
\hline $\begin{array}{l}\text { Low Retire - Low } \\
\text { Storage Cost }\end{array}$ & & Low & & & Low & & \\
\hline $\begin{array}{l}\text { High Retire - Low } \\
\text { Storage Cost }\end{array}$ & & Low & & & High & & \\
\hline $\begin{array}{l}\text { Low RE Cost - Low } \\
\text { Storage Cost }\end{array}$ & & Low & & & & Low & \\
\hline $\begin{array}{l}\text { High RE Cost - Low } \\
\text { Storage Cost }\end{array}$ & & Low & & & & High & \\
\hline \multicolumn{8}{|l|}{$\begin{array}{l}\text { W/ Growth Penalty - } \\
\text { Low Storage Cost }\end{array}$} \\
\hline 2 Cents & $2 \phi$ & & & & & & \\
\hline
\end{tabular}




\begin{tabular}{l|c|c|c|c|c|c|c}
\hline Scenario Name & $\begin{array}{c}2030 \text { PV } \\
\text { Cost }^{\mathrm{a}}\end{array}$ & $\begin{array}{c}\text { Battery } \\
\text { Cost }\end{array}$ & Electricity & $\begin{array}{c}\text { NG } \\
\text { Price }\end{array}$ & $\begin{array}{c}\text { Retire- } \\
\text { ments }\end{array}$ & $\begin{array}{c}\text { RE } \\
\text { Costs }\end{array}$ & CPP \\
\hline \hline SunShot & $3 \phi$ & Ref & Ref & Ref & Ref & Ref & None \\
\hline 4 Cents & $4 \phi$ & & & & & & \\
\hline $\begin{array}{l}2 \text { Cents - Low } \\
\text { Storage Cost }\end{array}$ & $2 \phi$ & Low & & & & & \\
\hline $\begin{array}{l}4 \text { Cents - Low } \\
\text { Storage Cost }\end{array}$ & $4 \phi$ & Low & & & & & \\
\hline \hline ATB Mid & ATB Mid & & & & & & \\
\hline ATB Mid CPP & ATB Mid & & & & & & National \\
\hline $\begin{array}{l}\text { ATB Mid - Low } \\
\text { Storage Cost }\end{array}$ & ATB Mid & Low & & & & & \\
\hline
\end{tabular}

${ }^{a} \mathrm{PV}$ cost is shown as an levelized cost of energy in cents/kWh or as the Annual Technology Baseline (ATB) mid-case projection (NREL 2016)

Because ReEDS and dGen use system costs instead of LCOE for their economic calculations, the 2030 target LCOE values were converted to overnight capital costs using the 2016 Annual Technology Baseline (ATB) spreadsheet (NREL 2016). The financing assumptions in ReEDS were left at the default values to ensure consistency across the technologies. ${ }^{31}$ The resulting capital cost trajectories are shown in Figure 33 through Figure 35. The 2015 cost value is taken from the 2016 Annual Technology Baseline, and the 2020 cost value is the original SunShot 2020 target (DOE 2012). Values between the 2015 and 2020 years and between the 2020 and 2030 years are linear interpolations. These trajectories represent the LCOE targets being reached primarily through capital cost reductions; however, these targets could instead be achieved through various combinations of technology cost reduction and/or more favorable financing terms (discussed below). Additional parameters - including fixed operations and maintenance costs, variable operations and maintenance costs, degradation rates, and physical lifetimes - are summarized in Table 7 for utility-scale PV in 2020 and 2030. These values are also ramped linearly between 2020 and 2030 for the SunShot scenarios.

\footnotetext{
${ }^{31}$ The financial calculations used were $8 \%$ interest rate (nominal), $13 \%$ rate of return on equity, $60 \%$ debt fraction for UPV, $80 \%$ debt fraction for DPV, $40 \%$ tax rate, and a five-year depreciation period. These values result in a weighted-average cost of capital (WACC) of 8.1\% nominal. More favorable financing costs (e.g., longer system life and lower cost of capital) would result in higher system costs than those shown in Figure 33, but they would result in the same model outputs. See
}

Table 9 and Table 10 for details. 


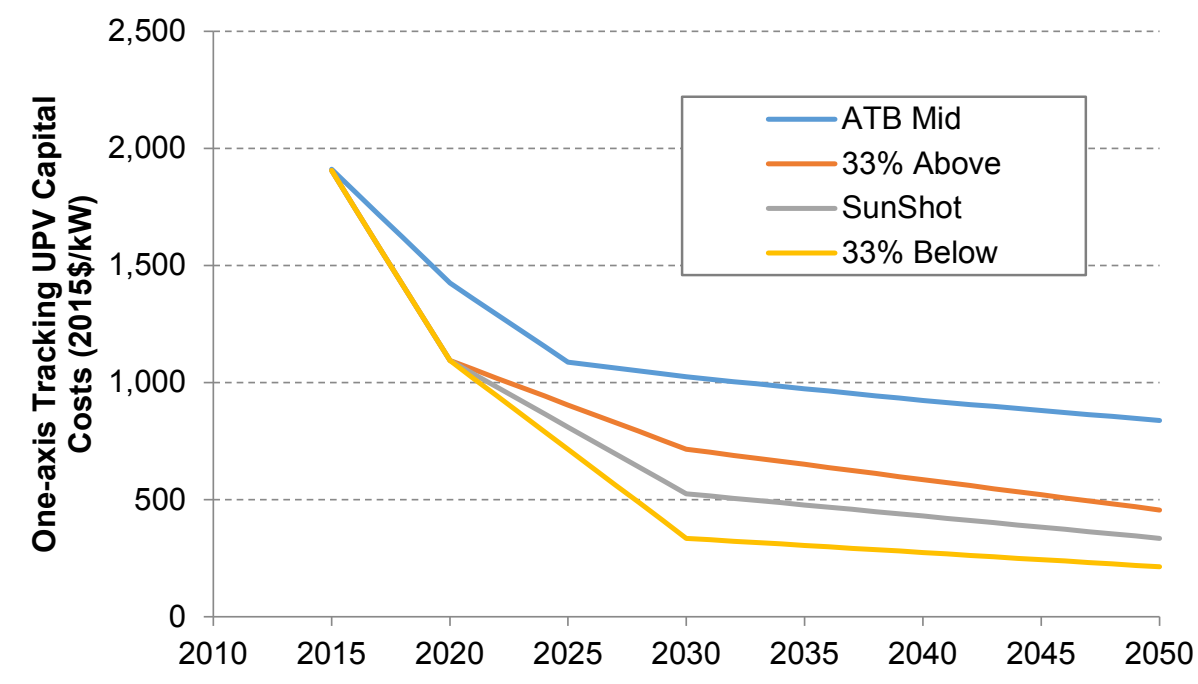

Figure 33. Utility-scale PV capital cost assumptions

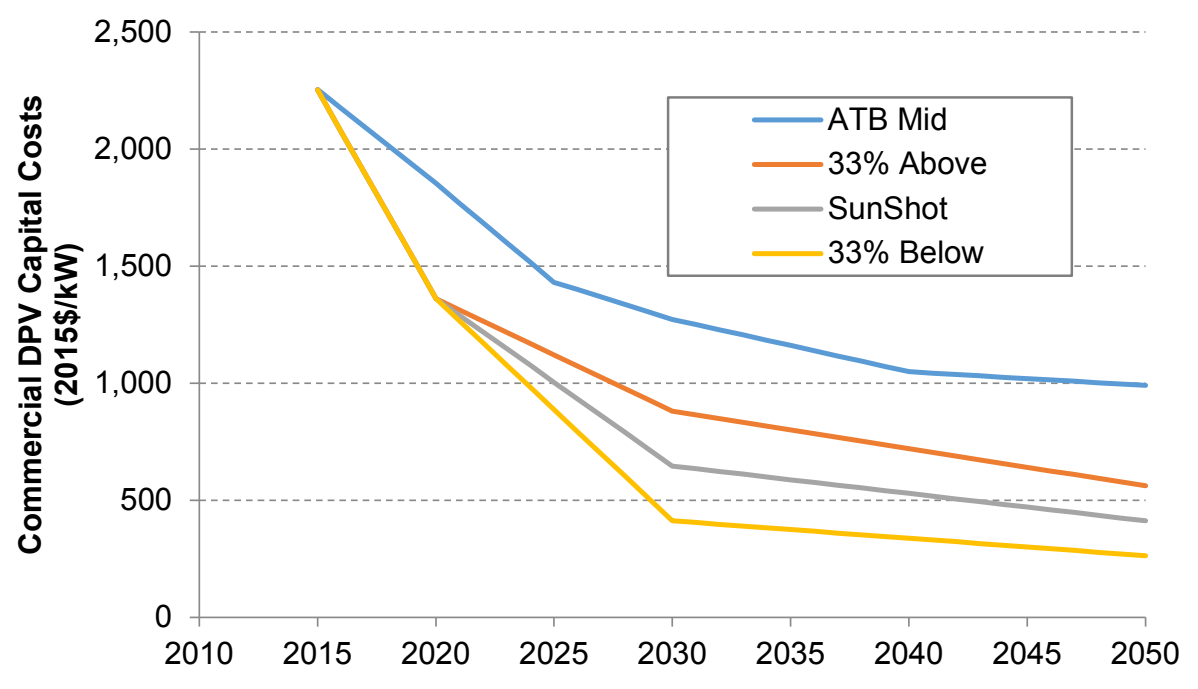

Figure 34. Commercial DPV capital cost assumptions 


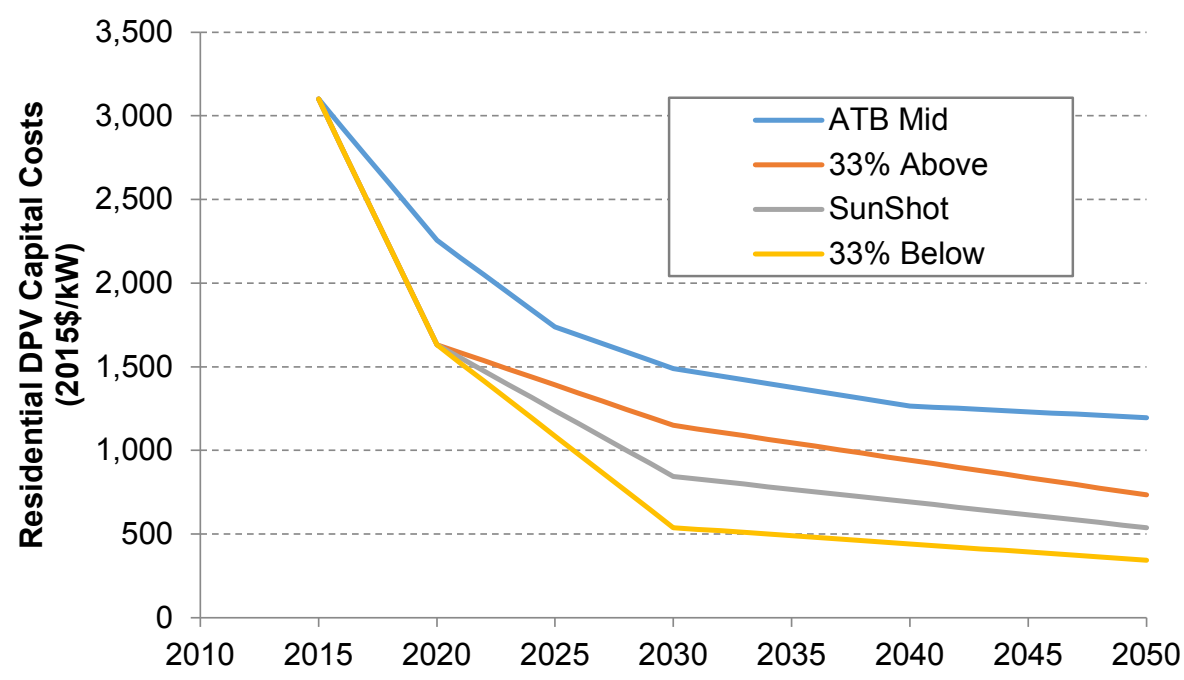

Figure 35. Residential DPV capital cost assumptions

Table 7. Utility-Scale PV Operational Costs (2015\$), Performance, and Lifetime Parameters in 2020, 2030, and 2050

\begin{tabular}{|l|c|c|c|}
\hline & $\mathbf{2 0 2 0}$ & $\mathbf{2 0 3 0}$ & $\mathbf{2 0 5 0}$ \\
\hline Fixed O\&M (\$/kW-yr) & & & \\
\hline ATB Mid & 12.1 & 8.1 & 8.1 \\
\hline Two, Three, and Four Cents & 7.7 & 4.4 & 4.4 \\
\hline Variable O\&M (\$/MWh) & 0 & 0 & 0 \\
\hline Degradation Rate & & & \\
\hline ATB Mid & $0.5 \% /$ year & $0.5 \% /$ year & $0.5 \% /$ year \\
\hline Two, Three, and Four Cents & $0.5 \% /$ year & $0.2 \% /$ year & $0.2 \% /$ year \\
\hline Lifetime & 30 years & 30 years & 30 years \\
\hline
\end{tabular}


Table 8. DPV Operational Costs (2015\$), Degradation, and Lifetime Parameters in 2020,2030 , and 2050

\begin{tabular}{|c|c|c|c|}
\hline & 2020 & 2030 & 2050 \\
\hline \multicolumn{4}{|l|}{$\begin{array}{l}\text { Residential Fixed O\&M } \\
\text { (\$/kW-yr) }\end{array}$} \\
\hline ATB Mid & 14.0 & 10.0 & 10.0 \\
\hline Two, Three, and Four Cents & 10.9 & 7.0 & 7.0 \\
\hline \multicolumn{4}{|l|}{$\begin{array}{l}\text { Commercial Fixed O\&M } \\
(\$ / k W-y r)\end{array}$} \\
\hline ATB Mid & 11.0 & 8.0 & 8.0 \\
\hline Two, Three, and Four Cents & 8.2 & 5.0 & 5.0 \\
\hline Variable O\&M (\$/MWh) & 0 & 0 & 0 \\
\hline Degradation Rate & $0.5 \% /$ year & $0.5 \% /$ year & $0.5 \% /$ year \\
\hline Lifetime & 25 years & 25 years & 25 years \\
\hline
\end{tabular}

Although the scenarios defined here use capital cost reductions as the primary metric to achieve the SunShot LCOE targets, the SunShot targets could be achieved through multiple paths, including declining technology costs and/or more favorable financing assumptions. 
Table 9 shows four different sets of capital cost and financing assumptions, which each result in a levelized cost of energy (LCOE) that achieves the $\$ 0.03 / \mathrm{kWh}(\$ 30 / \mathrm{MWh}$ ) utility-scale PV 2030 SunShot goal. For example, in the first row, which reflects the SunShot scenario, the $\$ 0.03 / \mathrm{kWh}$ LCOE target is reached primarily through capital cost reductions. Conversely, the second row assumes a higher capital cost but is able to reach the same LCOE goal by instead increasing the economic lifetime of PV plants. A third possible path to the same SunShot goal yields a higher capital cost by using a lower weighted average cost of capital (WACC). Finally, the last row demonstrates the combined effect of multiple favorable financing assumptions; with both a longer economic lifetime and lower WACC, PV capital costs can be much larger than in the previous cases while still achieving the SunShot 2030 goal.

Additional combinations of capital cost and financing assumptions are also possible, but these examples merely demonstrate the wide range of possible paths to the SunShot 2030 goal. These capital cost and financing parameters and associated cumulative LCOE values were calculated using the 2016 ATB spreadsheet (NREL 2016). Table 10 demonstrates a similar effect for residential and commercial PV systems. Discussion of other pathways that can lead to low-cost PV systems is included in Appendix D. 
Table 9. Example of Financing Assumptions to Reach the Utility-Scale PV SunShot 2030 Target

\begin{tabular}{|c|c|c|}
\hline & $\begin{array}{l}\text { Capital Cost and Financing } \\
\text { Assumptions }\end{array}$ & Levelized Cost of Energy ( $\$ / \mathrm{MWh})$ \\
\hline Default scenario & $\begin{array}{l}\text { Capital Cost }=\$ 525 / \mathrm{kW} \\
\text { Economic lifetime }{ }^{32}=20 \text { years } \\
\text { WACC }(\text { Nominal) }=8.1 \%\end{array}$ & $\$ 30 / \mathrm{MWh}$ \\
\hline $\begin{array}{l}\text { Longer economic } \\
\text { lifetime }\end{array}$ & $\begin{array}{l}\text { Capital Cost }=\$ 746 / \mathrm{kW} \\
\text { Economic lifetime }=50 \text { years } \\
\text { WACC }(\text { Nominal })=8.1 \%\end{array}$ & $\$ 30 / \mathrm{MWh}$ \\
\hline Lower WACC & $\begin{array}{l}\text { Capital Cost }=\$ 656 / \mathrm{kW} \\
\text { Economic lifetime }=20 \text { years } \\
\text { WACC }(\text { Nominal })=5.8 \%\end{array}$ & $\$ 30 / \mathrm{MWh}$ \\
\hline $\begin{array}{l}\text { Longer economic } \\
\text { lifetime and lower } \\
\text { WACC }\end{array}$ & $\begin{array}{l}\text { Capital Cost }=\$ 928 / \mathrm{kW} \\
\text { Economic lifetime }=50 \text { years } \\
\text { WACC }(\text { Nominal })=5.8 \%\end{array}$ & $\$ 30 / \mathrm{MWh}$ \\
\hline
\end{tabular}
Table 10. Example of Financing Assumptions to Reach the Residential and Commercial PV
SunShot 2030 Target $^{33}$

\begin{tabular}{|c|c|c|}
\hline & Financing Assumptions & Capital Cost \\
\hline SunShot scenario & $\begin{array}{l}\text { Economic lifetime }=30 \text { years } \\
\text { Discount rate }(\text { nominal })=8.1 \%\end{array}$ & $\begin{array}{l}\$ 646 / \mathrm{kW}=4 \phi / \mathrm{kWh} \\
\$ 884 / \mathrm{kW}=5 \phi / \mathrm{kWh}\end{array}$ \\
\hline Loan-financed & $\begin{array}{l}\text { Economic lifetime }=30 \text { years } \\
\text { Discount rate }(\text { nominal) }=8.1 \% \\
\text { Loan with } 20 \% \text { down payment } \\
\text { Interest rate = discount rate }\end{array}$ & $\begin{array}{l}\$ 1,032 / \mathrm{kW}=4 \phi / \mathrm{kWh} \\
\$ 1,310 / \mathrm{kW}=5 \phi / \mathrm{kWh}\end{array}$ \\
\hline $\begin{array}{l}\text { Loan-financed with } \\
\text { lower interest rate }\end{array}$ & $\begin{array}{l}\text { Economic lifetime }=30 \text { years } \\
\text { Discount rate }(\text { nominal })=8.1 \% \\
\text { Loan with } 20 \% \text { down payment } \\
\text { Interest rate }(\text { nominal })=5 \%\end{array}$ & $\begin{array}{l}\$ 1,205 / \mathrm{kW}=4 \phi / \mathrm{kWh} \\
\$ 1,529 / \mathrm{kW}=5 \phi / \mathrm{kWh}\end{array}$ \\
\hline All-cash payment & $\begin{array}{l}\text { Economic lifetime }=30 \text { years } \\
\text { Discount rate }(\text { nominal })=8.1 \%\end{array}$ & $\begin{array}{c}\$ 800 / \mathrm{kW}=4 \phi / \mathrm{kWh} \\
\$ 1,015 / \mathrm{kW}=5 \phi / \mathrm{kW0}\end{array}$ \\
\hline
\end{tabular}

\footnotetext{
${ }^{32}$ Economic lifetime is different than physical lifetime. Economic lifetime only considers the period over which the investment is to be recouped. Physical lifetimes of PV systems is much longer than the 20 -year economic lifetime considered under the default financing assumptions.

${ }^{33}$ Because of differences in tax rates and incentives (e.g., depreciation and tax write-offs), the capital costs were calculated assuming a commercially financed system (e.g., third-party ownership for residential homes). Other variations in the financing structure would lead to different capital costs.
} 
The reference and low-cost storage projections are taken as the mid-case and low-case storage cost projection from Cole, Marcy, et al. (2016). The projections for behind-the-meter systems use the same ratio of declines as the utility-scale systems but have different starting costs. The commercial capital costs were estimated as part of an ongoing project (McLaren et al. 2016), while the residential capital costs were adapted from Ardani et al. (2016). The utility-scale projections are shown in Figure 36 for an eight-hour duration battery storage system, and the behind-the-meter projections are shown in Figure 37 and Figure 38 for three-hour duration systems.

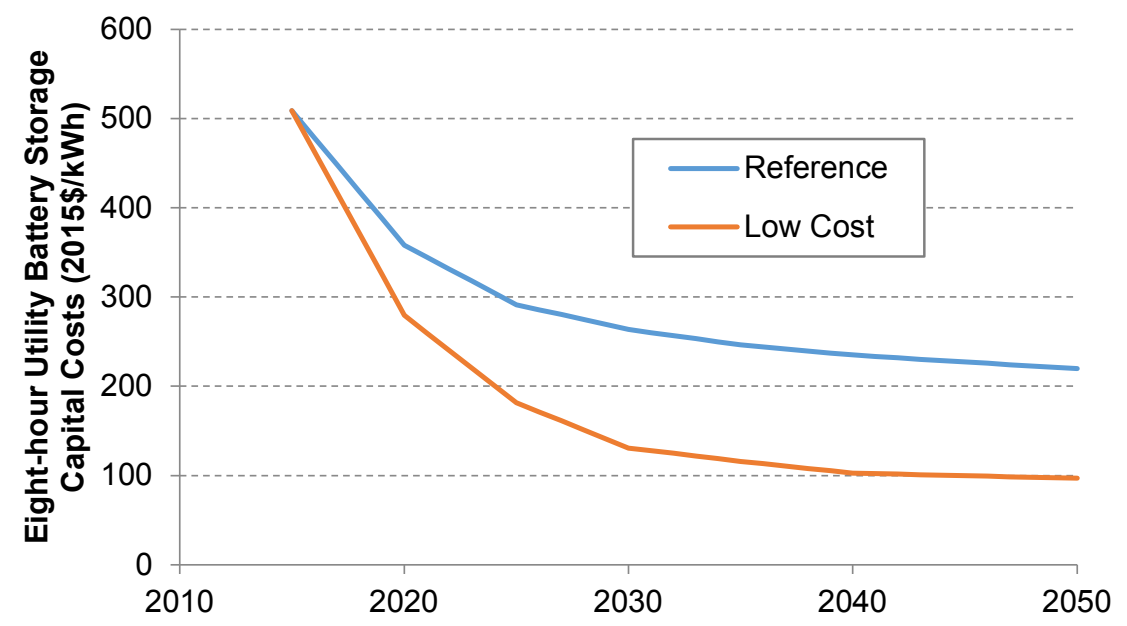

Figure 36. Capital cost projections for utility-scale battery storage systems

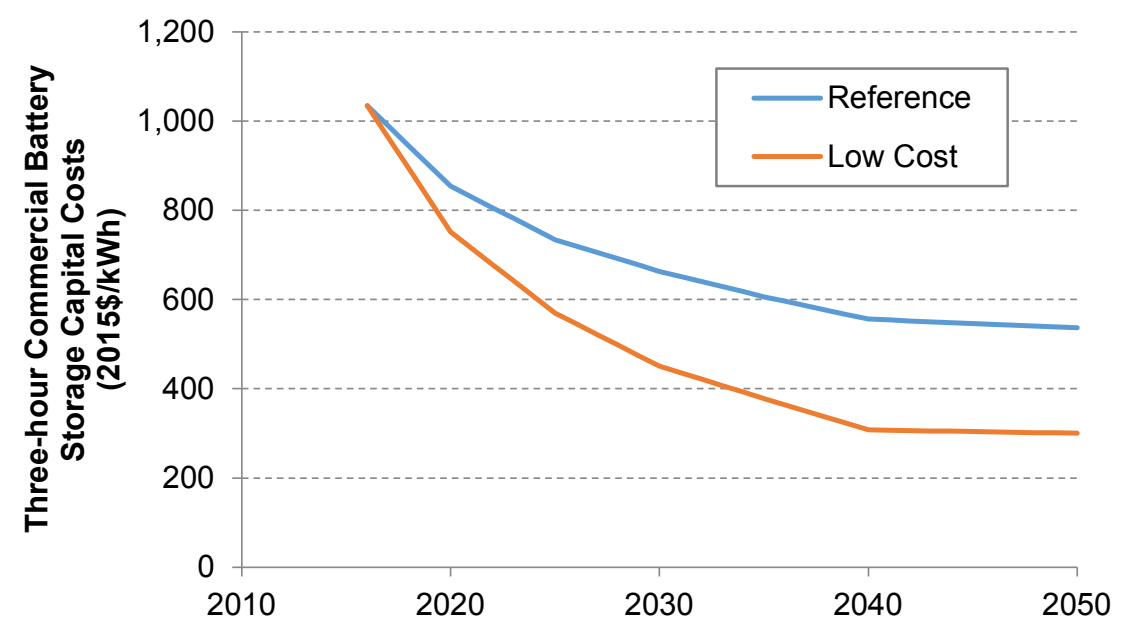

Figure 37. Capital cost projections for commercial behind-the-meter battery systems 


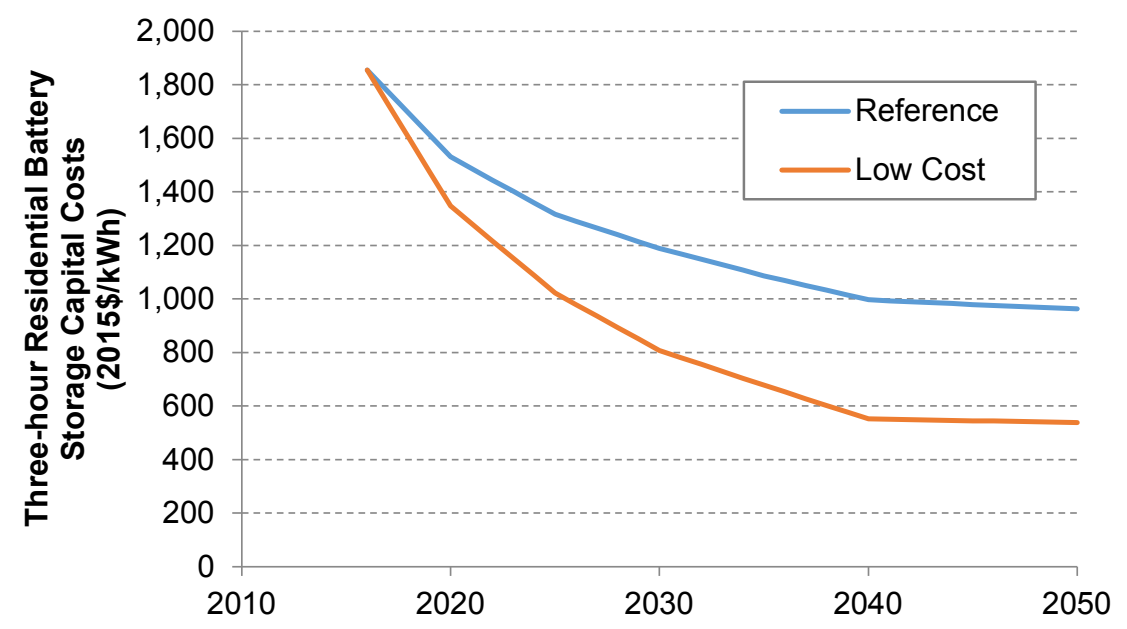

Figure 38. Capital cost projections for residential behind-the-meter battery systems

The battery systems are generic battery storage systems, but the projections by Cole, Marcy, et al. (2016) were generally based on lithium-ion systems. The round-trip efficiency is assumed to be $90 \%$ with a 15 -year lifetime at $\sim 1$ cycle per day. Additional cost details such as operations and maintenance cost projections are in Cole, Marcy, et al. (2016).

All other system costs not mentioned here are taken from the 2016 ATB mid-case projection (NREL 2016) with the exception of concentrating solar power (CSP) costs, which are assumed to achieve the SunShot 2020 target in 2020 and remain constant thereafter (DOE 2012). ${ }^{34}$

Electricity demand, natural gas prices, renewable energy cost trajectories, and retirement schedules are described below. The Clean Power Plan (CPP) is applied only in one scenario in order to provide a baseline both with and without the CPP present. ${ }^{35}$ As is seen in the results section, several of the scenarios have emission levels below the modeled limit such that if the CPP were included in the scenarios the modeled results would not change.

Aside from the CPP, all other state and federal regulations and policies are implemented according to current law as of June 1, 2016. Especially relevant to this work are the investment tax credit with its scheduled step-down, net metering policies, and state renewable portfolio standards. For details about the policies represented in the models and the methods used to represent them, see the models' documentation (Eurek et al. 2016; Benjamin Sigrin et al. 2016).

\footnotetext{
${ }^{34}$ Updated CSP targets were not announced with the SunShot 2030 targets for PV.

35 The CPP is implemented in the model as a mass-based policy with new source compliments and unrestricted national allowance trading. Other implementations will result in different outcomes from those included in this work.
} 


\section{Fossil Fuel Prices}

The natural gas input price points are based on the trajectories from the AEO 2016 (EIA 2016). The prices are shown in Figure 39 and are from the AEO 2016 Reference scenario, the Low Oil and Gas Resource and Technology scenario, and the High Oil and Gas Resource and Technology scenarios (EIA 2016). Actual natural gas prices in ReEDS are based on the AEO scenarios, but they are not exactly the same; instead, they are price-responsive to ReEDS natural gas demand. Each census region includes a natural gas supply curve that adjusts the natural gas input price based on both regional and national demand (Cole, Medlock III, and Jani 2016).
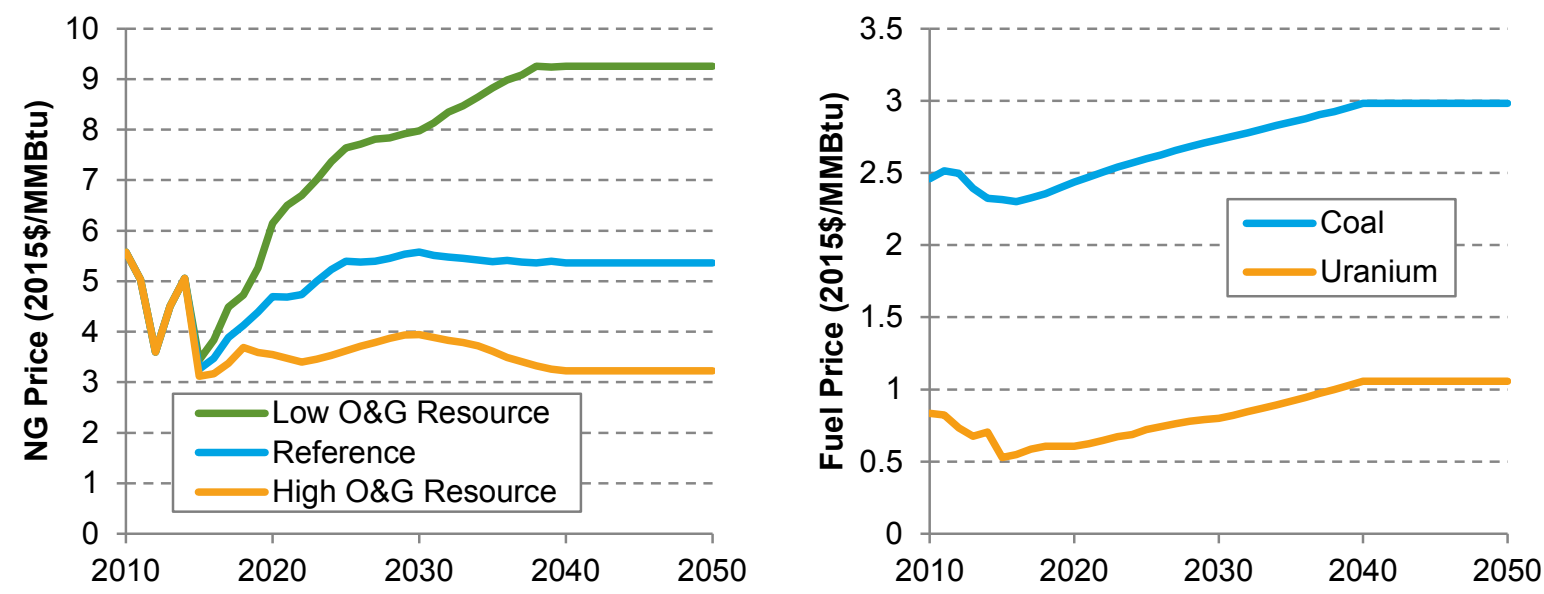

Figure 39. Fuel price trajectories used in the scenarios

The reference coal and uranium price trajectories are from AEO 2016 Reference scenario and are shown in Figure 39. Both coal and uranium prices are assumed to be fully inelastic. Because AEO 2016 fuel prices are only projected through 2040, fuel prices from 2040 to 2050 are held constant at the 2040 values.

\section{Demand Growth}

The Mid-case Scenario is based on the AEO 2016 Reference scenario load growth. The high and low load growth scenarios are also from AEO 2016 based on the Low and High Economic Growth scenarios, which use lower/higher rates of population growth, productivity, and lower/higher inflation than the Reference scenario (see Figure 40). For the years after the AEO 2016 horizon (which ends in 2040), we assume an annual growth rate equal to the average growth rate from 2030 to 2040. 


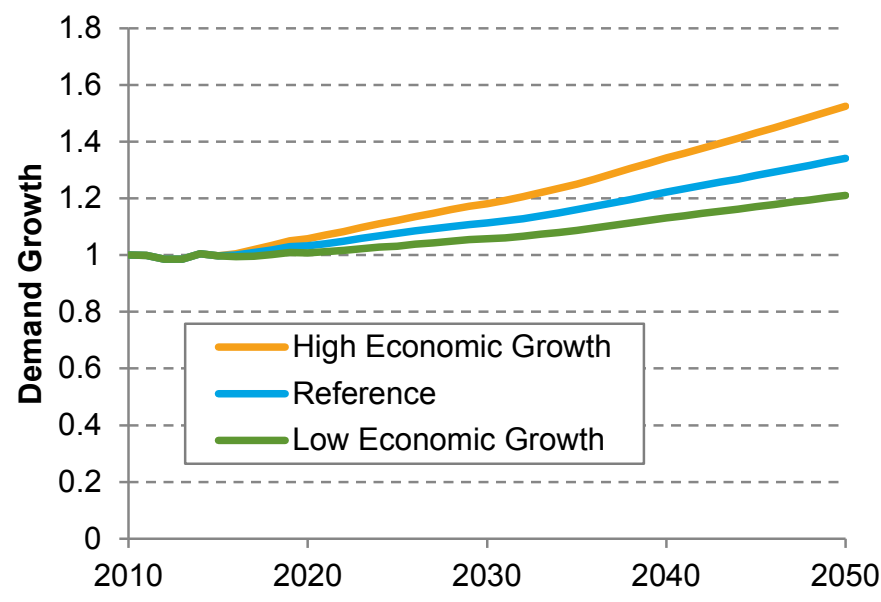

Figure 40. Demand growth trajectories used in the scenarios

\section{Technology Cost and Performance}

For non-PV technologies, cost and performance assumptions are taken from the 2016 ATB (NREL 2016). The ATB includes low, mid, and high cost and performance projections through 2050 for the generating technologies used in the ReEDS model. Technology LCOE ranges from the ATB are shown in Figure 41, Figure 42, and Figure 43 for 2015, 2030, and 2050 respectively. The mid-case LCOE projections from the ATB were used for all scenarios in this work except the Low RE Cost and High RE Cost scenarios, which used the ATB low and high projections respectively.

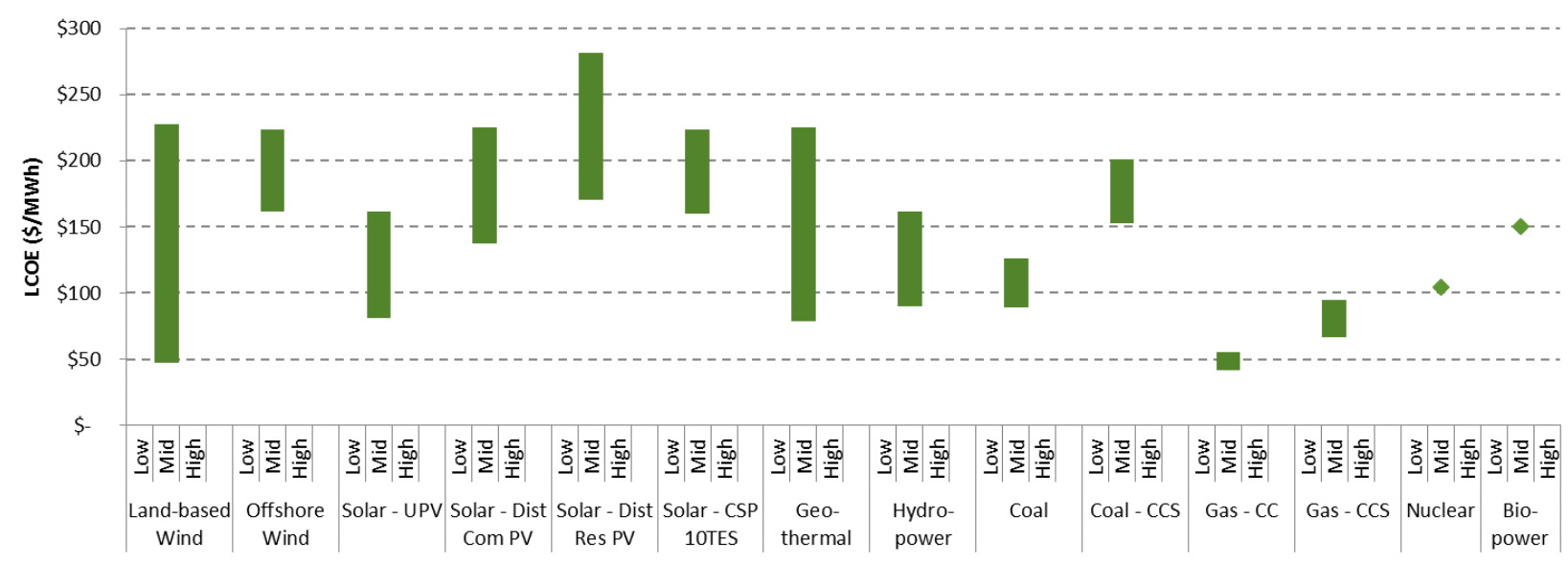

Figure 41. LCOE ranges from the 2016 ATB for 2015 


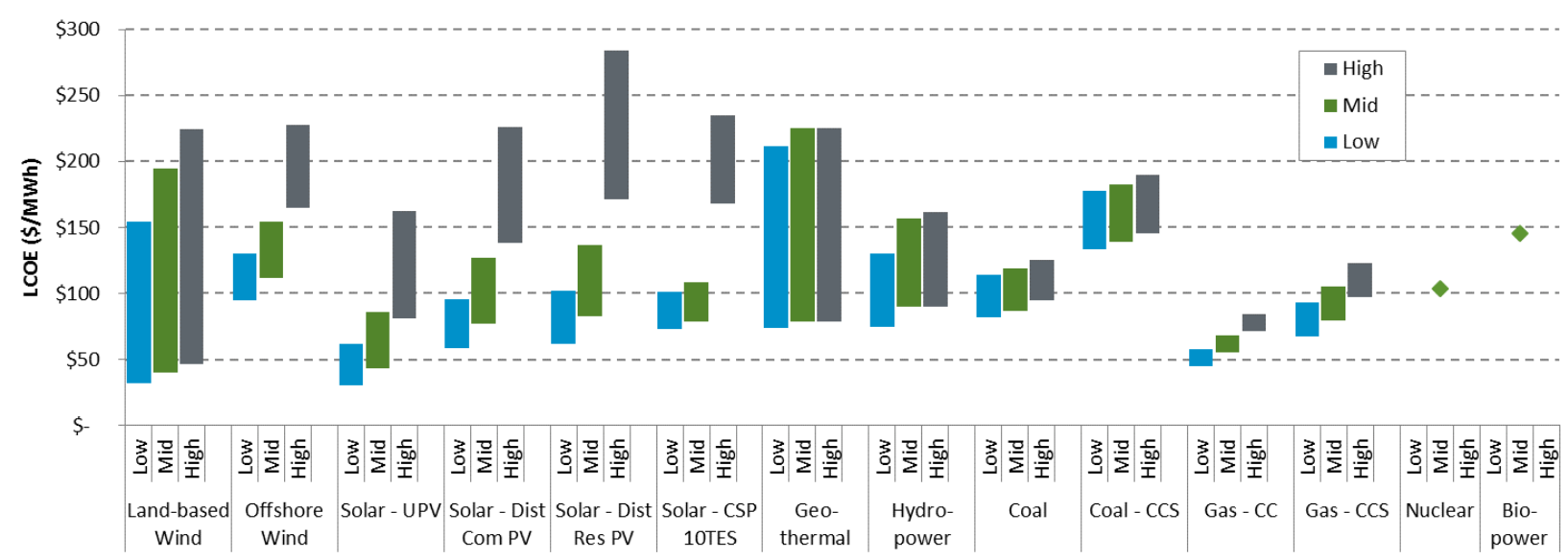

Figure 42. LCOE ranges from the 2016 ATB for 2030

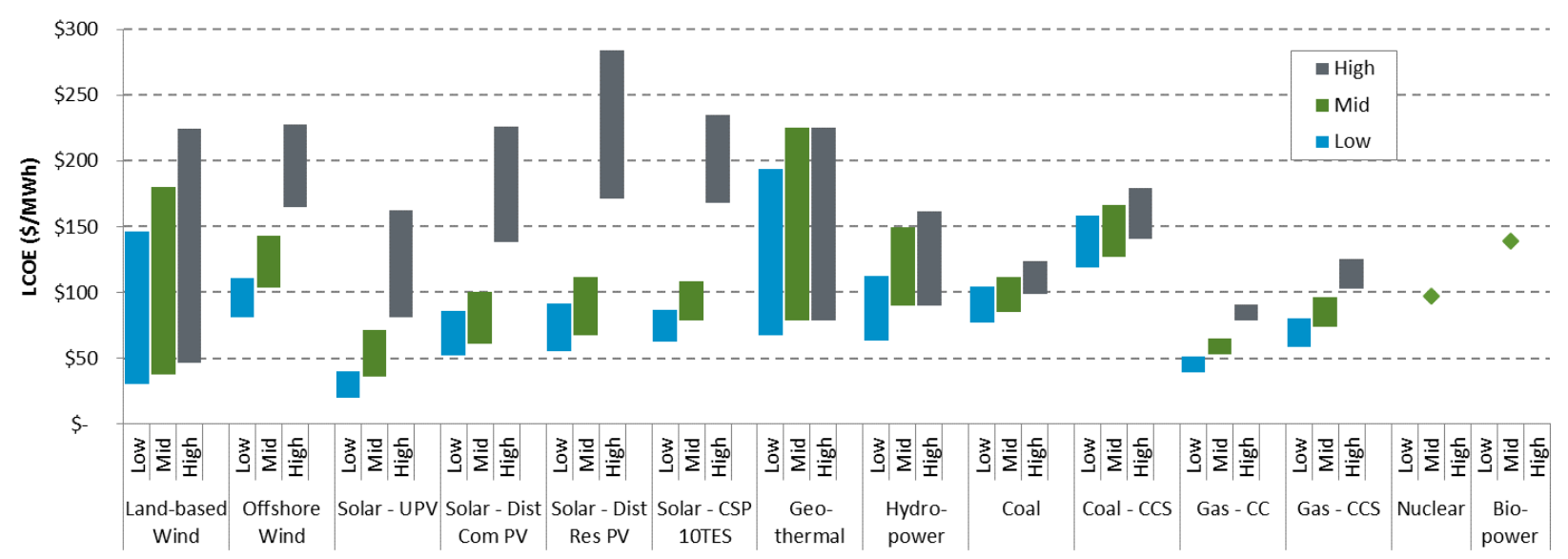

Figure 43. LCOE ranges from the 2016 ATB for 2050

\section{Existing Fleet Retirements}

Retirements for conventional power plants are taken from the ABB Velocity Suite database (ABB 2016a), which use age-based retirements unless an official retirement date has been announced. All other generator types use strictly age-based retirement schedules.

The Accelerated Coal Retirements scenario reduces coal plant lifetimes by 10 years. The Extended Nuclear Lifetime scenario assumes all nuclear plants (except those with an announced retirement date) receive a second relicense that that gives them an 80-year life.

\section{Utility PV Growth Penalty}

The W/ Growth Penalty scenario includes a growth penalty for utility PV systems. It increases utility PV capital costs by $12 \%$ when annual deployment is more than $2 \mathrm{GW}$ greater than the previous year and by $41 \%$ when annual deployment is more than $4 \mathrm{GW}$ greater than the previous year. For example, if $10 \mathrm{GW}$ of new utility PV capacity were added in 2020, $12 \mathrm{GW}$ could be added in 2021 without penalty. The 2-GW limit was developed based on average annual increases in utility PV deployment from 2010 to 2016 . The purpose of the growth penalty is 
to represent limitations in rapidly scaling up the deployment. Distributed PV is not impacted by growth penalties.

\section{Retail Rates and Net Metering}

Retail rates for the dGen model are taken from the Utility Rate Data Base ${ }^{36}$ and curated as of spring 2017. Retail rate structures are assumed not to change over time. For example, a residential customer who is currently on a flat retail rate will not be converted to a time-of-use tariff during the analysis period. However, the magnitude of the retail rates is adjusted according to the calculated electricity price from ReEDS. If ReEDS calculates that the electricity prices in a given region are 5\% higher in 2030 than in 2016, the rates used in dGen to project PV adoption are increased by $5 \%$ in 2030 . The electricity prices are passed from ReEDS to dGen at the census region level. ${ }^{37}$

Net metering policies are represented as of spring 2017. Conditions that lead to the discontinuation of net metering are captured in dGen. For example, if a net metering policy phases out after DPV penetration reaches $3 \%$, dGen will remove net metering once that penetration level is achieved.

${ }^{36}$ See en.openei.org/wiki/Utility_Rate Database.

${ }^{37}$ See www.eia.gov/outlooks/aeo/pdf/f1.pdf for a map of the census regions. 


\section{Appendix B: Modeling Tools}

For this analysis, we use electric sector models developed by the National Renewable Energy Laboratory (NREL). The primary modeling tool is the Regional Energy Deployment System (ReEDS) capacity expansion model of the contiguous United States that relies on system-wide least-cost optimization to estimate the type and location of future generation and transmission capacity. Because ReEDS does not explicitly model distributed generation, we also use the Distributed Generation (dGen) model, ${ }^{38}$ a consumer adoption model for the U.S. rooftop, distributed PV (DPV) market. dGen projects the future adoption of DPV and battery storage in the industrial, commercial, and residential sectors. This joint modeling approach captures the dynamic balances between growth in electricity consumption, plant retirements, competing generation options, policies, and the projected deployment and operation of behind-the-meter technologies - all of which affect the demand for new PV and storage resources. These modeling tools have been used for a wide variety of power sector analyses, especially those that require additional detailed representation of renewable energy, including the original SunShot Vision Study (DOE 2012), the Wind Vision Study (DOE 2015b), and policy valuations and impacts (Cole et al. 2015; Mai, Cole, et al. 2016; Mai, Wiser, et al. 2016). ${ }^{39}$

\section{ReEDS}

ReEDS is an electricity system capacity expansion model that simulates the construction and operation of generation and transmission capacity across the contiguous United States from present day ${ }^{40}$ to 2050 . We provide a brief overview here of the features most relevant to this study, but we refer the reader to the 2016 ReEDS Documentation (Eurek et al. 2016) and the 2016 Standard Scenarios report (Cole, Mai, et al. 2016) for detailed descriptions of the model's formulation and inputs. We use the ReEDS model 2016 version from these documents, with some variations, which we discuss at the end of this section.

ReEDS calculates the competing costs of differing energy supply options and selects the regional mix of technologies that meet physical and policy requirements of the electric sector at least cost. Model results are based on total system costs, which account for the type and location of fossil, nuclear, renewable, and storage resource development; the transmission infrastructure expansion requirements of those installations; and the generator dispatch and fuel needed to satisfy regional electricity consumption requirements and maintain grid system adequacy. The ReEDS model also considers technology, resource, and policy considerations such as state renewable portfolio standards (RPS). It also has the option of including the U.S. Environmental Protection Agency's Clean Power Plan (EPA 2015).

The primary outputs from ReEDS include the amount, type, year, and location of generator capacity; annual generation from each technology; storage capacity expansion; and transmission capacity expansion needed to satisfy regional electricity consumption requirements and maintain

\footnotetext{
${ }^{38}$ The dGen model is a rewrite of the original PVDS model (Denholm, Margolis, and Drury 2009) used in the original SunShot Vision Study.

${ }^{39}$ More complete lists of publications using the ReEDS and dGen models can be found at www.nrel.gov/analysis/reeds/related_pubs.html and www.nrel.gov/analysis/dgen/related_pubs.html respectively

${ }^{40}$ ReEDS includes all existing and under-construction projects as of April 2016 in the ABB Velocity Suite database (ABB 2016).
} 
grid system adequacy. The generation and storage technologies modeled in ReEDS include coalfired (pulverized coal with and without scrubbers, biomass cofiring, integrated gasification combined cycle with and without carbon capture and storage), natural-gas-fired (combined cycle and combustion turbines), oil and gas steam, nuclear, wind (land-based and offshore), biopower, geothermal, hydropower, UPV, concentrating solar power with and without thermal energy storage, pumped-hydropower storage, compressed-air energy storage (CAES), and utilityscale batteries.

ReEDS represents the electric sector with high spatial resolution to enable comparative electricity sector cost evaluation based on local costs, regional pricing, and the relative value of geographically and temporally constrained renewable power sources. The model divides the contiguous United States into 134 "balancing area" regions, wherein electricity supply and consumption are balanced and planning reserves are enforced. ReEDS also characterizes the quality, variability, uncertainty, and geographic resource constraints of renewable resources across these 134 regions; some technologies are further characterized into more resolved subregions. These regions are also aggregated into 18 regional transmission organization (RTOs) that very roughly represent regional cooperation areas. See Figure 44 for a map of these 134 balancing area and 18 RTO modeling regions. In addition, long-distance transmission is represented as single-path connections between most adjacent or near-adjacent modeling balancing area regions, and ReEDS models both existing transmission lines as well as new transmission capacity on these inter-region lines. ReEDS also models the intra-region "spur line" transmission costs required to interconnect renewable capacity from their resource region to the transmission grid or load centers.

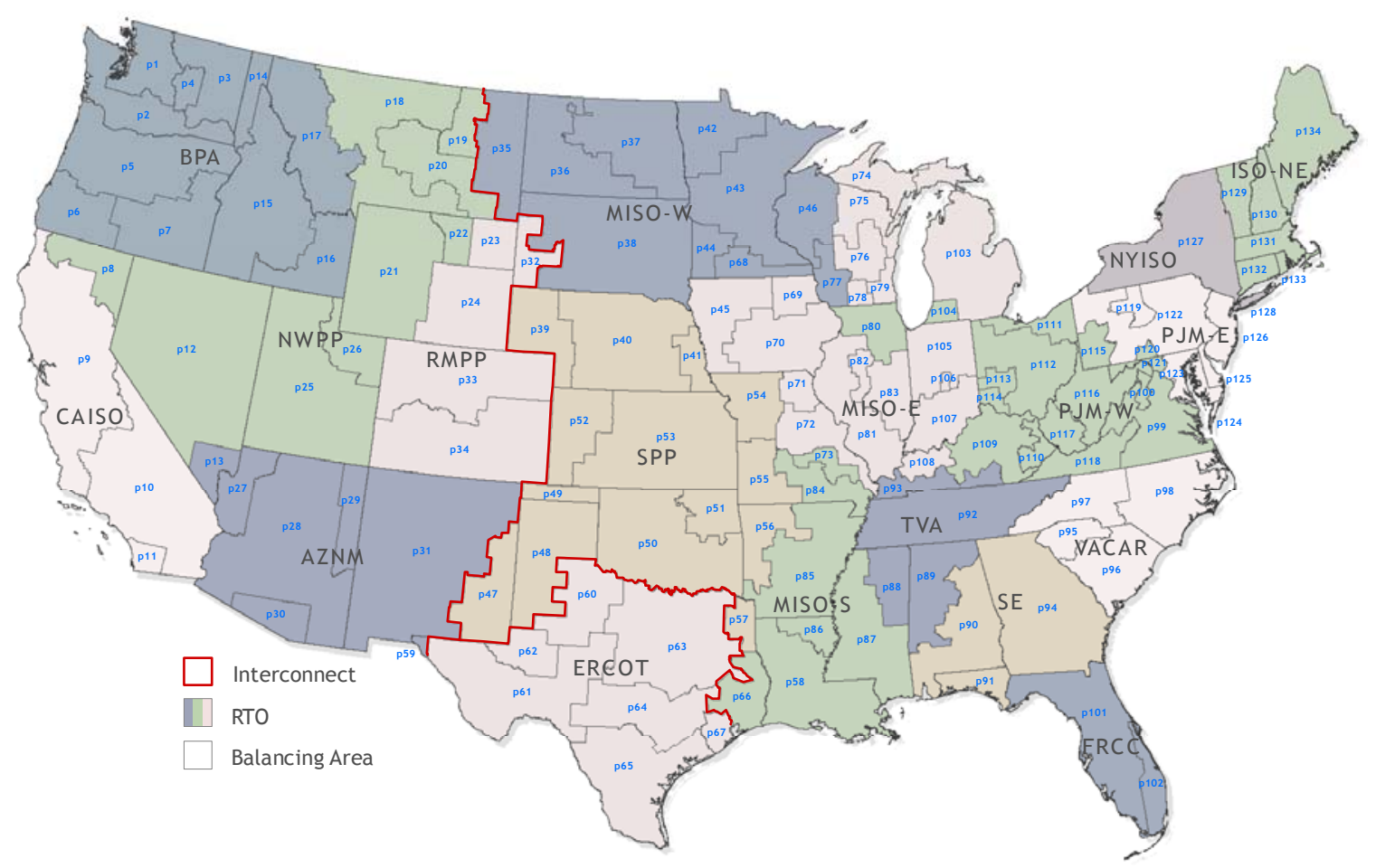

Figure 44. Map of ReEDS 134 "balancing area" regions and 18 "RTOs" 
ReEDS is temporally resolved into 17 "timeslices" that each reflect a set of hours in each day within a season. For each two-year solution interval from 2010 to 2050, ReEDS dispatches all generation in each of these 17 timeslices to capture seasonal and diurnal electricity load and renewable generation profiles. ReEDS explicitly and dynamically estimates and considers the need for new inter-regional transmission (limited through 2020), increases in operating reserve requirements, and changing contributions to planning reserves that may be driven by increases in renewable generation. For this purpose, ReEDS includes statistical parameters, such as capacity value for planning reserve requirements, forecast error operating reserve requirements, and estimated curtailments.

A key difference in the ReEDS model version used in this study from that described in the 2016 ReEDS documentation (Eurek et al. 2016) is the method for calculating capacity value. ReEDS has historically used a statistical approach, which connects the underlying hourly ("8760") load and resource data to the 17 timeslices through probability distributions, to estimate capacity value and curtailment metrics. In this study, we implement a new methodology that explicitly calculates the capacity value based on the load and variable generation (wind and PV) data for all 8,760 hours of the year. More specifically, these capacity value calculations utilize a capacity factor proxy that is applied to top hours in load and net load (load minus wind and PV) duration curves. A detailed description of this method is provided in Appendix E.

Other relevant modifications from the model version described in the 2016 ReEDS documentation and the 2016 Standard Scenarios report (Cole et al. 2016) include adjusted yearly PV growth penalties, ${ }^{41}$ updated DPV deployment projections from the dGen model, updated parameters for the ability of storage to recover curtailed energy, and the addition of residential battery storage profiles from the $\mathrm{dGen}$ model applied as exogenous load modifiers.

\section{dGen}

Because ReEDS does not natively project behind-the-meter energy system adoption, we use the $\mathrm{dGen}$ model to project the adoption of DPV and battery storage systems. We briefly describe the model here but refer the reader to the dGen model documentation (Sigrin et al. 2016) for a detailed description.

$\mathrm{dGen}$ is a customer adoption model that projects the adoption and operation of distributed energy technologies from the present day to 2050 for the residential, commercial, and industrial sectors of the contiguous United States. dGen projects the adoption of PV and batteries based on the "diffusion of innovations" framework, which posits that novel technologies "diffuse" into populations following a logistic pattern of early adopters, mass adoption, and late adopters. Rather than assuming all potential DPV customers are rational profit-maximizing agents who immediately adopt a profitable technology, the approach captures the diffusion of technologies through the population of potential customers based on the financial attractiveness of the investments.

\footnotetext{
${ }^{41}$ The updated growth penalties allow utility PV to increase the deployment rate by $2 \mathrm{GW} /$ year without penalty. Deployment rates above the additional $2 \mathrm{GW} /$ year experience a $12 \%$ cost penalty. For example, if $10 \mathrm{GW}$ of new utility PV were installed last year, $12 \mathrm{GW}$ could be installed this year without penalty. Distributed PV is not impacted by growth penalties.
} 
dGen generates thousands of statistically representative agents at the county-level to model potential adopter across the nation. Each agent has an assumed energy consumption profile, roof area, and other techno-economic attributes that are representative of the underlying population heterogeneity. DPV and battery finances are recalculated for each of the agents in each of the model's bi-annual solve years. Each agent will evaluate a discrete set of DPV and storage systems - either technology alone as well as various combinations of co-deployment - and consider adopting the system with the highest net present value. ${ }^{42}$ The storage systems are dispatched to minimize each customer's electric bill, with respect to the tariff to which they subscribe.

\section{Model Caveats and Limitations}

While ReEDS and dGen represent many aspects of the U.S. electricity system, like all models, they necessitate simplifications. We list some of the key limitations and caveats that result from these simplifications, highlighting those that are particularly relevant for the present analysis. This list is adapted from Eurek et al. (2016).

- System-wide optimization-ReEDS takes a system-wide least-cost perspective that does not necessarily reflect the perspective of individual decision makers, including specific investors, regional market participants, or corporate consumer choice of renewable power; nor does it model contractual obligations or non-economic decisions. In addition, like other optimization models, ReEDS finds the absolute least-cost solution that does not fully reflect real distributions and uncertainties in the parameters; however, the heterogeneity resulting from the high spatial resolution of ReEDS mitigates this to some degree.

- Foresight and behavior-Except for limited foresight of future natural gas prices, model decision-making does not account for anticipated changes to markets and policies. For example, anticipated tax credit expirations have historically led to acceleration of project development. By not including policy foresight and the associated behavior of specific plant developers, the models likely underestimate the year-to-year changes in renewable deployment coinciding with changes in tax credit values; however, the commencedconstruction provision mitigates this tendency to some extent.

- Project pipeline - The model incorporates data of planned or under-construction projects, but these data likely do not include all projects in progress.

- Manufacturing, supply chain, and siting - The models do not explicitly simulate manufacturing, supply chain, or siting and permitting processes. Potential bottlenecks or delays in project development stages for new generation or transmission would not be fully reflected in the results.

- Financing interactions-Financial parameters used in the models reflect long-term historical averages as opposed to current or near-term market conditions. In addition, the models do not fully capture financing interactions with tax credits (Bolinger 2014); however, we do model changes in capital structure for utility-scale wind and PV caused

\footnotetext{
${ }^{42}$ When agents evaluate systems, they are constrained by their own total consumption as well as the roof area available to them.
} 
by changes in tax credits (Mai, Cole, et al. 2015). Other interactions with tax equity investments are not reflected in the analysis.

- Technology learning-Future technology improvements are considered exogenously based on the assumptions in NREL's 2016 ATB (NREL 2016).

- Electricity tariff structures - dGen calculates the financial performance of DPV and behind-the-meter storage systems based on of a set of approximately 4,000 tariffs curated in 2016. The existing tariff components are scaled by changes in the cost of electricity as projected by ReEDS, but the structure of the tariffs does not change (e.g., the hours that define peak time-of-use periods will not shift). Thus, any tariff evolution that might occur in a high-PV future is not captured in this work.

While there are inherent methodological and data limitations in the development of any future projection, we use a self-consistent modeling framework that considers complex interactions between numerous different policies and technologies, while ensuring electric system reliability requirements are maintained within the resolution and scope of the models. In doing so, we can comprehensively estimate the cost and value of a wide range of technology options to the system, and we use the models to estimate future deployment portfolios across a range of scenarios. 


\section{Appendix C: Additional Scenario Results}

This section includes summary results from all 25 scenarios. Figure 45 through Figure 48 show the capacity and generation mixes in 2030 and 2050 across the 25 scenarios. 
Table 11 shows the PV deployment and penetration levels in the 25 scenarios.

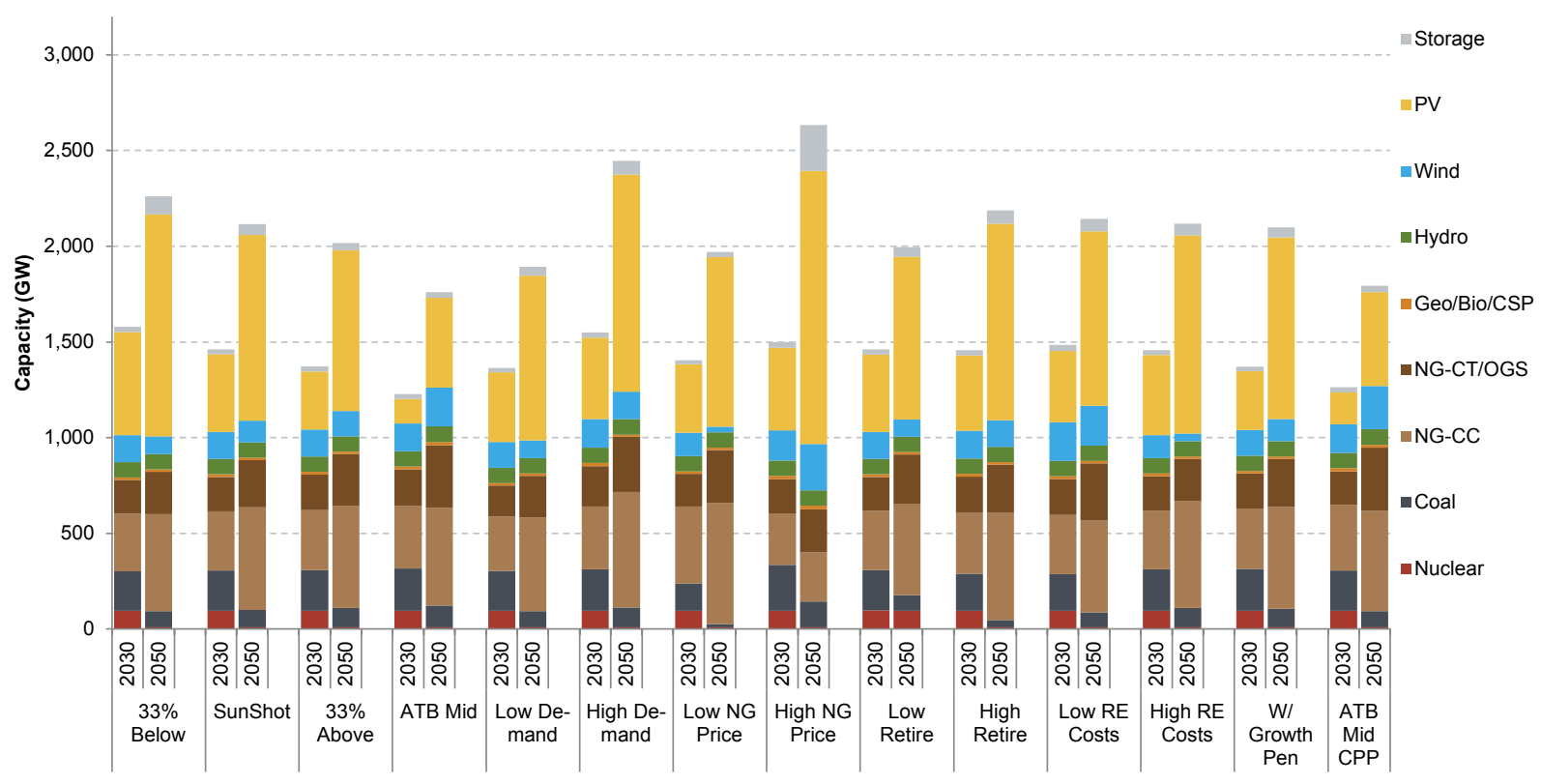

Figure 45. Cumulative installed capacity in 2030 and 2050 for all reference storage cost scenarios

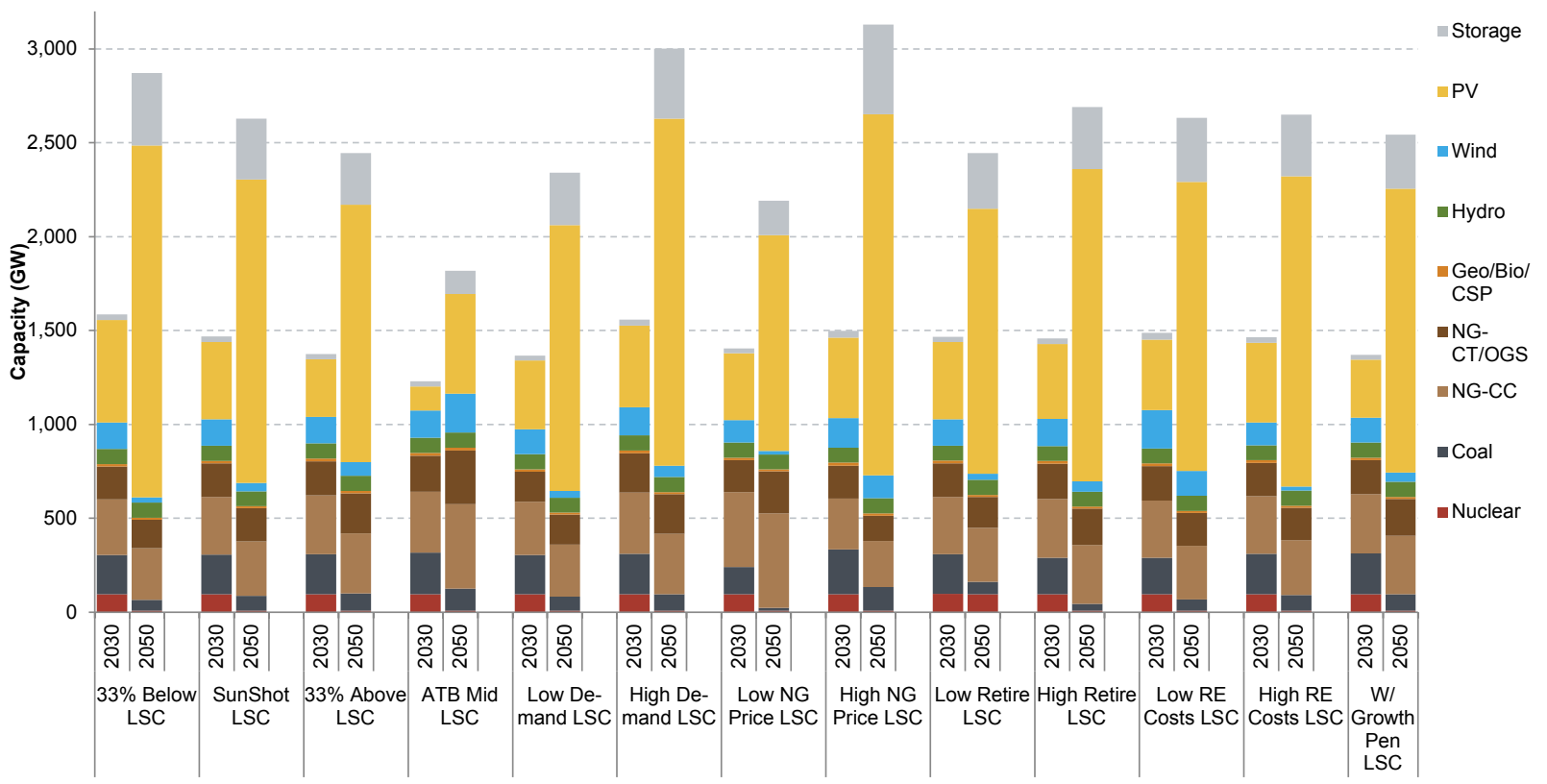

Figure 46. Cumulative installed capacity in 2030 and 2050 for all low storage cost (LSC) scenarios 


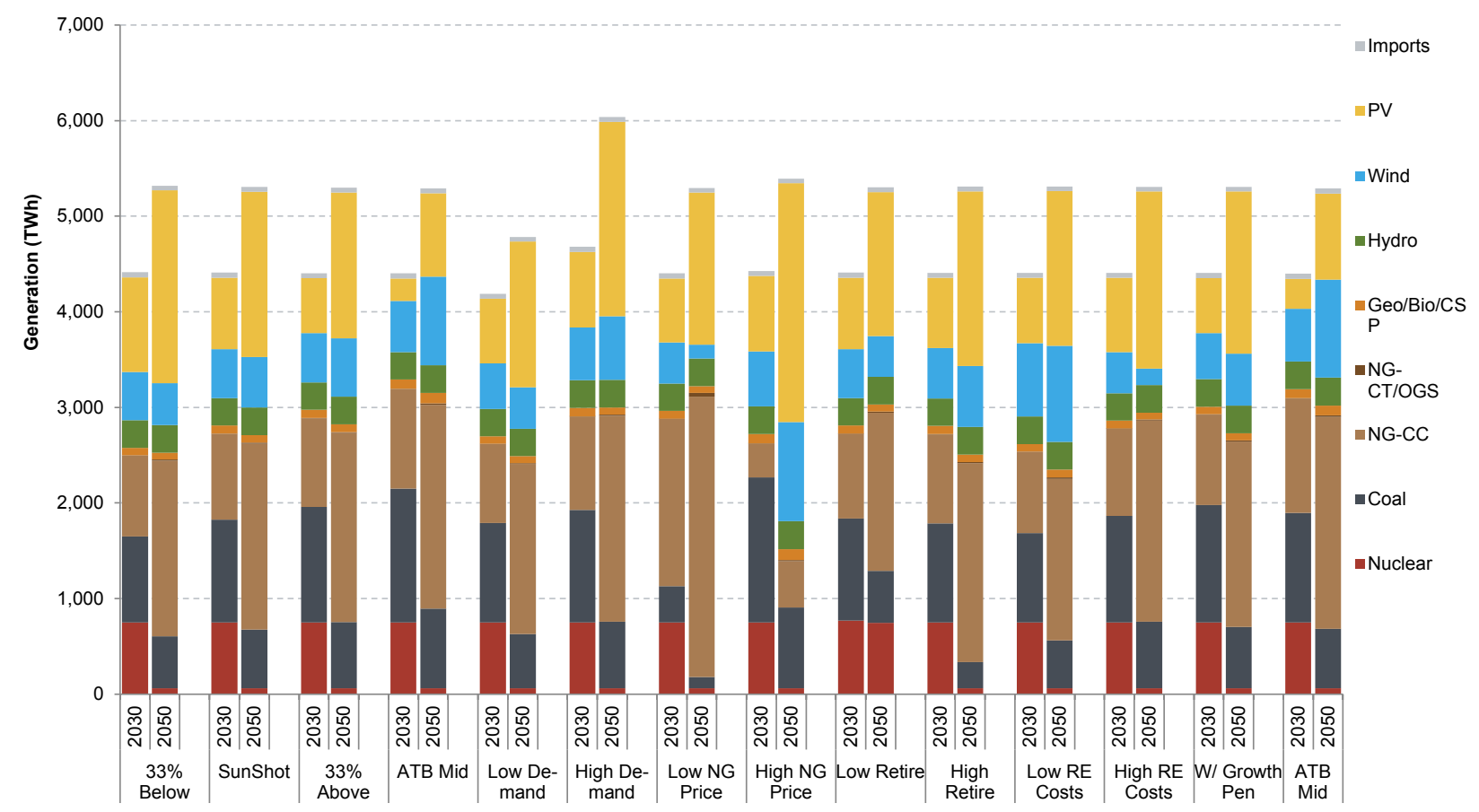

Figure 47. Generation in 2030 and 2050 for all default storage cost scenarios

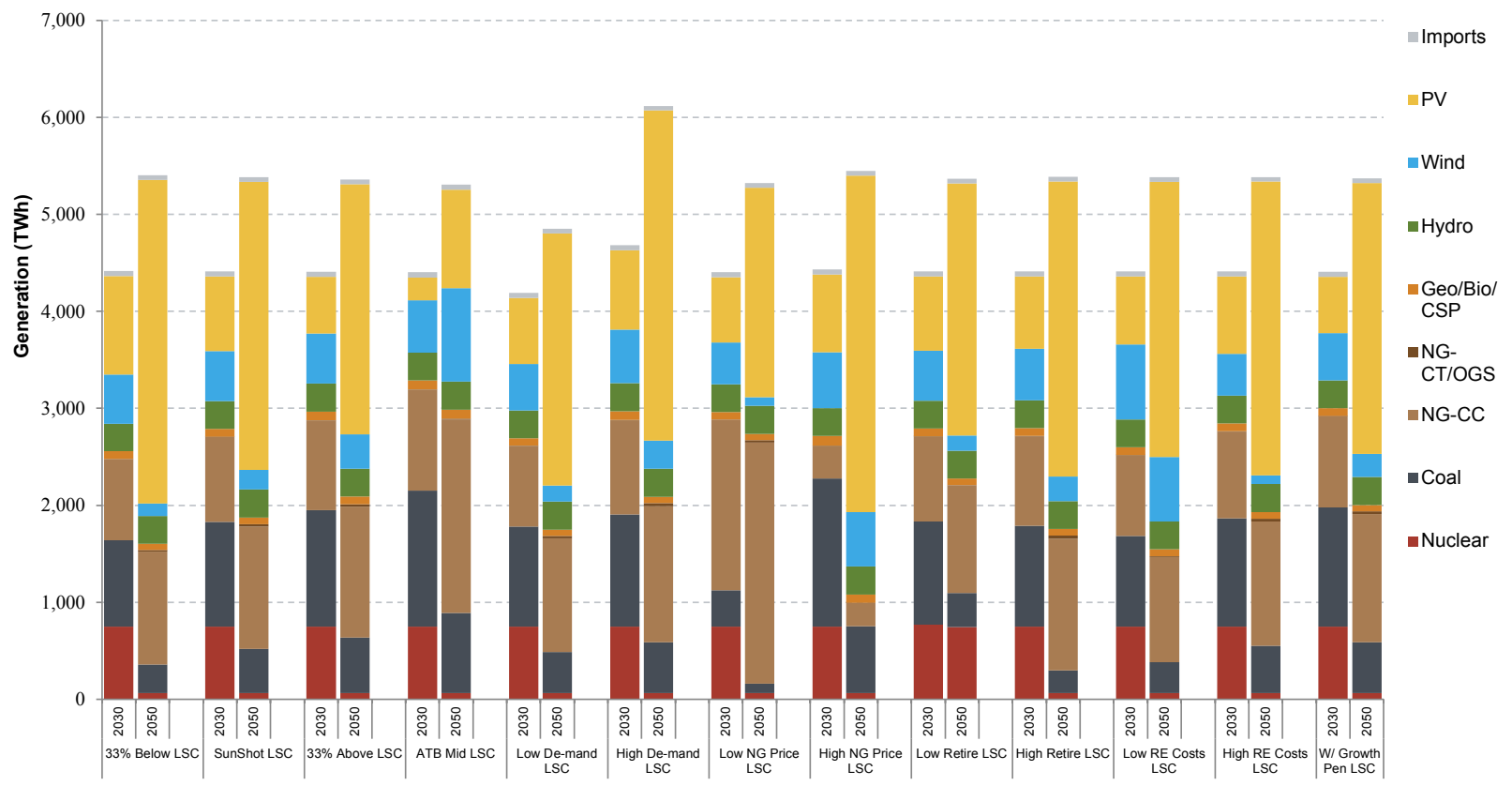

Figure 48. Generation in 2030 and 2050 for all low storage cost (LSC) scenarios 
Table 11. Summary PV Deployment and Penetration in 2030 and 2050 among the 25 Scenarios Included in this Analysis

\begin{tabular}{|c|c|c|c|c|}
\hline \multirow[t]{2}{*}{ Scenario } & \multicolumn{2}{|c|}{ PV Capacity (GW) } & \multicolumn{2}{|c|}{ PV Penetration } \\
\hline & 2030 & 2050 & 2030 & 2050 \\
\hline SunShot & 405 & 971 & $17 \%$ & $33 \%$ \\
\hline Low Demand & 365 & 862 & $16 \%$ & $32 \%$ \\
\hline High Demand & 426 & 1,134 & $17 \%$ & $34 \%$ \\
\hline Low NG Price & 357 & 884 & $15 \%$ & $30 \%$ \\
\hline High NG Price & 431 & 1,426 & $18 \%$ & $46 \%$ \\
\hline Low Retire & 404 & 850 & $17 \%$ & $28 \%$ \\
\hline High Retire & 395 & 1,027 & $17 \%$ & $34 \%$ \\
\hline Low RE Costs & 372 & 912 & $16 \%$ & $30 \%$ \\
\hline High RE Costs & 418 & 1,035 & $18 \%$ & $35 \%$ \\
\hline W/ Growth Penalty & 307 & 948 & $13 \%$ & $32 \%$ \\
\hline SunShot LSC & 412 & 1,618 & $17 \%$ & $55 \%$ \\
\hline Low Demand LSC & 365 & 1,416 & $16 \%$ & $54 \%$ \\
\hline High Demand LSC & 435 & 1,849 & $17 \%$ & $56 \%$ \\
\hline Low NG Price LSC & 356 & 1,148 & $15 \%$ & $41 \%$ \\
\hline High NG Price LSC & 429 & 1,923 & $18 \%$ & $64 \%$ \\
\hline Low Retire LSC & 410 & 1,412 & $17 \%$ & $48 \%$ \\
\hline High Retire LSC & 397 & 1,663 & $17 \%$ & $56 \%$ \\
\hline Low RE Costs LSC & 376 & 1,538 & $16 \%$ & $53 \%$ \\
\hline High RE Costs LSC & 425 & 1,652 & $18 \%$ & $56 \%$ \\
\hline W/ Growth Penalty LSC & 307 & 1,511 & $13 \%$ & $52 \%$ \\
\hline $33 \%$ Below & 537 & 1,158 & $22 \%$ & $38 \%$ \\
\hline $33 \%$ Above & 303 & 840 & $13 \%$ & $29 \%$ \\
\hline $33 \%$ Below LSC & 545 & 1,875 & $23 \%$ & $62 \%$ \\
\hline $33 \%$ Above LSC & 306 & 1,370 & $13 \%$ & $48 \%$ \\
\hline ATB Mid & 127 & 470 & $5 \%$ & $16 \%$ \\
\hline ATB Mid LSC & 127 & 532 & $5 \%$ & $19 \%$ \\
\hline ATB Mid CPP & 167 & 491 & $7 \%$ & $17 \%$ \\
\hline
\end{tabular}




\section{Appendix D: Pathways to Low-cost PV}

The higher deployment scenarios explored here would depend upon the ability of the PV industry and supporting research and development organizations to make further technology advancements and cost reductions. The PV SunShot scenario for utility-scale PV systems with the median U.S. solar resource and without the federal investment tax credit (ITC) represents approximately a 50\% decrease in LCOE from current (2017) levels by 2030, with an additional $33 \%$ reduction in LCOE by 2050.

There are a variety of pathways that exist to achieve the ultralow cost targets considered in the DOE's SunShot goals (Jones-Albertus et al. 2016; Woodhouse et al. 2016). Figure 49 shows six key inputs that drive the LCOE with their projected high and low values for the 2020 timeframe. At the extremes, we calculate LCOEs of 1.4 and 9.9 cents per $\mathrm{kWh}$ for U.S. utility-scale PV systems with the median solar resource and without the federal ITC. We also show a discrete set of inputs that could lead to the 3 cents per kWh target by 2030 and the 2 cents per kWh target by 2050, as well as a less aggressive set of assumptions that yield 4 cents per $\mathrm{kWh}$. For example, the 3 cents per $\mathrm{kWh}$ target could be achieved with a 30 cents per $\mathrm{W}$ module price, 50 cents per watt total balance-of-system hardware and soft costs, a $0.4 \% / y r$ system degradation rate, 40 -year system lifetime, $\$ 10 / \mathrm{kW}$-yr average annual operations and maintenance (O\&M) expense, and a $6.0 \%$ weighted average cost of capital (WACC). The figure includes illustrative pathways for achieving the SunShot targets defined and used throughout this work, but do not represent the only pathway possible. We do not assume a specific cost reduction pathway; instead, we assume that some combination of cost reductions in the six key categories is achieved and leads to the LCOE levels given by the scenario definitions.

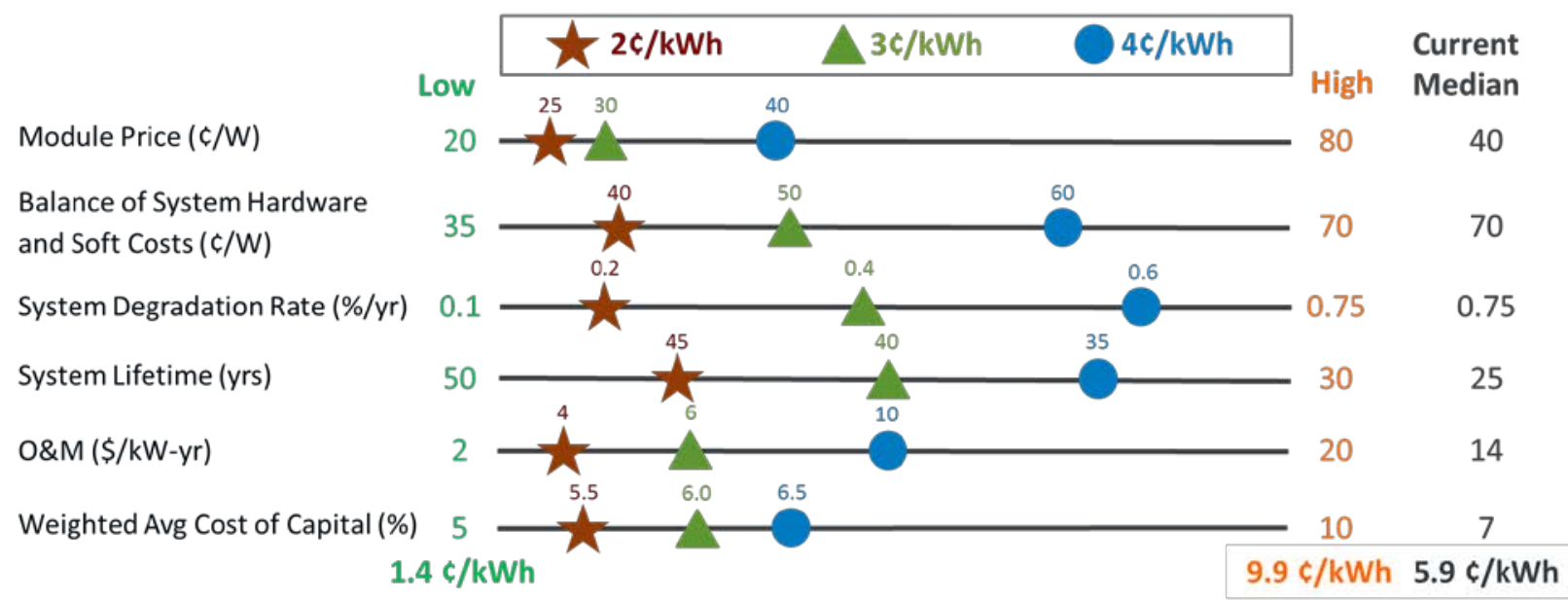

Figure 49. Six categories of LCOE input parameters and overall results under a range of assumptions.

The colored triangles, stars, and circles are illustrative cost reduction pathways that align with the 2, 3, and 4 cents/kWh scenarios, respectively. 


\section{Appendix E: 8760-Based Method for Representing Variable Generation Capacity Value}

Capacity expansion models (CEMs) are widely used to evaluate the least-cost portfolio of electricity generators, transmission, and storage needed to reliably serve demand over the evolution of many years or decades. Various forms are used to evaluate systems ranging from local utilities and regional entities (WECC 2013; ABB 2016b; Mai, Barrows, et al. 2015) to national systems (Eurek et al. 2016; Blanford, Merrick, and Young 2014; EPRI 2017; U.S. Energy Information Administration (EIA) 2014). The ReEDS model used in this analysis is one example of such a national CEM. Capacity expansion models can be computationally complex, and to achieve acceptable solve times are often are forced to estimate key parameters using simplified methods.

Existing grid integration analyses have shown that power systems will require greater levels of flexibility to accommodate higher levels of variable generation (VG) resources, such as wind and PV, which are variable and uncertain (Mai et al. 2014; Lew et al. 2013). In addition, at higher penetration levels, the contribution that VG resources can provide to reliability - specifically resource adequacy - becomes more sensitive to the interaction of both the existing system and potential new generators. For example, VG's useful capacity and energy contribution declines as more VG is added to the system due to the coincident nature of the resource. While many CEMs account for at least some aspect of this trend, many of the aforementioned modeling simplifications can result in inaccurate representations, particularly at high VG penetrations when the sensitivity and magnitude of these impacts are amplified.

Curtailment and capacity value (CV) are key parameters that reflect the flexibility and reliability impacts, respectively, of VG resources. This appendix focuses on a new method for estimating $\mathrm{CV}$ in the ReEDS CEM. ${ }^{43}$ Other factors that reflect the impact of VG on an evolving power system, which are not included in our alternative methods, include ramping capabilities, transient stability, system inertia, frequency response, inertia, and market rules (Miller et al. 2014; Ela et al. 2014).

\section{Capacity Value}

Capacity value $(\mathrm{CV})$ is a metric of the contribution of installed capacity to planning reserves that is typically used by power system planners in long-term reliability assessments. For example, a $100-\mathrm{MW}$ generator with a $30 \% \mathrm{CV}$ would be expected to reliably contribute $30 \mathrm{MW}$ of capacity during the highest "risk" hours. These hours are by definition those with the highest loss of load probability (LOLP) and are often (but not always) the hours with the highest load. The preferred method for assessing the CV of wind and PV generation is a probabilistic approach grounded in the well-known LOLP and related reliability metrics. Traditional methods include convolutionbased LOLP or effective load carrying capability (ELCC); for example, Keane et al. (2011) for wind and Duignan et al. (2012) for PV. ELCC can be calculated with a reliability model or by directly using historical hourly load and VG data, but some studies suggest that eight years of data are required to account for inter-annual variability and converge on long-term values

\footnotetext{
${ }^{43} \mathrm{CV}$ is synonymous with capacity credit throughout the literature. It is equivalent to the additional load that the electrical system could serve while maintaining the same level of reliability, which is the effective load carrying capability (ELCC).
} 
(Hasche, Keane, and O’Malley 2011; Milligan et al. 2017). Using these methods, CV can be calculated for conventional generators, VG resources, and storage.

Ideally CV values account for the impact of broader system components, such as transmission, storage, and the characteristics of the thermal fleet. For example, the impact of geo-spatial diversity - including the spatial distribution of VG resources, intra- and inter-regional transmission interconnections, and outages of these units and lines - can impact the contribution of local generators, storage devices, and reserve requirements to meeting resource adequacy and real time energy balancing requirements (Milligan et al. 2017; Ibanez and Milligan 2012). Transmission additions and operational changes, such as the implementation of a dispatch protocol for VG resources in MISO have resulted in significant curtailment reductions in the United States (Bird et al. 2016), highlighting the importance of transmission and market representations in CEMs. Storage charging and discharging modifies the underlying net load profiles, which can reduce curtailment during charging periods and modify and/or complement the contribution from VG resources during discharging periods. Thermal fleet operating constraints can limit the useful contribution from those units as well as that from VG resources.

\section{CEM Simplifications}

The ideal calculation of CV in CEMs would require an explicit co-optimized investmentdispatch treatment with many years of time-synchronous VG and load data at an hourly or subhourly resolution. Because of data and computational limitations, existing CEMs typically approximate these variability metrics with simplified methods, including the use of a subset of hours from a full year, screening curves, and other duration-curve-based approaches to evaluate generator performance and select the optimal mix of units (Sullivan, Eurek, and Margolis 2014; Ueckerdt et al. 2017). However, such simplifications reduce the accuracy of the CEMS to capture the impact of VG on the broader power system. At higher VG penetration levels, these inaccuracies can become amplified and have a greater impact on modeling results. Examples of approximation methods for CV primarily include approaches that:

- Relate the addition of new capacity and LOLP - for example, Z-method (Dragoon and Dvortsov 2006) and Garver's method (D’Annunzio and Santoso 2008; Garver 1966)

- Approximate CV as the capacity factor based on the hours of highest risk - for example, Hale, Stoll, and Mai (2016); Milligan and Parsons (1999); Madaeni, Sioshansi, and Denholm (2013); Pietzcker et al. (2017)_or predefined by VG resource supply bins (Patrick Sullivan, Krey, and Riahi 2013).

We are contributing to this broader set of approximation methods by implementing an alternate approach that characterizes the contribution of VG to system capacity during high load and net load (load minus VG) hours. This method utilizes hourly generation and load values across all hours of the year ("8760 data"), thereby capturing tail events that can be missed by simplification methods that only use a set of all hours from a year that are not explicitly selected based on LOLP, or by statistical methods that require assumptions about the load and resource distributions that may not match actual distributions. Our methods also capture the interactions between VG and conventional generators and takes into account how the system evolves within each of the scenarios. Other methods, such as those based on cost functions or exogenous regressions, lack this sort of self-consistent framework and could therefore result in erroneous 
extrapolations. Furthermore, our approach offers flexible application to any year and model given availability of 8760 data.

\section{New ReEDS CV Methodology}

Figure 50 shows how the current ReEDS timeslice approach misses key information in the load and net load duration tails that are captured by an 8760 methodology. The solid lines show the current ReEDS methodology which utilizes 17 representative timeslices (identified by numbers above curves), and the dashed lines show the new method using the 8760 time series. The new 8760-based ReEDS methodology is better able to capture the highest and lowest load hours on the duration curves, thereby providing a more accurate representation of key variability metrics. In addition to what is presented here, additional details of the methodology can be found in Frew et al. (2017).

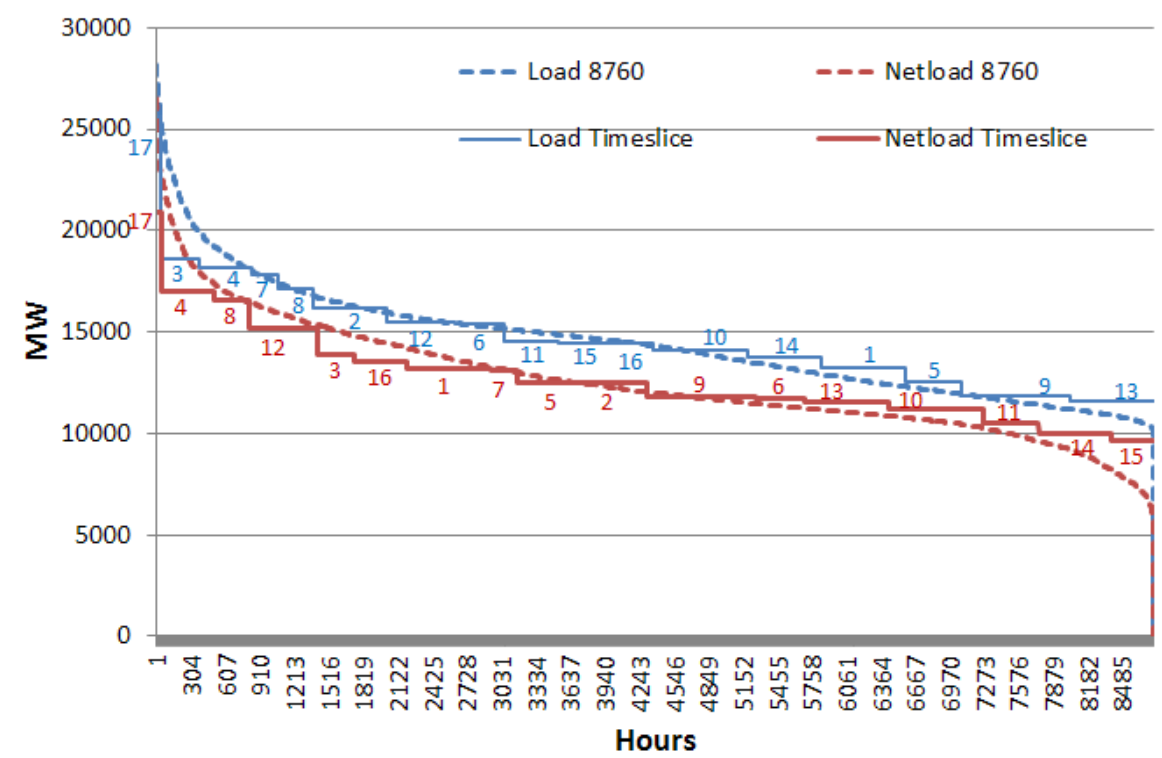

Figure 50. Representative load and net load duration curves for a single ReEDS region Timeslice identifiers are shown the duration curves.

To calculate CV metrics, we call an R-based script outside the core GAMS-based ReEDS code between each two-year solve period. This script implements the 8760 load and VG time series, as well as generator and storage capacities, timeslice-based generation, and transmission flows from the previous two-year solve period in ReEDS. The raw 8760 load data are adjusted based on ReEDS inter-regional transmission flow to account for the imports and exports between regions. The script returns the existing $\mathrm{CV}$ by $\mathrm{VG}$ technology type and region and marginal $\mathrm{CV}$ by VG technology type, resource class, and region.

The new ReEDS method for calculating CV utilizes duration curves of load and net load and is similar to the approach used by NREL's Resource Planning Model (RPM) (Hale, Stoll, and Mai 2016). Figure 51 illustrates this methodology. The load duration curve (LDC) reflects the total load in a given modeling region, which is sorted from the hours of highest load to lowest load and is shown by the blue line. The net load duration curve (NLDC) represents the total load 
minus the time-synchronous contribution from VG, where the resulting net load is then sorted from highest to lowest, as shown by the solid red line. ${ }^{44}$ The NLDC $(\delta)$ can also be created by subtracting the time-synchronous generation of an incremental capacity addition from the NLDC, where the resulting time series is again sorted from highest to lowest; this is shown by the dashed red line.

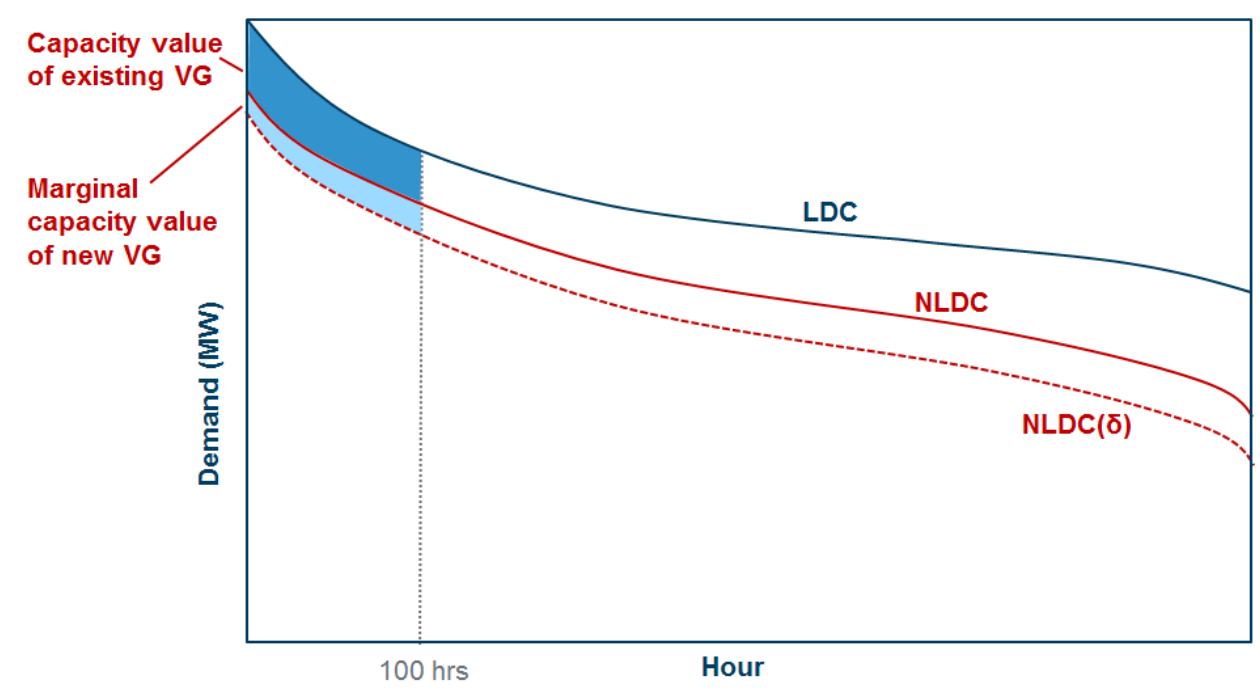

Figure 51. Load duration curve (LDC) based approach to calculating CV

The amount of load that the existing VG capacity can meet while maintaining the same level of reliability is the ELCC. We calculate the ELCC as the difference in the areas between the LDC and NLDC during the top 100 hours of the duration curves, as shown by the dark blue shaded area in Figure 51. These 100 hours are a proxy for the hours with the highest risk for loss of load (i.e., LOLP). ${ }^{45}$ Similarly, the contribution of an additional unit of capacity to meeting peak load is the difference in the areas between the NLDC and the NLDC $(\delta)$, as shown by the light blue shaded area. We assume $100 \mathrm{MW}$ for the incremental capacity size in ReEDS. These areas are divided by the corresponding installed capacity and number of top hours (100 in this case) to obtain a fractional annual-based CV result. These CV values are then fed into ReEDS to quantify each VG resource's capacity contribution to the planning reserve requirement, which is based on NERC planning reserve margin assessments and the peak load by region. Thus, these CV metrics inform the investment decision of new VG by impacting the capacity-based value of those new VG additions.

In the new ReEDS CV method, these calculations are done at regional and technology levels for the existing $\mathrm{CV}$ and at regional, technology, and resource class levels for marginal $\mathrm{CV}$. For existing units, the user can define the regional level to either the $134 \mathrm{ReEDS}$ regions or the 18 broader RTO regions; the default is the RTO level. All marginal calculations are performed at the 134 region level. Future work will refine the intra- and inter-regional transmission impacts.

\footnotetext{
${ }^{44}$ Residual LDC is an equivalent term to NLDC used in the literature.

${ }^{45}$ We currently use only a single year of wind, PV, and load data to calculate CV. Expansion of this method to use multiple years of data would increase the robustness of this calculation.
} 


\section{Validation of New ReEDS CV Method}

Because $\mathrm{CV}$ represents an explicit calculation based on the load and net load profiles, the new ReEDS method CV outputs were verified against a manual calculation of the difference between the load and net load in each their respective top 100 hours. Existing and marginal PV and wind $\mathrm{CV}$ outputs from this comparison are shown in Figure 52. In this figure, the wind generation level was held constant while PV capacity alone was increased to achieve higher RE penetration levels. Thus, the marginal PV CV values diminish at higher RE penetration levels due to the coincident nature of the PV resource, while the marginal CV of wind slightly increases in response to the shifting peak net load period to more windy (and less sunny) hours. This reduction in marginal PV CV is consistent with the literature, which shows rapid decrease in capacity contribution beyond 20\% penetration levels (Munoz and Mills 2015).

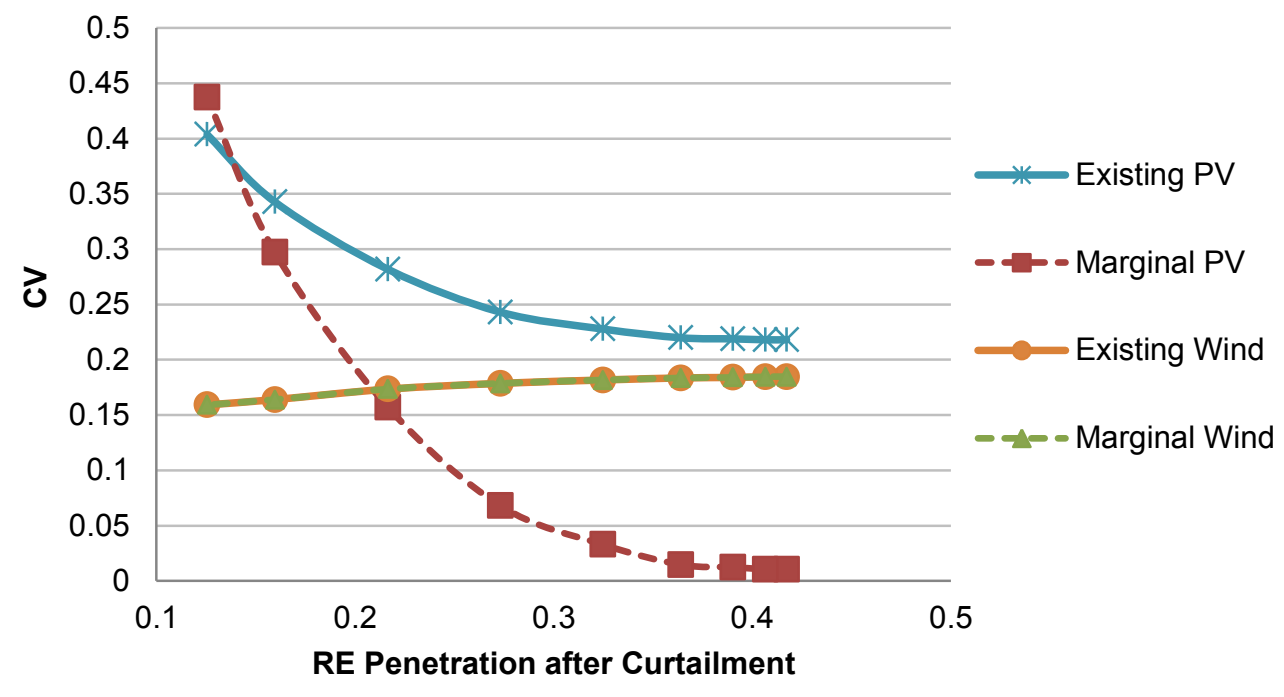

Figure 52. Marginal PV CV outputs from ReEDS and manual calculation with fixed minimum
generation of $7.5 \mathrm{GW}$

\section{Comparison of Existing and New ReEDS CV Methods}

Results to date suggest the hourly method in the new ReEDS method more accurately represents VG CV in ReEDS from the existing approximation method without prohibitive computational burdens. The marginal CV outputs for PV in the Austin, Texas (Figure 53), and southern California (Figure 54) areas show a more realistic reduction in value with higher penetration levels than the existing ReEDS statistical method. Note that because the existing ReEDS method calculates $\mathrm{CV}$ at the timeslice level, while our new method reports annual CV outputs, we show the existing method CV outputs from the timeslice with the largest marginal value in the planning reserve margin constraint. This is often (but not always) the summer afternoon or evening timeslices. 


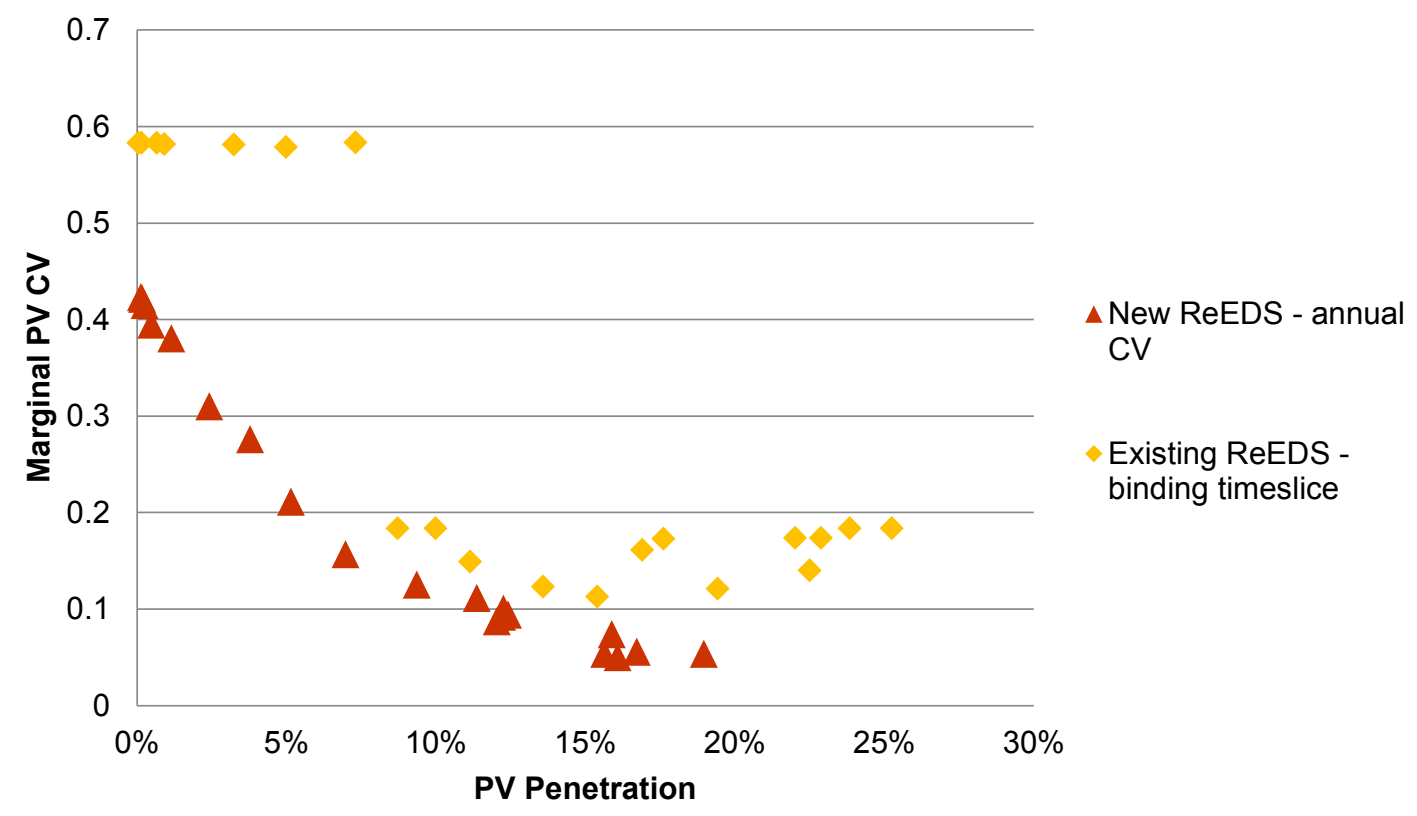

Figure 53. Incremental PV CV in the Austin, Texas, region using the existing and new ReEDS method

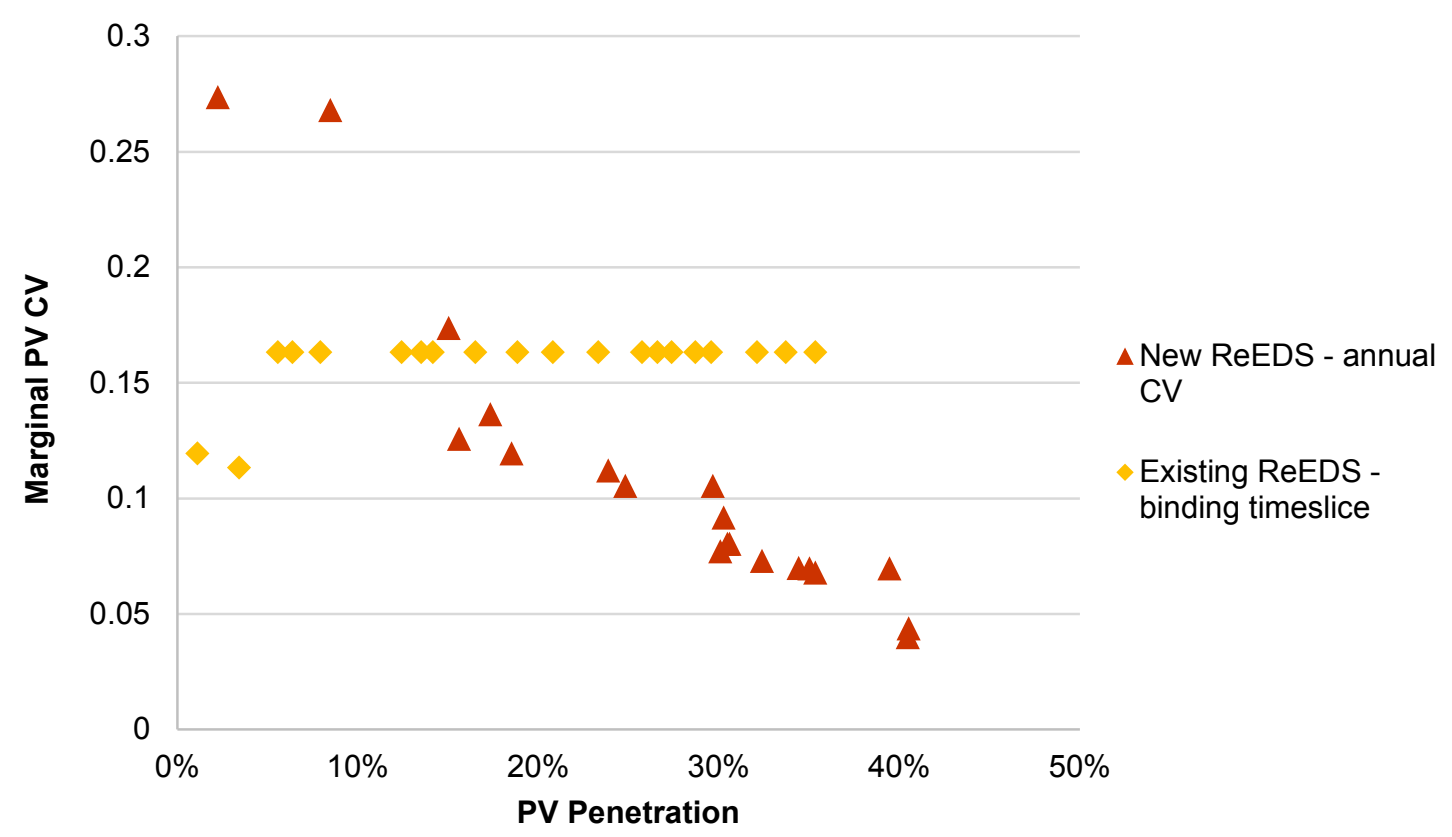

Figure 54. Incremental PV CV in the southern California region using the existing and new ReEDS method 
Previous work has shown that the existing ReEDS CV method yields abrupt changes in CV between the different timeslices, particularly between the summer afternoon and evening periods (Sigrin et al. 2014). These results can be seen by the sharp drop in the marginal CV around the 7\% PV penetration level in Figure 53, where the reserve margin binding timeslice shifts from summer afternoon to evening (yellow diamonds). Furthermore, the existing ReEDS method often estimates persistent $\mathrm{CV}$ for $\mathrm{PV}$ even at relatively high penetration levels due to the coarse timeslices, as shown again by the yellow diamonds in at higher penetration levels in both Figure 53 and Figure 54. The new method, which looks across all hours to calculate an annual CV results in a smoother and more rapid decline in $\mathrm{CV}$. 